\title{
Development and chamber evaluation of the MCM v3.2 degradation scheme for $\beta$-caryophyllene
}

\author{
M. E. Jenkin ${ }^{1}$, K. P. Wyche ${ }^{2}$, C. J. Evans ${ }^{3}$, T. Carr ${ }^{2}$, P. S. Monks ${ }^{2}$, M. R. Alfarra ${ }^{4,5}$, M. H. Barley ${ }^{5}$, G. B. McFiggans ${ }^{5}$, \\ J. C. Young ${ }^{6}$, and A. R. Rickard ${ }^{6,7, *}$ \\ ${ }^{1}$ Atmospheric Chemistry Services, Okehampton, Devon, EX20 1FB, UK \\ ${ }^{2}$ Atmospheric Chemistry Group, Department of Chemistry, University of Leicester, Leicester, LE1 7RH, UK \\ ${ }^{3}$ Molecular Properties Group, Department of Chemistry, University of Leicester, Leicester, LE1 7RH, UK \\ ${ }^{4}$ National Centre for Atmospheric Science (NCAS), School of Earth Atmospheric and Environmental Sciences, University of \\ Manchester, M13 9PL, UK \\ ${ }^{5}$ Centre for Atmospheric Science, School of Earth Atmospheric and Environmental Sciences, University of Manchester, \\ M13 9PL, UK \\ ${ }^{6}$ School of Chemistry, University of Leeds, LS2 9JT, UK \\ ${ }^{7}$ National Centre for Atmospheric Science (NCAS), School of Chemistry, University of Leeds, LS2 9JT, UK \\ * now at: National Centre for Atmospheric Science, Department of Chemistry, University of York, Heslington, York \\ YO105DD, UK
}

Correspondence to: M. E. Jenkin (atmos.chem@ btinternet.com)

Received: 22 December 2011 - Published in Atmos. Chem. Phys. Discuss.: 27 January 2012

Revised: 15 May 2012 - Accepted: 23 May 2012 - Published: 15 June 2012

\begin{abstract}
A degradation mechanism for $\beta$-caryophyllene has recently been released as part of version 3.2 of the Master Chemical Mechanism (MCM v3.2), describing the gas phase oxidation initiated by reaction with ozone, $\mathrm{OH}$ radicals and $\mathrm{NO}_{3}$ radicals. A detailed overview of the construction methodology is given, within the context of reported experimental and theoretical mechanistic appraisals. The performance of the mechanism has been evaluated in chamber simulations in which the gas phase chemistry was coupled to a representation of the gas-to-aerosol partitioning of 280 multi-functional oxidation products. This evaluation exercise considered data from a number of chamber studies of either the ozonolysis of $\beta$-caryophyllene, or the photo-oxidation of $\beta$-caryophyllene/ $\mathrm{NO}_{\mathrm{x}}$ mixtures, in which detailed product distributions have been reported. This includes the results of a series of photo-oxidation experiments performed in the University of Manchester aerosol chamber, also reported here, in which a comprehensive characterization of the temporal evolution of the organic product distribution in the gas phase was carried out, using Chemical Ionisation Reaction Time-of-Flight Mass Spectrometry (CIR-TOF-MS), in conjunction with measurements of $\mathrm{NO}_{\mathrm{x}}, \mathrm{O}_{3}$ and SOA mass
\end{abstract}

loading. The CIR-TOF-MS measurements allowed approximately 45 time-resolved product ion signals to be detected, which were assigned on the basis of the simulated temporal profiles of the more abundant MCM v3.2 species, and their probable fragmentation patterns. The evaluation studies demonstrate that the MCM v3.2 mechanism provides an acceptable description of $\beta$-caryophyllene degradation under the chamber conditions considered, with the temporal evolution of the observables identified above generally being recreated within the uncertainty bounds of key parameters within the mechanism. The studies have highlighted a number of areas of uncertainty or discrepancy, where further investigation would be valuable to help interpret the results of chamber studies and improve detailed mechanistic understanding. These particularly include: (i) quantification of the yield and stability of the secondary ozonide (denoted BCSOZ in MCM v3.2), formed from $\beta$-caryophyllene ozonolysis, and elucidation of the details of its further oxidation, including whether the products retain the "ozonide" functionality; (ii) investigation of the impact of $\mathrm{NO}_{\mathrm{x}}$ on the $\beta$-caryophyllene ozonolysis mechanism, in particular its effect on the formation of $\beta$-caryophyllinic acid (denoted 
$\mathrm{C} 137 \mathrm{CO} 2 \mathrm{H}$ in $\mathrm{MCM}$ v3.2), and elucidation of its formation mechanism; (iii) routine independent identification of $\beta$ caryophyllinic acid, and its potentially significant isomer $\beta$ nocaryophyllonic acid (denoted $\mathrm{C} 131 \mathrm{CO} 2 \mathrm{H}$ in MCM v3.2); (iv) more precise quantification of the primary yield of $\mathrm{OH}$ (and other radicals) from $\beta$-caryophyllene ozonolysis; (v) quantification of the yields of the first-generation hydroxy nitrates (denoted BCANO3, BCBNO3 and BCCNO3 in MCM v3.2) from the $\mathrm{OH}$-initiated chemistry in the presence of $\mathrm{NO}_{\mathrm{x}}$; and (vi) further studies in general to improve the identification and quantification of products formed from both ozonolysis and photo-oxidation, including confirmation of the simulated formation of multifunctional species containing hydroperoxide groups, and their important contribution to SOA under $\mathrm{NO}_{\mathrm{x}}$-free conditions.

\section{Introduction}

It is well established that the degradation of emitted volatile organic compounds (VOCs) has a major influence on the chemistry of the troposphere, contributing to the formation of ozone, secondary organic aerosol (SOA) and other secondary pollutants (e.g., Haagen-Smit and Fox, 1954; Went, 1960; Andreae and Crutzen, 1997; Jenkin and Clemitshaw, 2000; Hallquist et al., 2009). Approximately $90 \%$ of organic material emitted globally is estimated to originate from biogenic sources, with reactive biogenic VOCs having important contributions from isoprene $\left(\mathrm{C}_{5} \mathrm{H}_{8}\right)$, and a variety of structurally complex monoterpenes $\left(\mathrm{C}_{10} \mathrm{H}_{16}\right)$ and sesquiterpenes $\left(\mathrm{C}_{15} \mathrm{H}_{24}\right)$, comprised of two and three isoprene units, respectively (e.g., Guenther et al., 1995; Kanakidou et al., 2005; Duhl et al., 2008).

Although isoprene and monoterpenes are generally emitted more abundantly, sesquiterpenes have received increasing interest in recent years owing to the exceptionally high reactivity of some species, particularly towards ozone (e.g., Atkinson and Arey, 2003; Jardine et al., 2011), and their general high propensity to form SOA upon oxidation (e.g., Hoffmann et al., 1997; Jaoui et al., 2004; Lee et al. 2006a, b; Ng et al., 2007). $\beta$-caryophyllene has received particular attention, being one of the most reactive and abundant sesquiterpenes, and SOA yields have been reported in a number of ozonolysis and photo-oxidation studies (Hoffmann et al., 1997; Griffin et al., 1999; Jaoui et al., 2003; Lee et al. 2006a, b; Winterhalter et al., 2009; Alfarra et al., 2012). As a result, its atmospheric degradation has been the subject of a number of experimental and theoretical mechanistic appraisals (Calogirou et al., 1997; Jaoui et al., 2003; Lee et al., 2006b; Kanawati et al., 2008; Winterhalter et al., 2009; Nguyen et al., 2009; Zhao et al., 2010; Li et al., 2011; Chan et al., 2011), and several established oxidation products have been used in tracer studies to show that $\beta$-caryophyllene-derived SOA makes potentially important contributions to ambient fine particulate mat- ter at a number of locations (Jaoui et al. 2007; Kleindienst et al. 2007; Parshintsev et al. 2008).

Atmospheric modelling studies in which the oxidation of $\beta$-caryophyllene (and/or other sesquiterpenes) has been treated, have invariably used highly simplified or parameterized representations of the chemistry (e.g., Lane et al., 2008; Sakulyanontvittaya et al., 2008; Carlton et al., 2010; Zhang and Ying, 2011), with SOA formation represented by assigning empirically-derived yields and partitioning coefficients to notional products, based on the results of chamber studies. Whilst such approaches are practical and economical, it is generally acknowledged that the gas phase formation and evolution of low volatility products of VOC oxidation are sensitive to the prevailing atmospheric conditions (e.g., level of $\mathrm{NO}_{\mathrm{x}}$, relative humidity), and that it is ideally necessary to understand and represent the competitive reactions involved over several generations of oxidation, if SOA formation, and its dependence on conditions, is to be represented rigorously (e.g., Kroll and Seinfield, 2008; Hallquist et al., 2009). In this respect, a degradation mechanism for $\beta$-caryophyllene has recently been released as part of version 3.2 of the Master Chemical Mechanism (MCM v3.2), describing in moderate detail the gas phase chemical processes involved in its complete atmospheric oxidation, as initiated by reaction with ozone $\left(\mathrm{O}_{3}\right), \mathrm{OH}$ radicals and $\mathrm{NO}_{3}$ radicals. Although such a mechanism cannot be used directly in applications requiring great computational efficiency, it potentially provides a traceable link to elementary kinetic and mechanistic studies, and a reference benchmark mechanism against which to develop and evaluate reduced chemical mechanisms. In this paper, a detailed overview of the construction methodology of the MCM v3.2 $\beta$-caryophyllene mechanism is given, within the context of reported kinetic and mechanistic information.

The performance of the mechanism has been evaluated in chamber simulations in which the gas phase chemistry was coupled to a representation of the gas-to-aerosol partitioning of 280 multi-functional oxidation products. This evaluation considered the results of a number of more recently reported chamber studies (Lee et al., 2006b; Li et al., 2011; Chan et al., 2011), which studied either the ozonolysis of $\beta$-caryophyllene, or the photo-oxidation of $\beta$-caryophyllene $/ \mathrm{NO}_{\mathrm{x}}$ mixtures, and the detailed distributions of oxidation products in the gaseous and condensed phases are compared with those reported. The most extensive evaluation made use of the results of a series of photo-oxidation experiments performed in the University of Manchester aerosol chamber (also reported here), which included a comprehensive characterization of the temporal evolution of the organic product distribution in the gas phase, using Chemical Ionisation Reaction Time-of-Flight Mass Spectrometry (CIR-TOF-MS), in conjunction with measurements of $\mathrm{NO}_{\mathrm{x}}, \mathrm{O}_{3}$ and SOA mass loading. The composition and ageing of SOA in the same series of experiments has also been characterized, as reported elsewhere (Alfarra et al., 2012). The results of these evaluation studies are presented 
and discussed, and areas of uncertainty in the mechanistic understanding are highlighted.

\section{Chemistry of $\beta$-caryophyllene degradation in MCM v3.2}

The complete degradation chemistry of $\beta$-caryophyllene, as represented in MCM v3.2, can be viewed and downloaded using the subset mechanism assembling facility, available as part of the MCM website (http://mcm.leeds.ac.uk/MCM). The general methodology of mechanism construction was based on the rules described in detail by Jenkin et al. (1997) and Saunders et al. (2003), with the chemistry adjusted and augmented (in certain areas substantially) to represent information reported in a number of experimental and theoretical studies of $\beta$-caryophyllene degradation available at the time of construction (Shu and Atkinson, 1994; Calogirou et al., 1997; Atkinson and Arey, 2003; Jaoui et al., 2003; Lee et al., 2006a, b; Kanawati et al., 2008; Winterhalter et al., 2009; Nguyen et al., 2009). The complete mechansim consists of 1626 reactions of 591 closed-shell and radical species. It is therefore moderately detailed, but necessarily contains a number of simplification measures, described by Jenkin et al. (1997) and Saunders et al. (2003), without which the mechanism could easily contain up to $\sim 10^{12}$ species (Aumont et al., 2005). The resultant level of simplification tends to increase with successive generations of oxidation, and it is unlikely that the mechanism contains all species which might be detected in experimental studies. However, it is designed to provide a representation of the most important degradation routes, and thus provides a basis for the initial simulation of systems where a representation of chemical detail is required. The mechanism includes the chemistry initiated by reaction with $\mathrm{O}_{3}, \mathrm{OH}$ and $\mathrm{NO}_{3}$. Salient features of the $\mathrm{O}_{3}$ and $\mathrm{OH}-$ initiated chemistry are now summarized, within the context of information reported in the above studies and in more recent experimental mechanistic studies (Li et al., 2011; Chan et al., 2011). For the photo-oxidation and ozonolysis conditions considered in the present paper, the systems are insensitive to the $\mathrm{NO}_{3}$-initiated chemistry, which is therefore not discussed further.

\subsection{First-generation chemistry}

\subsubsection{Reaction with ozone}

The main features of the $\mathrm{O}_{3}$-initiated degradation chemistry to first-generation products are summarized in Fig. 1. $\beta$-caryophyllene is reported to be highly reactive with $\mathrm{O}_{3}$ (Atkinson and Arey, 2003), such that ozonolysis is likely to be the major fate under most atmospheric conditions. The mechanism in MCM v3.2 proceeds exclusively via addition of $\mathrm{O}_{3}$ to the endocyclic double bond in $\beta$-caryophyllene, which is reported to be two orders of magnitude more reactive than the exocyclic double bond (Winterhalter et al.,

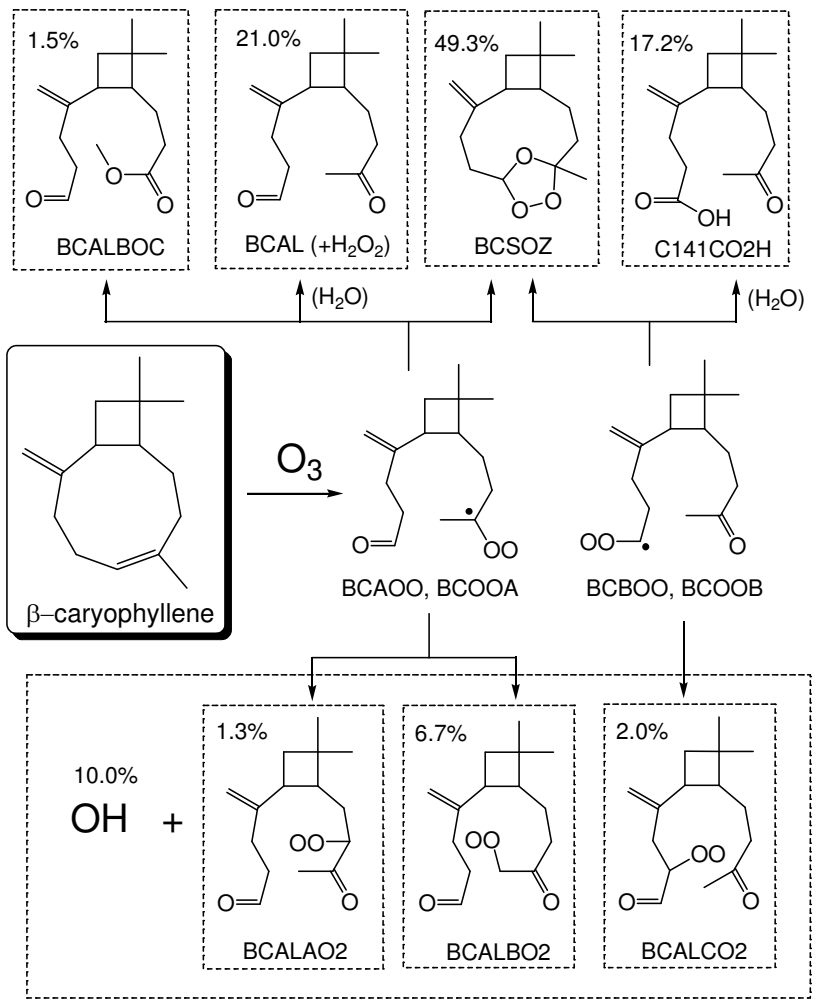

Fig. 1. Simplified schematic of the first-generation product distribution from the ozonolysis of $\beta$-caryophyllene, as represented in MCM v3.2. The displayed (molar) product yields correspond to ozonolysis at $298 \mathrm{~K}$ in 760 Torr air at $50 \%$ relative humidity; with cyclohexane present to scavenge all $\mathrm{OH}$ radicals. The further chemistry of BCALAO2, BCALBO2 and BCALCO2 is shown in Fig. 3. The figure omits to represent additional minor ozonolysis channels accounting for $1 \%$ of the chemistry, which are fully represented in MCM v3.2.

2009). This leads to formation of an (unrepresented) energy rich primary ozonide, which decomposes rapidly by two ring opening channels to form a set of isomeric $\mathrm{C}_{15}$ carbonylsubstituted Criegee intermediates. In MCM v3.2, these are represented by two pairs of species (BCAOO and BCOOA; $\mathrm{BCBOO}$ and $\mathrm{BCOOB}$ ), as shown in Fig. 1. In each case, the pairs essentially represent "excited" and "stabilized" forms of the same structure, which can participate in a series of unimolecular and bimolecular reactions to form the distribution of products shown in Fig. 1. This distribution is dominated by a set of closed-shell products, denoted $\mathrm{BCSOZ}, \mathrm{C} 141 \mathrm{CO} 2 \mathrm{H}$, BCAL and BCALBOC, which account for almost $90 \%$ of the product distribution (see Figs. 1 and 2). The formation of $\beta$-caryophyllon aldehyde (BCAL) and/or $\beta$-caryophyllonic acid $(\mathrm{C} 141 \mathrm{CO} 2 \mathrm{H})$ has been positively identified in a number of ozonolysis studies (e.g., Calogirou et al., 1997; Kanawati et al., 2008; Winterhalter et al., 2009; Li et al., 2011), with respective molar yields of $17.3 \%$ and $13.0 \%$ reported by Jaoui et al. (2003) at $\sim 80 \%$ relative humidity, in the absence of 


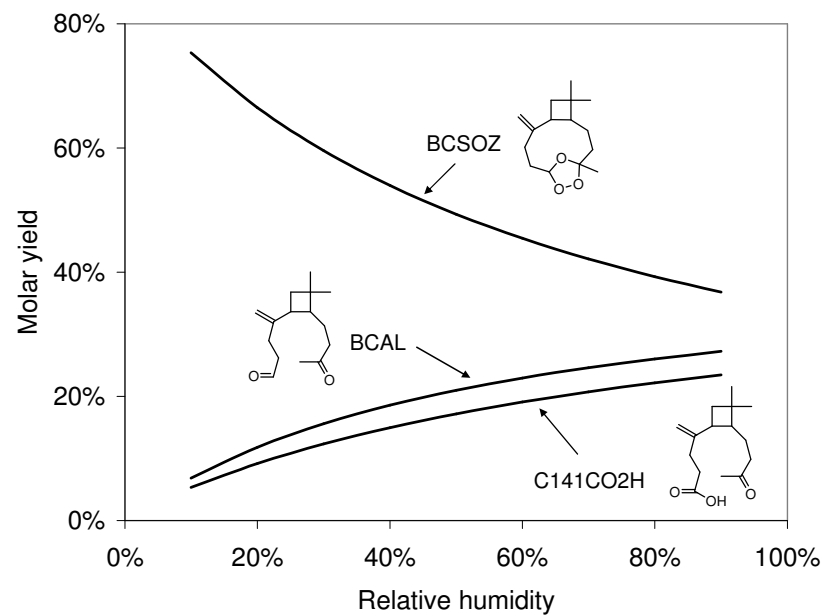

Fig. 2. Molar yields of the secondary ozonide (BCSOZ), $\beta$ caryophyllonaldehyde (BCAL) and $\beta$-caryophyllonic acid $(\mathrm{C} 141 \mathrm{CO} 2 \mathrm{H})$ as a function of relative humidity for $\beta$-caryophyllene ozonolysis at $298 \mathrm{~K}$ in 760 Torr air, with cyclohexane present to scavenge $\mathrm{OH}$ radicals, as calculated with $\mathrm{MCM}$ v3.2.

an $\mathrm{OH}$ scavenger. The theoretical calculations of Nguyen et al. (2009) propose an important role for the thermally-stable secondary ozonide (BCSOZ), formed by ring-closure of the Criegee intermediates, and suggest it should be the dominant gas phase ozonolysis product (molar yield $\geq 65 \%$ ). The experimental study of Winterhalter et al. (2009) provided some qualitative support for BCSOZ formation, and established that its yield apparently decreases with increasing relative humidity, consistent with its formation occurring at least partially in competition with the bimolecular reactions of the Criegee intermediates with water vapour. In the absence of other gas phase mechanistic information, the representation in MCM v3.2 is broadly based on this information, although it is noted that confirmatory studies of BCSOZ formation, and quantification of its yield, are required. The formation of the multifunctional ester, BCALBOC, has been reported by Kanawati et al. (2008) and Winterhalter et al. (2009), and it was calculated to be a minor ozonolysis product by Nguyen et al. (2009), consistent with its representation in MCM v3.2.

The ozonolysis of $\beta$-caryophyllene also generates $\mathrm{OH}$ radicals with a relatively low yield of $10 \%$ in MCM v3.2, consistent with the values of $\left(6_{-2}^{+3}\right) \%$ and $(10.4 \pm 2.3) \%$ reported by Shu and Atkinson (1994) and Winterhalter et al. (2009), respectively. As shown in Fig. 1, OH is formed in conjunction with a set of $\beta$-oxo peroxy radicals, denoted BCALAO2, $\mathrm{BCALBO} 2$ and $\mathrm{BCALCO} 2$, which occurs by rearrangement and decomposition of the Criegee intermediates BCOOA and BCOOB via the well-established "hydroperoxide" mechanism (e.g., see Winterhalter et al., 2009). The subsequent conventional chemistry of these $\beta$-oxo peroxy radicals generates a large number of species formed in low yield, as shown in Fig. 3. Detection of many of these species (i.e.,

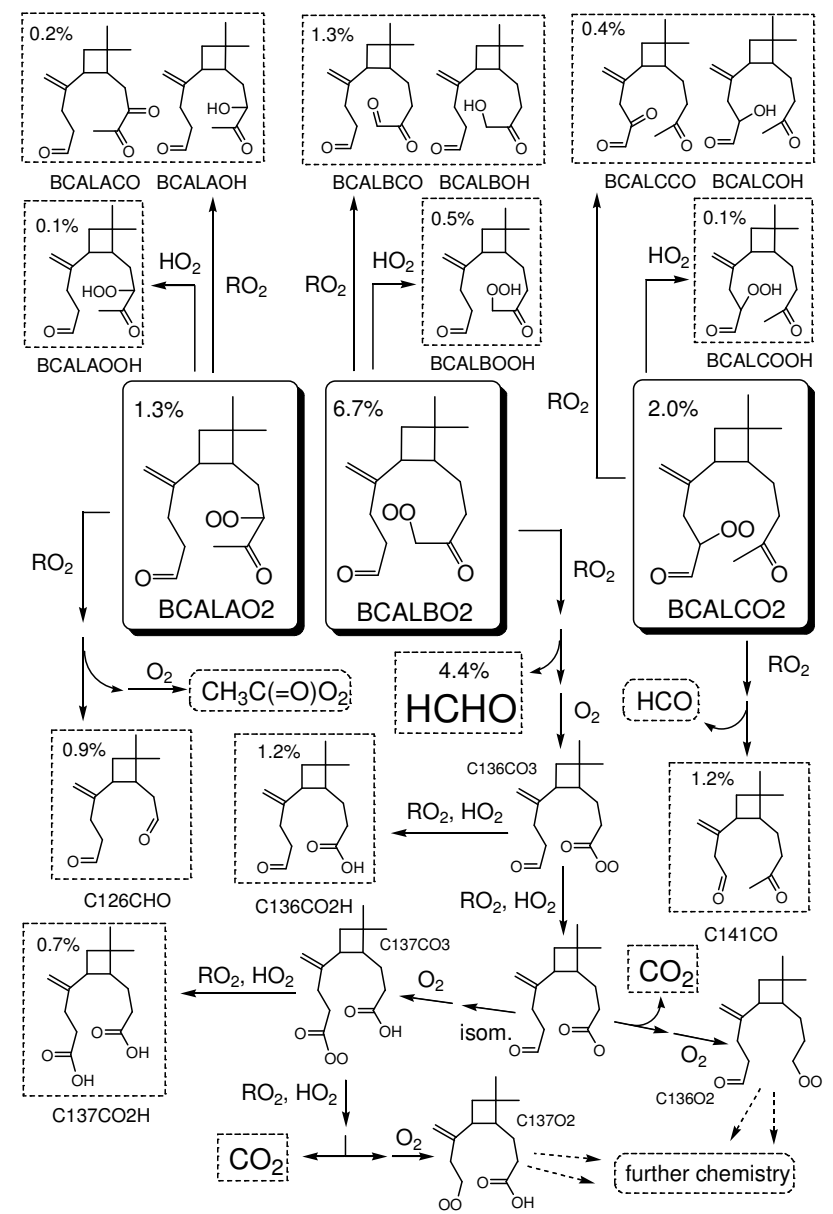

Fig. 3. Partial schematic of the product distribution from the further chemistry of BCALAO2, BCALBO2 and BCALCO2, formed from $\beta$-caryophyllene ozonolysis in MCM v3.2, as shown in Fig. 1. The displayed (molar) product yields correspond to ozonolysis at $298 \mathrm{~K}$ in 760 Torr air at $50 \%$ relative humidity; with cyclohexane present to scavenge all $\mathrm{OH}$ radicals (the displayed products account for $\approx 89 \%$ of the total product carbon from the onward reaction of these peroxy radicals).

BCALAOH, BCALBOH, BCALCOH, BCALACO, BCAL$\mathrm{BCO}, \mathrm{C} 141 \mathrm{CO}$ and $\mathrm{C} 137 \mathrm{CO} 2 \mathrm{H}$ ) has been reported in the experimental studies referred to above, and this chemistry generally provides plausible routes to their formation. In the specific case of $\beta$-caryophyllinic acid $(\mathrm{C} 137 \mathrm{CO} 2 \mathrm{H})$, the formation mechanism from BCALBO2 is more speculative, being analogous to that proposed for the production of pinic acid from $\alpha$-pinene by Jenkin et al. (2000), involving an acyloxy radical isomerisation. Although that mechanism has received some experimental support (e.g., Ma et al., 2008), it is noted that it has been refuted by the theoretical calculations of Vereecken and Peeters (2009). Nevertheless, the characterisation of analogous diacid formation in a number of terpene systems in the experimental mechanistic studies of $\mathrm{Ma}$ et al. $(2008,2009 \mathrm{a}, \mathrm{b})$ suggest that $\mathrm{C} 137 \mathrm{CO} 2 \mathrm{H}$ is most likely 
formed from the chemistry of BCALBO2, and the adoption of the Jenkin et al. (2000) mechanism is regarded as a reasonable provisional measure until alternative mechanisms are available.

The relative formation efficiencies of the three $\beta$-oxo peroxy radicals, formed as $\mathrm{OH}$ co-products, aims to provide yields of experimentally quantified products which are consistent with the literature. As a result, the formation of BCALBO2 from BCOOA is strongly favoured over BCALAO2 in MCM v3.2, this being in accord with the results of the calculations of Nguyen et al. (2009). The chemistry of $\mathrm{BCALBO} 2$ is believed to provide the major route to first-generation $\mathrm{HCHO}$ formation in the system (Winterhalter et al., 2009), and the preferential formation of BCALBO2 allows an HCHO yield of $4.4 \%$ (see Fig. 3), which is consistent with the value of $(7.7 \pm 4.0) \%$, reported by Winterhalter et al. (2009). It also allows $\mathrm{C} 137 \mathrm{CO} 2 \mathrm{H}$ to be formed with a yield of approaching $1 \%$, which is broadly comparable to the yields of analogous diacids reported for a number of terpene systems (e.g., Ma et al., 2008, 2009a, b; and references therein). It is, however, somewhat lower than the value of $4 \%$ reported specifically for $\beta$-caryophyllinic acid from $\beta$-caryophyllene ozonolysis by Jaoui et al. (2003), with detection completely in the aerosol phase. This may be indicative of a contribution to this yield resulting from aerosolphase chemistry although, as indicated above, further characterisation of potential gas phase formation routes is required. As shown in Fig. 3, the formation of $\mathrm{CO}$ in the firstgeneration MCM v3.2 chemistry is due to the chemistry of BCALCO2, with $\mathrm{CO}_{2}$ being formed from the chemistry of both BCALAO2 and BCALBO2. This leads to respective yields of $1.1 \%$ and $5.8 \%$ for $\mathrm{CO}$ and $\mathrm{CO}_{2}$, which are also consistent with the approximate values of $(2.0 \pm 1.8) \%$ and $(3.8 \pm 2.8) \%$ reported by Winterhalter et al. (2009).

The product yields presented in Fig. 3 represent those calculated by MCM v3.2 from ozonolysis in the absence of $\mathrm{NO}_{\mathrm{x}}$. It should be noted that formation of many of the displayed products is inhibited in the presence of $\mathrm{NO}_{\mathrm{x}}$, when $\mathrm{NO}$ (or possibly $\mathrm{NO}_{2}$ for acyl peroxy radicals) may provide the major reaction partner for the peroxy radicals. Assuming exclusive reaction of peroxy radicals with the $\mathrm{NO}_{\mathrm{x}}$ species, the majority of products in Fig. 3 (including $\mathrm{C} 137 \mathrm{CO} 2 \mathrm{H}$ ) are not formed, the exceptions being $\mathrm{C} 126 \mathrm{CHO}(1.3 \%)$, $\mathrm{C} 141 \mathrm{CO}(2.0 \%)$ and $\mathrm{HCHO}(6.7-8.0 \%)$. It also provides the possibility of formation of PAN $\left(\mathrm{CH}_{3} \mathrm{C}(=\mathrm{O}) \mathrm{OONO}_{2}\right)$ from the reaction of $\mathrm{CH}_{3} \mathrm{C}(=\mathrm{O}) \mathrm{O}_{2}$ with $\mathrm{NO}_{2}$, and a number of complex PANs (e.g., C136PAN and C137PAN) from the reactions of the corresponding acyl peroxy radicals (see $\mathrm{C} 136 \mathrm{CO} 3$ and $\mathrm{C} 137 \mathrm{CO} 3$ in Fig. 3) with $\mathrm{NO}_{2}$.

\subsubsection{Reaction with $\mathrm{OH}$ radicals}

The main features of the $\mathrm{OH}$-initiated degradation chemistry of $\beta$-caryophyllene to first-generation products, as represented in MCM v3.2, are summarized in Fig. 4. Although

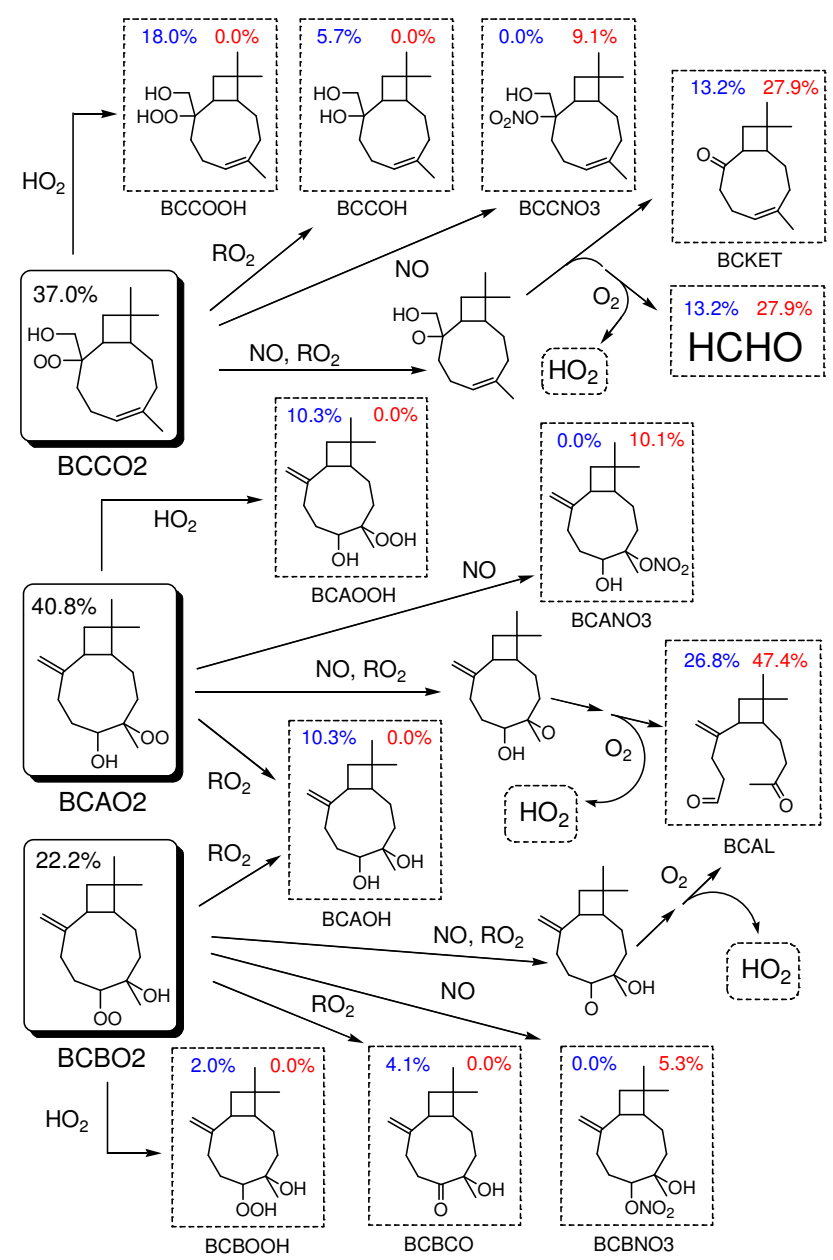

Fig. 4. Simplified schematic of the first-generation product distribution from the $\mathrm{OH}$-initiated degradation of $\beta$-caryophyllene, as represented in MCM v3.2. The peroxy radicals, BCAO2, BCBO2 and $\mathrm{BCCO} 2$ are formed from the initial sequential addition of $\mathrm{OH}$ and $\mathrm{O}_{2}$ to $\beta$-caryophyllene. The displayed (molar) product yields correspond to $298 \mathrm{~K}$ and 760 Torr. Yields in blue are for NOx-free conditions; yields in red are for conditions when there is sufficient NO present to provide the exclusive reaction partner for the $\mathrm{RO}_{2}$ radicals (but insufficient to react significantly with $\mathrm{RO}$ radicals).

reaction with $\mathrm{OH}$ under atmospheric conditions is usually less significant than ozonolysis, the $\mathrm{OH}$-initiated chemistry supplements $\beta$-caryophyllene removal in $\mathrm{OH}$ scavenger-free ozonolysis experiments, and its importance is potentially amplified in photo-oxidation experiments when $\mathrm{NO}_{\mathrm{x}}$ is present. In contrast to ozonolysis, reaction with $\mathrm{OH}$ is expected to occur significantly by addition to both the exocyclic and endocyclic double bonds (e.g., Kwok and Atkinson, 1995; Jenkin et al., 1997). The formation of the tertiary and secondary peroxy radicals, $\mathrm{BCAO} 2$ and $\mathrm{BCBO} 2$, thus result from sequential addition of $\mathrm{OH}$ and $\mathrm{O}_{2}$ to either ends of the endocyclic bond. Addition to the exocylic bond is represented by the single isomer, $\mathrm{BCCO} 2$, as formation of a tertiary peroxy radical 
is strongly favoured over a primary one (e.g., Peeters et al., 1994).

The subsequent conventional chemistry of these $\beta$ hydroxy peroxy radicals generates the distribution of species shown in Fig.4. In the absence of $\mathrm{NO}_{\mathrm{x}}$, this includes a set of isomeric hydroxy-hydroperoxides $(\mathrm{BCAOOH}, \mathrm{BC}-$ $\mathrm{BOOH}$ and $\mathrm{BCCOOH}$; accounting for $30.3 \%$ of the products), formed from the terminating reactions of the peroxy radicals with $\mathrm{HO}_{2}$; and a set isomeric dihydroxy species (BCAOH and $\mathrm{BCCOH}$; accounting for $16.0 \%$ of the products) and a hydroxyketone species (BCBCO; accounting for $4.1 \%$ of the products), formed from terminating channels of the peroxy radical permutation reactions (i.e., reactions with the available pool of peroxy radicals, denoted " $\mathrm{RO}_{2}$ "). The propagating channels of the peroxy radical permutation reactions lead to the formation of $\mathrm{HO}_{2}$ and the carbonyl products BCAL $(26.8 \%)$, from $\mathrm{BCAO} 2$ and $\mathrm{BCBO} 2$, and BCKET ( $\beta$ nocaryophyllone) and $\mathrm{HCHO}(13.2 \%)$, from $\mathrm{BCCO} 2$. In the presence of $\mathrm{NO}_{\mathrm{x}}$ (and assuming the peroxy radicals react exclusively with NO) the respective yields of these carbonyl products are increased to $47.4 \%$ and $27.9 \%$, owing to the greater importance of the propagating channels of these reactions. The remaining flux leads to the formation of a set of isomeric hydroxy-nitrates (BCANO3, BCBNO3 and BC$\mathrm{CNO} 3$; accounting for $24.7 \%$ of the products), formed from the terminating channels.

Although the product distribution in Fig. 4 is largely predicted on the basis of the conventional chemical processes generally applied in MCM v3.2 (Jenkin et al., 1997; Saunders et al., 2003), there is limited experimental support for some aspects of the chemistry. Support for the formation of BCKET from the $\mathrm{OH}$-initiated chemistry has been reported in $\mathrm{OH}$ scavenger-free ozonolysis systems (e.g., Jaoui et al., 2003) and in photo-oxidation systems designed to elevate the importance of OH-initiation (Lee et al., 2006b). It has generally not been reported as a product in ozonolysis experiments with $\mathrm{OH}$ radical scavenging, although it may potentially be formed in very low yield from the minor $(1 \%)$ attack of $\mathrm{O}_{3}$ at the exocyclic double bond in $\beta$-caryophyllene (this not being represented in MCM v3.2). BCAL is believed to be formed significantly from both the $\mathrm{OH}$ and $\mathrm{O}_{3}$-initiated chemistry, and has therefore generally been identified as a major product in almost all of the reported studies. Detection of the dihydroxy species, $\mathrm{BCAOH}$, has been reported in the $\mathrm{OH}$ scavenger-free ozonolysis experiments of Kanawati et al. (2008). There is currently no reported evidence for production of any of the other species in Fig. 4.

\subsection{Higher generation chemistry}

The presence of a residual double bond in the first-generation products makes them susceptible to attack from both $\mathrm{O}_{3}$ and $\mathrm{OH}$ radicals. Because of the exceptionally high reactivity of the endocyclic double bond in $\beta$-caryophyllene to-

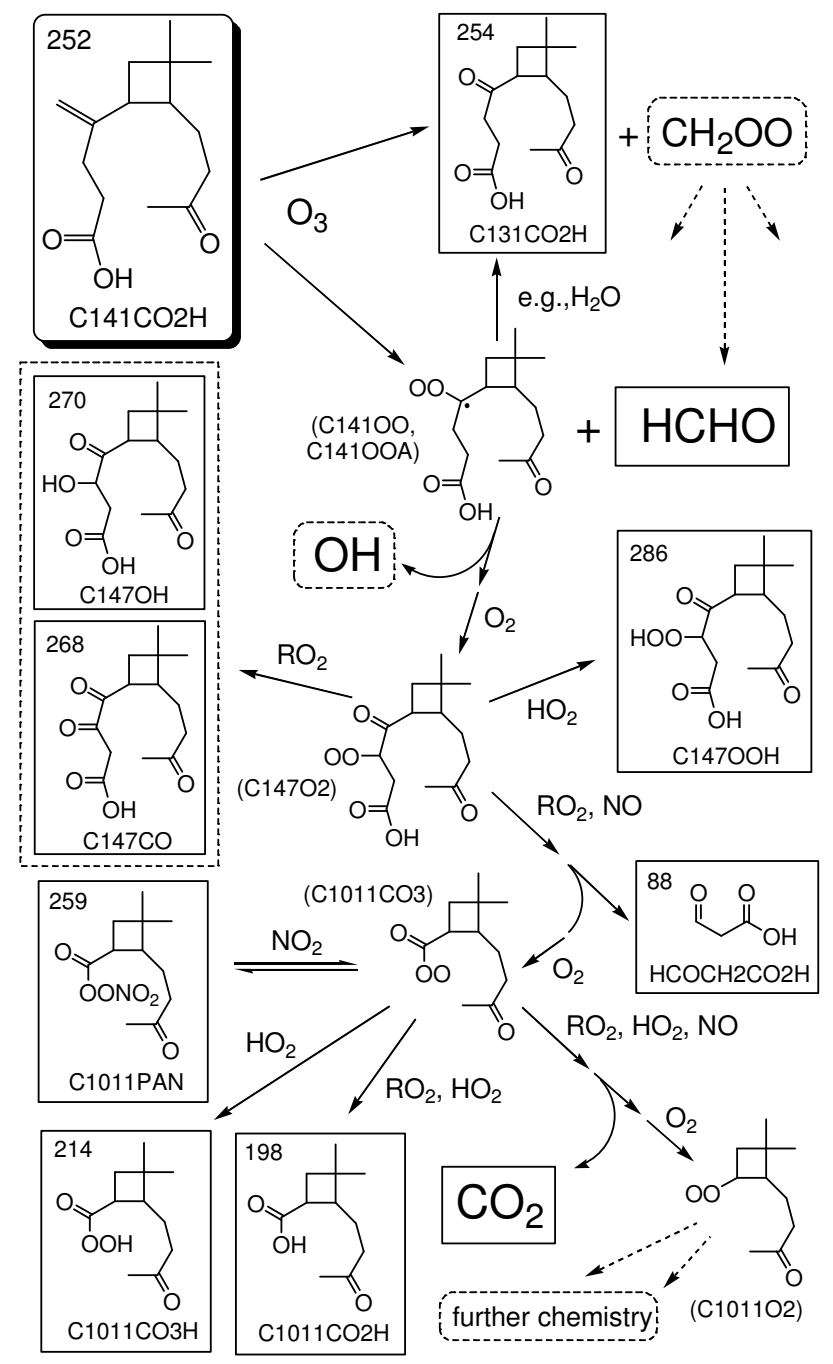

Fig. 5. Mechanism and selected products of the ozonolysis of the major first-generation product, $\beta$-caryophyllonic acid $(\mathrm{C} 141 \mathrm{CO} 2 \mathrm{H})$. The displayed values indicate the molecular masses of the products.

wards ozonolysis, the "exocyclic" double bond remains in the majority of the first-generation products. Although this is two orders of magnitude less reactive than the endocyclic double bond, it is nonetheless still sufficiently reactive for ozonolysis to make some contribution to product removal under many conditions. Fig. 5 shows the main features of the $\mathrm{O}_{3}$-initiated degradation chemistry for the example major first-generation product $\beta$-caryophyllonic acid $(\mathrm{C} 141 \mathrm{CO} 2 \mathrm{H})$ in MCM v3.2, with analogous pathways being represented

\footnotetext{
${ }^{1}$ When referring to the residual double bond following oxidation of the $\beta$-caryophyllene endocyclic double bond, we place the term "exocyclic" in quotes because the cycle to which the bond was originally exocyclic in $\beta$-caryophyllene no longer exists in many of the products. In these cases, the bond is strictly not exocyclic, and the term is being used as a convenient label.
} 


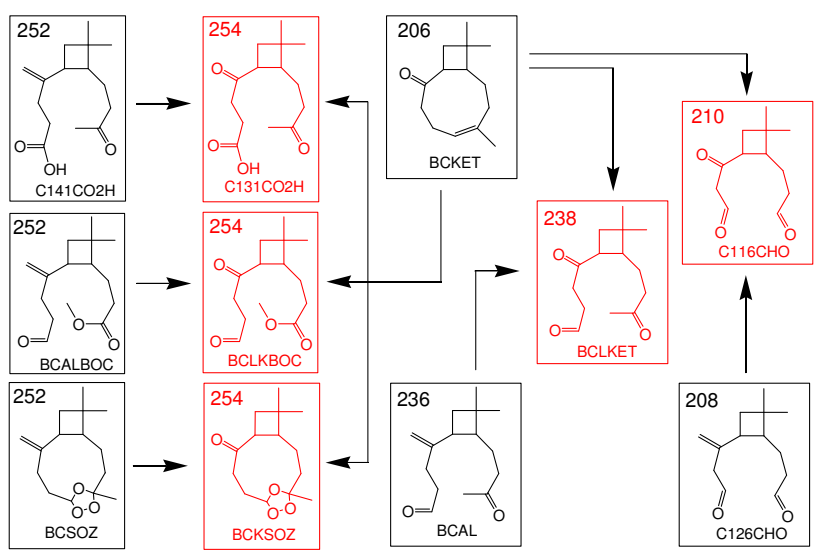

Fig. 6. Simplified schematic of ozonolysis conversion routes for selected first-generation products (shown in black) to selected secondgeneration products (shown in red). With the exception of BCKET, all processes represent the partial formation of a second-generation carbonyl product from ozonolysis of the residual "exocyclic" double bond in the corresponding first-generation product. In the case of BCKET, the schematic shows the formation of the same series of second-generation products following ozonolysis of the residual endocyclic bond. The displayed values indicate the molecular masses of the products.

for many of the other first-generation products which retain the "exocyclic" double bond. Once again, the mechanism proceeds via production of an (unrepresented) energy rich primary ozonide, which decomposes by two possible channels, forming either $\mathrm{HCHO}$ and a $\mathrm{C}_{14}$ Criegee intermediate (in nominally "excited" and "stabilized" forms, denoted $\mathrm{C} 141 \mathrm{OOA}$ and $\mathrm{C} 141 \mathrm{OO}$ ); or $\beta$-nocaryophyllonic acid $(\mathrm{C} 131 \mathrm{CO} 2 \mathrm{H})$ and the Criegee intermediate, $\mathrm{CH}_{2} \mathrm{OO}$ (again in nominally "excited" and "stabilized" forms). As shown in Fig. 5, the stabilized Criegee intermediates undergo bimolecular reactions, leading to additional formation of $\mathrm{HCHO}$ and $\mathrm{C} 131 \mathrm{CO} 2 \mathrm{H}$, which are therefore major ozonolysis products. Similarly, it is anticipated that ozonolysis of many of the firstgeneration products in which the "exocyclic" double bond is retained, also generate $\mathrm{HCHO}$ and a corresponding complex carbonyl product in which the first-generation functionalities are retained (as discussed, for example, by Winterhalter et al., 2009).

This is further illustrated in Fig. 6 for ozonolysis of a series of such first-generation products (BCSOZ, $\mathrm{C} 141 \mathrm{CO} 2 \mathrm{H}$, BCALBOC, BCAL and $\mathrm{C} 126 \mathrm{CHO}$ ), showing the corresponding second-generation products (BCKSOZ, C131CO2H, BCLKBOC, BCLKET and C116CHO), as represented in MCM v3.2. Of these, evidence for formation of $\beta$-nocaryophyllonic acid $(\mathrm{C} 131 \mathrm{CO} 2 \mathrm{H})$ and/or $\beta$ nocaryophyllone aldehyde (BCLKET) has been reported in a number of experimental studies where secondary ozonolysis of the first-generation product distribution was likely to be important (Calogirou et al., 1997; Jaoui et al., 2003; Li et al., 2011). Because of the importance of the secondary ozonide, BCSOZ, as a first-generation product in MCM v3.2 (as discussed above and shown in Fig. 2), the corresponding second-generation product, BCKSOZ, is inevitably predicted to make a major contribution to the second-generation product distribution. This further emphasises the need for studies to quantify the yield of BCSOZ from $\beta$-caryophyllene ozonolysis, and to elucidate the details of its further oxidation - including whether or not the products retain the "ozonide" functionality. Secondary ozonolysis of the first-generation ozonolysis product distribution also produces $\mathrm{HCHO}$ with a molar yield of between $59 \%$ and $63 \%$ (depending on relative humidity), in good agreement with the value of $(60 \pm 6) \%$ reported by Winterhalter et al. (2009), and also consistent with the yield of $(76 \pm 20) \%$ reported by Lee et al. (2006a) (which represents the sum of the first- and second-generation $\mathrm{HCHO}$ yields).

As shown in Fig. 5, the ozonolysis of C141CO2H in MCM v3.2 also partially generates $\mathrm{OH}$ radicals in conjunction with the (multifunctional) $\beta$-oxo peroxy radical, $\mathrm{C} 147 \mathrm{O} 2$, via the "hydroperoxide" mechanism operating on C1410OA. This leads to the formation of a set of $\mathrm{C}_{14}$ products (via terminating reaction channels), which retain the original acid functionality, of which detection of $\mathrm{C} 147 \mathrm{OH}$ has been reported by Li et al. (2011). It also leads to fragmentation (via propagating reaction channels) to form the smaller acyl peroxy radical, $\mathrm{C} 1011 \mathrm{CO} 3$, in conjunction with loss of the $\mathrm{C}_{3}$ species $\mathrm{HCOCH}_{2} \mathrm{C}(=\mathrm{O}) \mathrm{OH}$, which retains the original acid functionality. In practice, $\mathrm{C} 1011 \mathrm{CO} 3$ can also be formed (in conjunction with $\mathrm{HCOCH}_{2} \mathrm{CHO}$ ) from the analogous chemistry of BCAL, such that $\mathrm{C} 1011 \mathrm{CO} 3$, and its reaction products shown in Fig. 5, are potentially formed from the ozonolysis of two major first-generation products. Accordingly, $\mathrm{Li}$ et al. (2011) have also reported detection of $\mathrm{C} 1011 \mathrm{CO} 2 \mathrm{H}$, although its formation was not attributed to precisely this reaction mechanism.

Under conditions where reaction with $\mathrm{OH}$ contributes to $\beta$-caryophyllene removal (e.g., $\mathrm{OH}$ scavenger-free ozonolysis systems), some of the first-generation products retain the endocyclic double bond. Of these, $\beta$-nocaryophyllone (BCKET) is a particularly significant product (see Fig. 4), and it is likely that ozonolysis is its major fate under many conditions. In MCM v3.2, its ozonolysis is treated completely analogously to that of $\beta$-caryophyllene itself (e.g., as illustrated in Figs. 1 and 3). Figure 6 shows selected features of the chemistry, which indicate that BCKET ozonolysis can provide additional routes to the series of second-generation products described above (i.e., BCKSOZ, C131CO2H, BCLKBOC, BCLKET and C116CHO). Other first-generation products that retain the endocyclic double bond are generally formed in very low yield, and their ozonolysis chemistry is not currently represented in MCM v3.2 (consistent with the scheme simplification measures defined in Jenkin et al., 1997). Although this is not expected to have a major impact on overall mechanism performance 

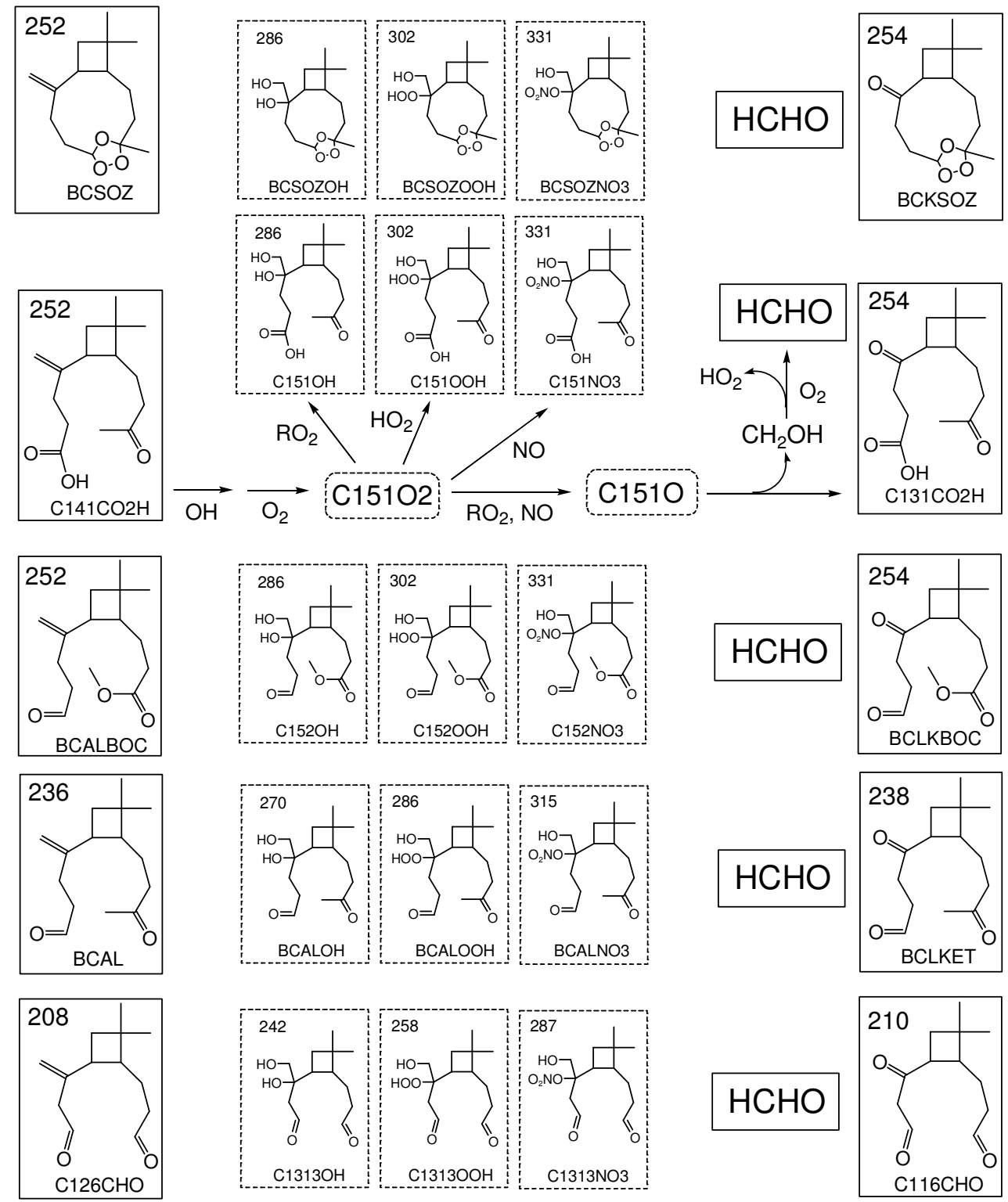

Fig. 7. Schematic of the mechanism and products of the OH-initiated oxidation of a series of first-generation products, shown in the lefthand column, following attack of $\mathrm{OH}$ at the residual "exocyclic" double bond. The details of the mechanism are summarised only for $\beta$-caryophyllonic acid $(\mathrm{C} 141 \mathrm{CO} 2 \mathrm{H})$; but the mechanisms for the other species follow analogous pathways. The displayed values indicate the molecular masses of the products.

in many applications, it may potentially influence modelmeasurement comparisons for the particular species in detailed evaluation studies.

Figure 7 shows the main features of the OH-initiated degradation chemistry in MCM v3.2, for the same series of significant first-generation products that retain the "exocyclic" double bond. In each case, this is represented by sequential addition of $\mathrm{OH}$ and $\mathrm{O}_{2}$ to the double bond to form a (strongly-favoured) tertiary $\beta$-hydroxy peroxy radical. The subsequent conventional chemistry of this set of peroxy radicals generates the series of species shown in Fig. 7 .
The propagating reaction channels (with $\mathrm{NO}$ and $\mathrm{RO}_{2}$ ) once again lead to the formation of $\mathrm{HCHO}$ and the same set of second-generation carbonyl-substituted products discussed above for the ozonolysis chemistry, thereby providing additional mechanisms for their generation. The terminating reaction channels (with $\mathrm{NO}, \mathrm{HO}_{2}$ and $\mathrm{RO}_{2}$ ) form a set of high molecular weight multifunctional hydroxy-nitrates, hydroxyhydroperoxides and dihydroxy species that would be expected to show a high propensity to transfer to the aerosol phase. In this respect, evidence for the presence of a hydrated form of $\mathrm{C} 151 \mathrm{NO} 3$ in $\beta$-caryophyllene SOA has been 


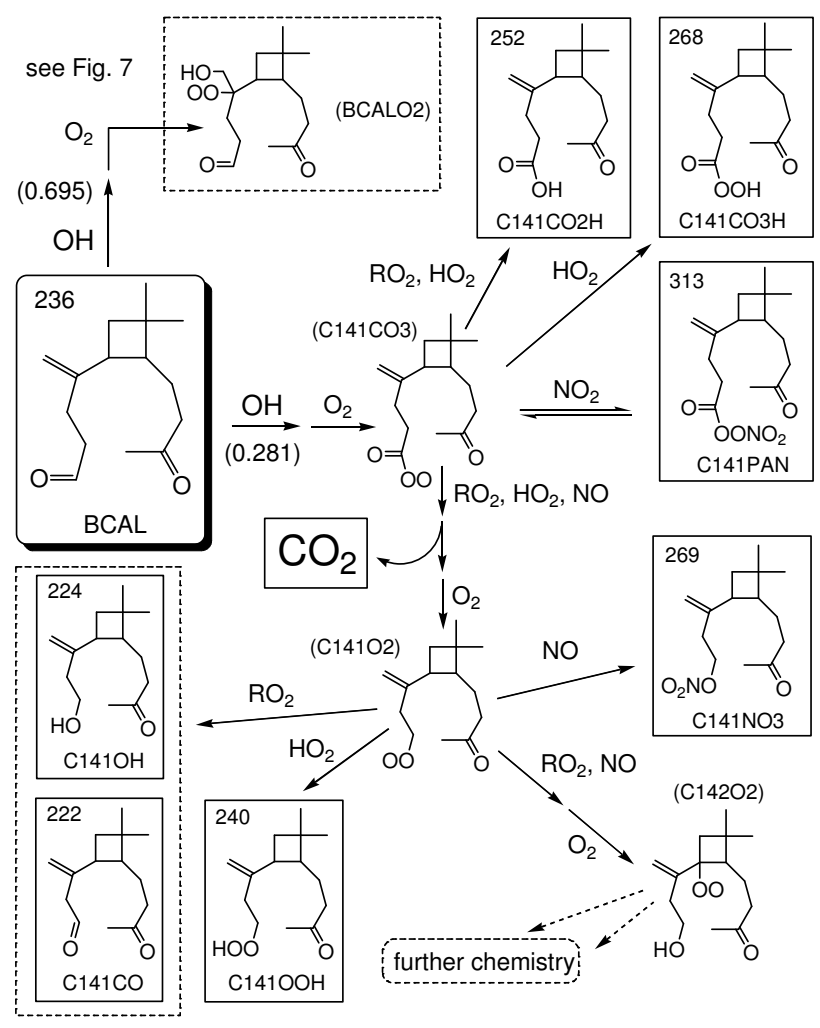

Fig. 8. Schematic of the mechanism and selected products of the $\mathrm{OH}$-initiated oxidation of $\beta$-caryophyllon aldehyde (BCAL), focusing on the chemistry following abstraction of the aldehydic $\mathrm{H}$ atom. The displayed values indicate the molecular masses of the products.

reported by Chan et al. (2011), their experiments being performed under photo-oxidation conditions with a likely important contribution from $\mathrm{OH}$-initiated degradation of firstgeneration products

Although addition of $\mathrm{OH}$ to the double bond is the major (or exclusive) reaction channel for the series of firstgeneration products in Fig. 7, $\mathrm{H}$ atom abstraction channels are also included in MCM v3.2, where significant. This is particularly the case for species containing aldehyde groups, as illustrated for the most important aldehyde product, $\beta$ caryophyllon aldehyde (BCAL) in Fig. 8. This leads to formation routes for $\beta$-caryophyllonic acid $(\mathrm{C} 141 \mathrm{CO} 2 \mathrm{H})$, a corresponding percarboxylic acid $(\mathrm{C} 141 \mathrm{CO} 3 \mathrm{H})$ and a complex PAN (C141PAN); and also routes to breakdown to smaller second-generation products, including $\beta$-norcaryophyllone aldehyde $(\mathrm{C} 141 \mathrm{CO})$, as partially shown in Fig. 8 . The supplementary formation of $\mathrm{C} 141 \mathrm{CO} 2 \mathrm{H}$ and $\mathrm{C} 141 \mathrm{CO}$ in the second generation of oxidation illustrates that it is not always possible to label a structure as uniquely a product of a particular generation, as is even more apparent for smaller breakdown products such as $\mathrm{HCHO}$.

The further degradation of the product distribution in successive generations follows the rules described in detail by
Jenkin et al. (1997) and Saunders et al. (2003), and is developed until it feeds into the production of smaller species already present in the MCM database. As part of a general update in MCM v3.2, the reactions of acyl peroxy radicals with $\mathrm{HO}_{2}$ throughout the mechanism have been revised to include propagating channels, as follows:

$\mathrm{RC}(=\mathrm{O}) \mathrm{O}_{2}+\mathrm{HO}_{2} \rightarrow \mathrm{RC}(=\mathrm{O}) \mathrm{O}+\mathrm{OH}+\mathrm{O}_{2}$

The IUPAC recommendation for the reaction of $\mathrm{CH}_{3} \mathrm{C}(\mathrm{O}) \mathrm{O}_{2}$ with $\mathrm{HO}_{2}$ (http://www.iupac-kinetic.ch.cam.ac.uk/) has been adopted for the branching ratio of this reaction channel, this being based on the experimental determinations of Hasson et al. (2004), Jenkin et al. (2007) and Dillon and Crowley (2008).

\section{Experimental datasets}

The experimental datasets used to evaluate the MCM v3.2 representation of $\beta$-caryophyllene degradation are summarized in Table 1. In some cases (Jaoui et al., 2003; Winterhalter et al., 2009), the reported information contributed directly to the construction of the mechanism, as described above, and the evaluation is limited to a comparison of the observed SOA yields with those simulated for the reported conditions (see Sect. 4). In other cases, the reported product distributions and their temporal profiles (where available) are used to evaluate the chemical detail in the MCM v3.2 chemistry for both ozonolysis and photo-oxidation conditions, using detailed chamber simulations.

The most extensive evaluation makes use of a subset of a series of $\beta$-caryophyllene/ $\mathrm{NO}_{\mathrm{x}}$ photo-oxidation experiments performed as part of the Aerosol Coupling in the Earth System (ACES) project. These experiments are described in detail elsewhere (Alfarra et al., 2012), and only an overview is therefore provided here.

\subsection{Reaction chamber}

The experiments were carried out in a collapsible $18 \mathrm{~m}^{3}$ FEP Teflon chamber at the University of Manchester. The chamber is equipped with a set of halogen lamps and a $6 \mathrm{~kW}$ Xenon arc lamp and surrounded by reflective surfaces, providing even illumination of the chamber space and a well-characterized photolysing radiation. This is designed to mimic the atmospheric actinic spectrum over the wavelength range $290-800 \mathrm{~nm}$, and has a maximum total actinic flux of $0.7 \times 10^{18}$ photons $\mathrm{s}^{-1} \mathrm{~m}^{-2} \mathrm{~nm}^{-1}$ over the region $460-500 \mathrm{~nm}$.

The air supply into the chamber was dried and filtered for gaseous impurities and particles using a series of Purafil (Purafil Inc., USA), charcoal and HEPA (Donaldson Filtration) filters, prior to humidification with ultrapure deionised water. $\beta$-caryophyllene was introduced via direct liquid injection into a heated glass bulb, which was flushed into 
Table 1. Summary of experimental datasets used to evaluate the MCM v3.2 $\beta$-caryophyllene scheme.

\begin{tabular}{|c|c|c|c|c|c|c|c|c|}
\hline Reference & Experiment $^{\mathrm{a}}$ & {$[\beta \text {-caryophyllene }]_{0}$} & {$[\text { ozone }]_{0}$} & OH scavenger & $T$ & Relative humidity & {$[\mathrm{SOA}]^{\mathrm{b}}$} & \\
\hline \multicolumn{2}{|c|}{ Ozonolysis experiments } & \multirow{2}{*}{$\frac{\mathrm{ppb}}{601}$} & \multicolumn{2}{|l|}{$\mathrm{ppb}$} & $\mathrm{K}$ & $\%$ & \multicolumn{2}{|l|}{$\mu \mathrm{g} \mathrm{m}^{-3}$} \\
\hline Jaoui et al. (2003) & - & & 640 & none & 288 & 82.5 & $2090(2170)$ & \\
\hline \multirow{2}{*}{ Winterhalter et al. (2009) } & BC1210 & 296 & 200 & cyclohexane & 296 & 36 & $420(399)$ & \\
\hline & $\mathrm{BC} 1310$ & 295 & 200 & cyclohexane & 296 & 36 & $440(399)$ & \\
\hline \multirow[t]{4}{*}{ Li et al. $(2011)^{\mathrm{c}}$} & 1 & 1.7 & $50^{\mathrm{d}}$ & cyclohexane & 298 & 40 & $0.5(0.6)$ & \\
\hline & 2 & 6.7 & $50^{\mathrm{d}}$ & cyclohexane & 298 & 40 & $3.4(5.9)$ & \\
\hline & 3 & 13.3 & $50^{\mathrm{d}}$ & cyclohexane & 298 & 40 & $7.7(16.2)$ & \\
\hline & 4 & 46.4 & $50^{\mathrm{d}}$ & cyclohexane & 298 & 40 & $29.1(79.8)$ & \\
\hline Reference & Experiment $^{\mathrm{a}}$ & {$[\beta \text {-caryophyllene }]_{0}$} & {$[\mathrm{NO}]_{0}$} & {$\left[\mathrm{NO}_{2}\right]_{0}$} & $T$ & Relative humidity & [ozone $^{\mathrm{e}}$ & {$[\mathrm{SOA}]^{\mathrm{b}}$} \\
\hline \multicolumn{2}{|c|}{ Photo-oxidation experiments } & ppb & $\mathrm{ppb}$ & $\mathrm{ppb}$ & $\mathrm{K}$ & $\%$ & $\mathrm{ppb}$ & $\mu \mathrm{g} \mathrm{m}^{-3}$ \\
\hline Lee et al., $2006 \mathrm{~b}$ & - & 42 & 16 & $16^{\mathrm{f}}$ & 295 & 56 & $13(21)$ & $212(111)$ \\
\hline \multirow[t]{4}{*}{ ACES, Alfarra et al. (2012) } & $30-06-08$ & 31.1 & 6.9 & 22.6 & 297.5 & 69.8 & $7.6(20.7)$ & $45(98)$ \\
\hline & 03-07-08 & 42.7 & 10.6 & 43.4 & 297.8 & 68.6 & $10.3(25.6)$ & $66(144)$ \\
\hline & 04-07-08 & 48.0 & 10.9 & 41.0 & 297.8 & 68.1 & $7.9(20.8)$ & $61(147)$ \\
\hline & $10-07-08$ & 48.1 & 10.9 & 62.5 & 297.5 & 69.5 & $11.2(27.0)$ & $66(166)$ \\
\hline
\end{tabular}

${ }^{a}$ Experiment identified on the basis of assignment in original reference; ${ }^{b}$ maximum observed SOA concentration; figure in brackets is the maximum simulated concentration, using the base MCM v3.2 scheme; sensitivity tests described in text; ${ }^{\mathrm{c}}$ experiments performed with ammonium sulphate seed aerosol; ${ }^{\mathrm{d}}$ maintained excess mixing ratio;

e maximum observed $\mathrm{O}_{3}$ mixing ratio; figure in brackets is the maximum simulated mixing ratio, using the base MCM v3.2 scheme; sensitivity tests described in text;

$\mathrm{f}_{\text {initial }} \mathrm{NO}_{2}$ mixing ratio includes an unspecified contribution from $\mathrm{HONO}$; simulation initialised with 9.6 ppb $\mathrm{NO}_{2}$ and $6.4 \mathrm{ppb} \mathrm{HONO}$ (see text).

the chamber with a flow of filtered, high purity $\mathrm{N}_{2}$ (ECD grade, $99.997 \%)$. $\mathrm{NO}_{\mathrm{x}}$ was introduced, primarily in the form of $\mathrm{NO}_{2}$, by injection from a cylinder into the charge line. Relative humidity and temperature were measured at several points throughout the chamber (by dewpoint hygrometer and a series of cross-calibrated thermocouples and resistance probes), and were controlled by diverting air through the inlet humidification circuit and by controlling the air conditioning set-point, respectively.

\subsection{CIR-TOF-MS measurements}

The gas phase organic compounds within the chamber (including the precursor $\beta$-caryophyllene) were measured using Chemical Ionisation Reaction Time-of-Flight Mass Spectrometry (CIR-TOF-MS), as described in detail by Wyche et al. (2007). The CIR-TOF-MS instrument comprises a bespoke, temperature controlled $\left((40 \pm 1)^{\circ} \mathrm{C}\right)$ radioactive $\left({ }^{241} \mathrm{Am}\right)$ ion source/drift tube assembly, coupled via a system of ion transfer optics to an orthogonal time-of-flight mass spectrometer (Kore Technology, UK). In order to provide enhanced mass resolution, the TOF-MS is equipped with a reflectron array $(\mathrm{m} / \Delta \mathrm{m} \sim 1500-3000)$.

During all ACES experiments, proton transfer reaction ionisation was employed as the chemical ionisation technique, utilizing hydrated hydronium ions (e.g. $\mathrm{H}_{3} \mathrm{O}^{+} \cdot\left(\mathrm{H}_{2} \mathrm{O}\right)$ ) as the primary reagent ions. These were generated from a humidified $\mathrm{N}_{2}$ carrier gas ( $99.9999 \%$ purity), delivered directly to the ion source. Chamber air containing the analyte organic compounds was supplied directly to the drift cell reactor at a continuous flow rate of $230 \mathrm{sccm}$. Depending on the properties of the analyte (M) (e.g. proton affinity and dipole mo- ment), an ion-molecule reaction involving it and the hydrated hydronium ion can occur at the collision-limited rate to yield a protonated analyte ion $\left(\mathrm{MH}^{+}\right)$(e.g. de Gouw and Warneke, 2007; Blake et al., 2009):

$\mathrm{H}_{3} \mathrm{O}^{+}\left(\mathrm{H}_{2} \mathrm{O}\right)+\mathrm{M} \rightarrow \mathrm{MH}^{+}+2 \mathrm{H}_{2} \mathrm{O}$

If the energies involved in Reaction (R2) are sufficiently high (and particularly if the analyte contains certain functional groups), the $\mathrm{MH}^{+}$product may undergo fragmentation to produce various daughter ions, as described in more detail in Sects. 6.3.1-6.3.4. In order to limit analyte fragmentation and hence increase sensitivity and selectivity, the main reactor cell of the drift tube was operated at an electric field/gas number density $(\mathrm{E} / \mathrm{N})$ of $\sim 90 \mathrm{Td}$. A tuned energy ramp was applied at the base of the drift cell to facilitate the removal of unwanted cluster ions (e.g. $\mathrm{MH}^{+} \cdot \mathrm{H}_{2} \mathrm{O}$ ) (Wyche et al., 2007).

The CIR-TOF-MS was calibrated for a range of oxygenated and non-oxygenated volatile organic compounds using three different methods: (i) stepwise dilution and measurement of a commercially sourced gas standard (BOC Special Gases, UK); (ii) analysis of gas standards generated from permeation tubes (Eco-Scientific Ltd, UK and Vici Inc., US) using a commercial calibration and humidification unit (Kintec, model 491); and (iii) analysis of $10 \mathrm{~L}$ Teflon sample bags (SKC Inc. US) following liquid injection of the target organic compound into a nitrogen matrix. The precursor $\beta$ caryophyllene was calibrated for using method (iii), which was validated via cross comparisions with methods (i) and (ii).

For the major oxidation products of $\beta$-caryophyllene, no experimentally-derived calibration sensitivity values are available for their quantification. For a number of species 
Table 2. Proton affinities (PA), dipole moments $\left(\mu_{\mathrm{D}}\right)$, polarizabilities $(\alpha)$ and proton transfer reaction rate coefficients $(k)$ calculated for $\beta$-caryophyllene and selected oxidation products that potentially contribute to the major CIR-TOF-MS product ions, $m / z 253$ and $m / z 237$. Organic reagent masses and reduced reagent molecular masses $(\mu)$ are also given.

\begin{tabular}{|c|c|c|c|c|c|c|c|}
\hline \multirow[t]{2}{*}{ Ion-Molecule Reaction } & \multirow[t]{2}{*}{ Mass/g mol${ }^{-1}$} & \multirow[t]{2}{*}{$\mu / \mathrm{kg}$} & \multirow[t]{2}{*}{$\mathrm{PA} / \mathrm{kJ} \mathrm{mol}^{-1}$} & \multirow[t]{2}{*}{$\mu_{\mathrm{D}} /$ Debye } & \multirow[t]{2}{*}{$\alpha / \AA^{3}$} & \multicolumn{2}{|c|}{$k / \mathrm{cm}^{3}$ molecule ${ }^{-1} \mathrm{~s}^{-1}$} \\
\hline & & & & & & $298 \mathrm{~K}$ & $313 \mathrm{~K}$ \\
\hline$\beta$-caryophyllene $+\mathrm{H}_{3} \mathrm{O}^{+}$ & 204.188 & $2.88644 \times 10^{-26}$ & 859.2 & 0.35 & 27.52 & $3.13 \times 10^{-9 *}$ & $3.13 \times 10^{-9}$ \\
\hline$\beta$-caryophyllene $+\mathrm{H}_{3} \mathrm{O}^{+} \cdot\left(\mathrm{H}_{2} \mathrm{O}\right)$ & 204.188 & $5.20146 \times 10^{-26}$ & 859.2 & 0.35 & 27.52 & $2.33 \times 10^{-9^{*}}$ & $2.33 \times 10^{-9}$ \\
\hline $\mathrm{BCAL}+\mathrm{H}_{3} \mathrm{O}^{+}$ & 236.178 & $2.92011 \times 10^{-26}$ & 817.1 & 2.04 & 28.61 & $3.78 \times 10^{-9}$ & $3.76 \times 10^{-9}$ \\
\hline $\mathrm{BCAL}+\mathrm{H}_{3} \mathrm{O}^{+} \cdot\left(\mathrm{H}_{2} \mathrm{O}\right)$ & 236.178 & $5.31183 \times 10^{-26}$ & 817.1 & 2.04 & 28.61 & $2.80 \times 10^{-9}$ & $2.79 \times 10^{-9}$ \\
\hline $\mathrm{BCSOZ}+\mathrm{H}_{3} \mathrm{O}^{+}$ & 252.173 & $2.93396 \times 10^{-26}$ & 828.7 & 1.63 & 29.05 & $3.58 \times 10^{-9}$ & $3.57 \times 10^{-9}$ \\
\hline $\mathrm{BCSOZ}+\mathrm{H}_{3} \mathrm{O}^{+} \cdot\left(\mathrm{H}_{2} \mathrm{O}\right)$ & 252.173 & $5.35786 \times 10^{-26}$ & 828.7 & 1.63 & 29.05 & $2.65 \times 10^{-9}$ & $2.64 \times 10^{-9}$ \\
\hline $\mathrm{BCALBOC}+\mathrm{H}_{3} \mathrm{O}^{+}$ & 252.173 & $2.93396 \times 10^{-26}$ & 809.3 & 2.26 & 29.17 & $3.92 \times 10^{-9}$ & $3.90 \times 10^{-9}$ \\
\hline $\mathrm{BCALBOC}+\mathrm{H}_{3} \mathrm{O}^{+} \cdot\left(\mathrm{H}_{2} \mathrm{O}\right)$ & 252.173 & $5.35786 \times 10^{-26}$ & 809.3 & 2.26 & 29.17 & $2.90 \times 10^{-9}$ & $2.88 \times 10^{-9}$ \\
\hline $\mathrm{C} 141 \mathrm{CO} 2 \mathrm{H}+\mathrm{H}_{3} \mathrm{O}^{+}$ & 252.173 & $2.93396 \times 10^{-26}$ & 883.8 & 1.95 & 20.90 & $3.34 \times 10^{-9}$ & $3.32 \times 10^{-9}$ \\
\hline $\mathrm{C} 141 \mathrm{CO} 2 \mathrm{H}+\mathrm{H}_{3} \mathrm{O}^{+} \cdot\left(\mathrm{H}_{2} \mathrm{O}\right)$ & 252.173 & $5.35786 \times 10^{-26}$ & 883.8 & 1.95 & 20.90 & $2.47 \times 10^{-9}$ & $2.46 \times 10^{-9}$ \\
\hline
\end{tabular}

* Su and Chesnavich (1982) and Su (1988) reported calculated values of $k=3.1 \times 10^{-9} \mathrm{~cm}^{3}$ molecule $\mathrm{s}^{-1}$ for $\beta$-caryophyllene $+\mathrm{H}_{3} \mathrm{O}^{+}$, and $k=2.3 \times 10^{-9} \mathrm{~cm}^{3}$ molecule $\mathrm{s}^{-1}$ for $\beta$-caryophyllene $+\mathrm{H}_{3} \mathrm{O}^{+} \cdot\left(\mathrm{H}_{2} \mathrm{O}\right)$.

(shown in Table 2) that are simulated to contribute to the major product ion signals, concentrations were calculated using the steady state approximation in Eq. (1), which can be derived from Reaction (R2) assuming that the proton transfer reaction obeys pseudo first-order kinetics (e.g. Hansel et al., 1995):

$[M]=\frac{i\left(\mathrm{MH}^{+}\right)}{i\left(\left(\mathrm{H}_{3} \mathrm{O}^{+} \cdot\left(\mathrm{H}_{2} \mathrm{O}\right)\right)_{0}\right)} \frac{1}{k t}$

Here, $i\left(\mathrm{MH}^{+}\right)$is the normalised, protonated analyte ion signal, $i\left(\mathrm{H}_{3} \mathrm{O}^{+} \cdot\left(\mathrm{H}_{2} \mathrm{O}\right)\right)_{0}$ is the normalised reagent ion signal, $[\mathrm{M}]$ is the analyte concentration (molecule $\mathrm{cm}^{-3}$ ), $k$ is the proton transfer reaction rate constant $\left(\mathrm{cm}^{3}\right.$ molecule $\left.{ }^{-1} \mathrm{~s}^{-1}\right)$ and $t$ is the reaction time $(s)$.

For the species under investigation the analyte proton affinities were calculated using the computational chemistry method MP2(FC)/6-311+G(d,p)//HF/6-31G(d), developed by Maksic and Kovacevic (1999) when looking at the proton affinities of amino acids. The method is suitable for large systems and is computationally cheap. The calculated proton affinity values are estimated to be within $3 \%$ of the experimental values.

The values of $k$ (shown in Table 2) were estimated using the dipole moments and polarizability values obtained from a Density Functional Theory calculation at the B3LYP/6$31 \mathrm{G}(\mathrm{d}, \mathrm{p})$ level of theory on the non-protonated species. This level of theory has been previously utilized by Zhao and Zhang (2004), who looked at 78 hydrocarbon and 58 nonhydrocarbon compounds and assessed their proton transfer reaction rates. $k$ values for this work were calculated using the following expression ( $\mathrm{Su}$ and Bower, 1973):

$k=\left(2 \pi q / \mu^{0.5}\right)\left[\alpha^{0.5}+C \mu D(2 / \pi k T)^{0.5}\right]$

where $q$ is the charge of the ion, $\mu$ is the reduced mass of the reactants, $\alpha$ is the polarizability, and $\mu_{\mathrm{D}}$ is the permanent dipole moment of the neutral species. $C$ has been parameterized to have a value between 0 and 1 . Zhao and Zhang (2004) showed that the calculated proton transfer rate constants were, on average, within $\pm 20 \%$ of the experimental value. The overall CIR-TOF-MS measurement uncertainty values, considering both instrument precision and calibration/calculation accuracy (accounting for measurement reproducibility and known systematic uncertainty), were determined to be of the order of $\pm 40 \%$.

\subsection{Additional measurements}

$\mathrm{NO}$ and $\mathrm{NO}_{2}$ mixing ratios were measured using a chemiluminescence gas analyser (Model 42i, Thermo Scientific, MA, USA). Production of $\mathrm{O}_{3}$ was measured using a UV photometric gas detector (Model 49C, Thermo Scientific, MA, USA). The total SOA particle number concentration was measured using an ultrafine water-based condensation particle counter (wCPC 3786, TSI, Inc.), with a minimum size cut-off of $2.5 \mathrm{~nm}$. The size distribution of the generated SOA particles was measured using a Differential Mobility Particle Sizer. This consisted of two Differential Mobility Analysers, for particles in the size ranges 3-34 nm and $20-500 \mathrm{~nm}$, coupled with TSI 3025A and TSI 3010 condensation particle counters (CPC). Particle numbers and size distributions in the diameter size range from 3-500 nm were thus obtained every $10 \mathrm{~min}$. This information was used to determine volumetric concentrations of SOA, which were converted into mass concentrations using a density of $1.3 \mathrm{~g} \mathrm{~cm}^{-3}$ (Bahreini et al., 2005; Varutbangkul et al., 2006). 


\section{Model description}

Chamber simulations of $\beta$-caryophyllene degradation were carried out using the FACSIMILE for Windows kinetics integration package, v3.5 (MCPA Software). The chamber model simply represents a well-mixed chamber volume, with the reagent mixing ratios and experimental conditions initialised at, or constrained to, the values for the study under consideration, as given in Table 1.

\subsection{Chamber auxiliary mechanism}

For simulations of photo-oxidation experiments, a number of chamber-dependent processes were represented. The rates of gas phase photolysis processes for application with MCM v3.2 were calculated using spectral distributions and intensities for the photolysing radiation, in conjunction with evaluated absorption cross sections and quantum yield data for the individual species and reactions, as provided on the MCM website. As indicated in Sect. 3, the photolysing radiation in the ACES experiments was fully characterized for the chamber. For illustrative simulation of the photo-oxidation experiment in the Caltech chamber, reported by Lee et al. (2006b), a representative blacklight spectrum emitting over the range $330-400 \mathrm{~nm}\left(\lambda_{\max } \approx 355 \mathrm{~nm}\right)$ was assumed, and the intensity was scaled to provide simulated profiles of $\beta$-caryophyllene, $\mathrm{NO}_{\mathrm{x}}$ and ozone that were comparable with those reported.

The impact of chamber wall effects for simulations of the ACES experiments was represented using the mechanism characterized for the PSI chamber, as reported by Metzger et al. (2008), that being an FEP Teflon chamber of similar volume and light source to the Manchester chamber. The auxiliary mechanism includes a conventional description of wall sources of radicals and the reactivity of background organics, and adsorption or desorption of oxidised nitrogen species. In practice, sensitivity tests showed simulations to be very insensitive to inclusion of these processes, as discussed further in Sect. 6.1. However, it was found to be necessary to optimise an additional decaying source of NO within about the first hour of each experiment to recreate the precise forms of the NO profiles. This typically amounted to an additional $10 \%$ input of $\mathrm{NO}_{\mathrm{x}}$, and had a much more subtle (and unimportant) influence on the temporal profiles simulated for species other than NO. Partitioning of $\beta$-caryophyllene oxidation products to the chamber walls was also represented and optimised, as described below.

Because the $\mathrm{NO}_{\mathrm{x}}$ measurements in the considered studies were made using conventional chemiluminescent analysers, simulations of $\mathrm{NO}_{2}$ mixing ratios were assumed to include quantitative contributions from HONO and PANs. Along with $\mathrm{NO}_{2}$, these species are likely to be converted efficiently to $\mathrm{NO}$ in the heated molybdenum converters, and therefore contribute to the reported $\mathrm{NO}_{2}$ signals (e.g., Winer et al., 1974; Cox, 1974). For the conditions of the ACES experiments, these interferences are simulated to be relatively small, contributing $\leq 10 \%$ to the measured $\mathrm{NO}_{2}$ signal. For the illustrative simulation of the photo-oxidation experiment of Lee et al. (2006b), reagent HONO is inferred to make a major contribution (40\%) in the early stages of the experiment (see Sect. 6.3.5), with product PANs simulated to contribute up to about $12 \%$ by the end of the experiment.

\subsection{Gas-aerosol and gas-wall partitioning}

Gas-aerosol partitioning was represented for 280 closed-shell products of $\beta$-caryophyllene oxidation, on the basis of the absorptive partitioning model of Pankow (1994), which has been widely used to help interpret organic aerosol formation in chamber studies. Phase-partitioning of a given species is thus defined by the thermodynamic equilibrium of that species between the gas phase and absorbed in a condensed organic phase, with an associated (equilibrium) partitioning coefficient, $K_{\mathrm{p}}$, which is given by:

$K_{\mathrm{p}}=\frac{7.501 \times 10^{-9} R T}{\mathrm{MW}_{\mathrm{om}} \zeta p_{\mathrm{L}}^{\circ}}$

where $R$ is the ideal gas constant $\left(8.314 \mathrm{~J} \mathrm{~K}^{-1} \mathrm{~mol}^{-1}\right), T$ is temperature $(\mathrm{K}), \mathrm{MW}_{\mathrm{om}}$ is the mean molecular weight of the condensed organic material $\left(\mathrm{g} \mathrm{mol}^{-1}\right), \zeta$ is the activity coefficient of the given species in the condensed organic phase, and $p_{\mathrm{L}}^{\circ}$ is its (probably sub-cooled) liquid vapour pressure (Torr). The numerical constant in the numerator is consistent with units of $\mathrm{m}^{3} \mu \mathrm{g}^{-1}$ for $K_{\mathrm{p}}$. A unity value was assumed for $\zeta$, consistent with partitioning of a given oxidation product in an aerosol droplet composed of a mixture of similar species.

On the basis of the critical appraisal of Barley and McFiggans (2010), the applied values of $p_{\mathrm{L}}^{\circ}$ were calculated using the method of Nannoolal et al. (2008), in conjunction with species boiling temperatures estimated by the method of Nannoolal et al. (2004). For simplicity, all vapour pressures applied in the current work were calculated for a temperature of $298 \mathrm{~K}$. The value used for $p_{\mathrm{L}}^{\circ}$ for a given species clearly has a critical impact on the calculated value of $K_{\mathrm{p}}$, but estimating $p_{\mathrm{L}}^{\circ}$ values for complex multifunctional oxygenates remains subject to considerable uncertainty, as very few quantitative data are available for checking the predicted values.

The magnitude of $K_{\mathrm{p}}$ determines the extent of gas-aerosol partitioning of a given species, in accordance with the following equation:

$[\mathrm{X}]_{\mathrm{OA}} /[\mathrm{X}]_{\mathrm{g}}=K_{\mathrm{p}} \cdot[\mathrm{OA}]$

where $[\mathrm{X}]_{\mathrm{g}}$ and $[\mathrm{X}]_{\mathrm{OA}}$ are its concentrations in the gaseous and organic aerosol phases, respectively, and $[\mathrm{OA}]$ is the total mass concentration of condensed organic material (in $\mu \mathrm{g} \mathrm{m}^{-3}$ ). In the present work, the equilibrium partitioning was assumed to be achieved instantaneously, and no chemical processes in the aerosol phase were represented. 
An initial assessment of the representation of gas-aerosol partitioning (in conjunction with the MCM v3.2 gas phase chemistry) was carried out by simulating conditions representative of all the datasets in Table 1 . The simulations of the conditions of the ozonolysis experiments reported by Jaoui et al. (2003) and Winterhalter et al. (2009) showed prompt SOA formation and final SOA yields that were in good agreement with the reported observations. The simulations of the ozonolysis conditions of Li et al. (2011), and of the final stages of the photo-oxidation experiments of Alfarra et al. (2012), showed a tendency towards overestimation (by up to a factor of about 2.5). The simulations of the photooxidation conditions of Lee et al. (2006b), and of the early stages of the ACES photo-oxidation experiments of Alfarra et al. (2012), showed a tendency towards underestimation (by a factor of about 2). In view of the uncertainties in parameter estimation, these results are regarded as generally acceptable, although there must clearly be reasons for the variability in performance for the different conditions of the studies.

For the detailed appraisal of the ACES photo-oxidation experiments, the impact of partitioning of the 280 oxygenated products into the Teflon walls of the Manchester chamber was also represented and optimised during the course of this work, as discussed further in Sect. 6.2. This was represented on the basis of the results of Matsunaga and Ziemann (2010), who characterized the partitioning of a series of long-chain alkanes, alkenes, 2-alcohols and 2-ketones under dry conditions in two Teflon chambers, $1.7 \mathrm{~m}^{3}$ and $5.9 \mathrm{~m}^{3}$ in volume. Gas-wall equilibrium partitioning was represented to occur in direct competition with, and analogously to, gas-aerosol partitioning:

$[\mathrm{X}]_{\mathrm{wall}} /[\mathrm{X}]_{\mathrm{g}}=K_{\mathrm{p}} \cdot[\text { wall }]_{\mathrm{eff}}$

where $[\mathrm{X}]_{\text {wall }}$ is the concentration of a given species in the Teflon wall, and [wall $]_{\text {eff }}$ is an effective wall mass concentration. In accordance with the results presented by Matsunaga and Ziemann (2010) for the most strongly absorbed species considered in their study (high molecular weight 2ketones), the optimisation process initially assumed a value of [wall $]_{\mathrm{eff}}=24 \mathrm{mg} \mathrm{m}^{-3}$, with an effective molecular weight of $200 \mathrm{~g} \mathrm{~mol}^{-1}$. An associated 1/e time constant $\left(\tau_{\mathrm{gw}}\right)$ of $2.7 \mathrm{~min}$ was imposed for the gas-wall partitioning process, which is also consistent with the equilibration time reported by Matsunaga and Ziemann (2010). The value of [wall] eff was varied to optimise agreement with the ACES observations, with $\tau_{\mathrm{gw}}$ varied in inverse proportion.

\section{Results and discussion: ozonolysis conditions}

Evaluation of the MCM v3.2 scheme under dark ozonolysis conditions focused on the set of experiments reported recently by $\mathrm{Li}$ et al. (2011). Those experiments were carried out in flowing mode, with a characteristic chamber residence time of $3.6 \mathrm{~h}$, and with $\mathrm{O}_{3}$ maintained at a con- stant excess mixing ratio. Cyclohexane was present to scavenge $\mathrm{OH}$ radicals, so that sequential ozonolysis of the $\beta$ caryophyllene endocyclic double bond, followed by ozonolysis of the "exocyclic" double bonds in the first-generation products would occur. The present simulations considered a subset of four experiments with $50 \mathrm{ppb}_{3}$, as summarized in Table 1, with simulations carried out up to the $3.6 \mathrm{~h}$ residence time. The final simulated SOA mass concentrations were comparable to those observed, albeit showing an increasing tendency towards overestimation with increasing reagent $\beta$ caryophyllene mixing ratio (see Table 1).

Figure 9 shows the simulated time evolution of the SOA mass loading up to the $3.6 \mathrm{~h}$ experimental residence time, for the conditions of "experiment 3" reported by Li et al. (2011). This logically shows prompt SOA formation with an initial dominant contribution from first-generation products to SOA; but with a progressively increasing contribution of second-generation products. This reflects that the respective lifetimes of $\beta$-caryophyllene and the first generation products with respect to reaction with $50 \mathrm{ppb}$ ozone are about $70 \mathrm{~s}$ and $2 \mathrm{~h}$, and that both the first- and second-generation product distributions are sufficiently condensable for at least some transfer to the aerosol phase to occur. The simulated SOA composition at $3.6 \mathrm{~h}$ is dominated by secondgeneration products, with these accounting for $73 \%$ of the mass loading. This is in broad agreement with the results of Li et al. (2011), who reported a second-generation contribution of about $90 \%$. The simulated SOA composition at $3.6 \mathrm{~h}$ has an average molecular formula of $\mathrm{C}_{13.97} \mathrm{H}_{22.11} \mathrm{O}_{4.21}$ $(\mathrm{MW}=257.3)$.

Li et al. (2011) reported detection of 15 ozonolysis products in SOA, of which 11 are represented in the MCM v3.2 scheme. Many of these species were consistently found to be in the top 20 simulated SOA contributors at $3.6 \mathrm{~h}$, although other species were also simulated to make important contributions. The lower panel in Fig. 9 shows the top 11 simulated contributors at $3.6 \mathrm{~h}$, for the conditions of "experiment 3", with these collectively accounting for about $90 \%$ of the total simulated SOA mass loading. The first-generation products have important simulated contributions from $\beta$-caryophyllonic acid $(\mathrm{C} 141 \mathrm{CO} 2 \mathrm{H})$ and $\beta$ caryophyllinic acid $(\mathrm{C} 137 \mathrm{CO} 2 \mathrm{H})$, in agreement with the results of Li et al. (2011), and as also reported to be important SOA contributors in other studies of $\beta$-caryophyllene ozonolysis (Jaoui et al., 2003; Kanawati et al., 2008; Winterhalter et al., 2009). The other important simulated firstgeneration contributors $(\mathrm{C} 139 \mathrm{OOH}$ and $\mathrm{BCALBOOH})$ are multifunctional hydroperoxides, which have not been detected in any reported study. These are formed (along with $\mathrm{C} 137 \mathrm{CO} 2 \mathrm{H})$ from the chemistry of the $\mathrm{OH}$ co-product, BCALBO2 (see Fig. 3). This suggests that the simulated contribution of first-generation products to SOA is sensitive to the yield assigned to $\mathrm{OH}$ (and co-radicals) in the mechanism, by virtue of the associated products generally possessing a greater degree of multi-functionality than those formed from 

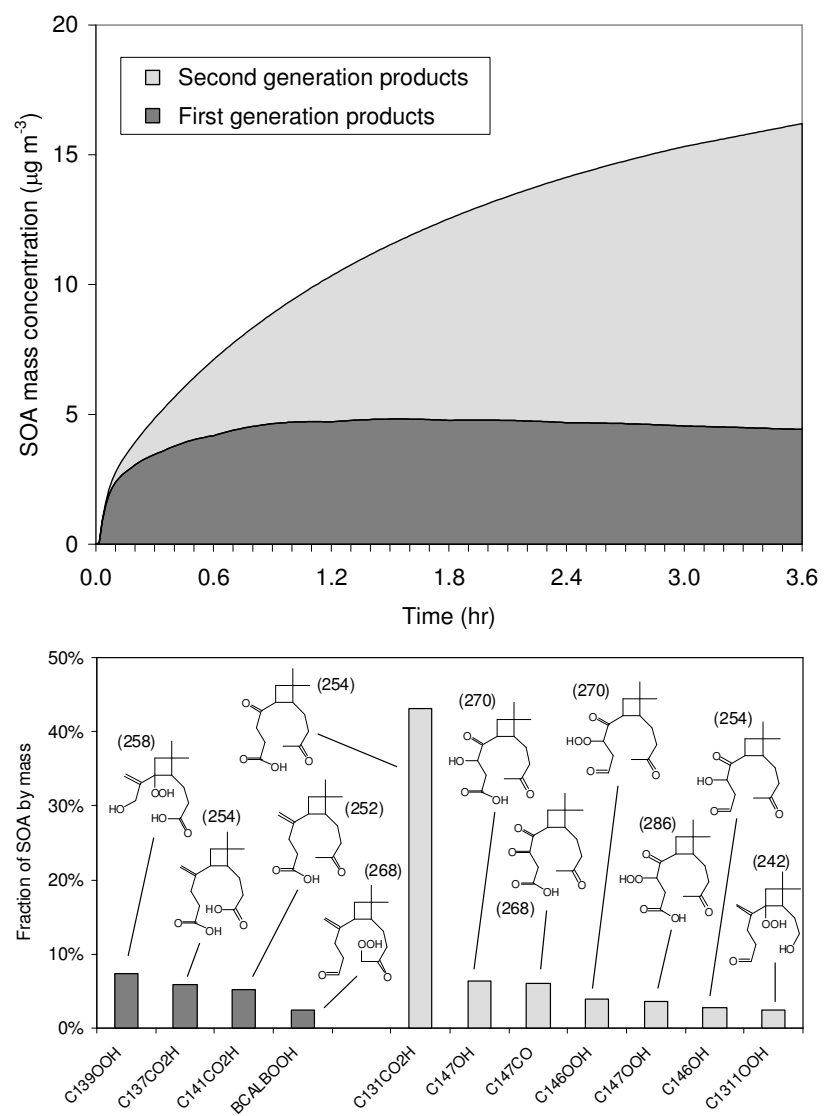

Fig. 9. Results of simulations of the conditions of ozonolysis experiment 3 reported by Li et al. (2011) (see Table 1 for conditions). The upper panel shows the simulated time evolution of the SOA mass loading up to the $3.6 \mathrm{~h}$ experimental residence time; and the contributions of first and second-generation products to SOA. The lower panel shows the top 11 simulated contributors at $3.6 \mathrm{~h}$, these accounting for $\sim 90 \%$ of the total simulated SOA mass loading. The displayed values indicate the molecular masses of the products.

the non-radical channels. For example, an illustrative reduction in this yield from $10 \%$ to $6 \%$ led to a reduction in the simulated first-generation contribution from $27 \%$ to $20 \%$.

As shown in Fig. 9, a number of second-generation products make important simulated contributions to SOA, with the majority of these resulting from the ozonolysis of $\beta$ caryophyllonic acid $(\mathrm{C} 141 \mathrm{CO} 2 \mathrm{H})$ and $\beta$-caryophyllon aldehyde (BCAL). Of these, only $\mathrm{C} 147 \mathrm{OH}$ was actually reported by $\mathrm{Li}$ et al. (2011), although others $(\mathrm{C} 131 \mathrm{CO} 2 \mathrm{H}$ and $\mathrm{C} 146 \mathrm{OH})$ are structurally similar isomers of species that were reported. Again, there are important contributions from a number of multifunctional species containing hydroperoxy groups (C146OOH, $\mathrm{C} 147 \mathrm{OOH}$ and $\mathrm{C} 1311 \mathrm{OOH})$, which have not been detected in reported studies. However, such products are potentially reactive in the condensed phase, and may therefore be difficult to detect. Indeed, hydroperoxides have been reported to undergo association reactions with carbonyls to form high molecular weight peroxyhemiacetals (e.g., Tobias and Ziemann, 2000). It is also possible that any subsequent decomposition of the peroxyhemiacetals (within the course of an experiment or during aerosol analysis) may potentially produce alternative products (e.g., an acid and an alcohol - by analogy with the mechanism of the BaeyerVilliger oxidation of carbonyls by peroxyacids), such that the hydroperoxides might act as condensed phase oxidants (e.g., see discussion in Jenkin, 2004).

The present calculations predict a particularly important contribution from $\beta$-nocaryophyllonic acid $(\mathrm{C} 131 \mathrm{CO} 2 \mathrm{H})$, which is simulated to be the most abundant SOA component. Although not specifically identified by Li et al. (2011), $\mathrm{C} 131 \mathrm{CO} 2 \mathrm{H}$ has been reported as an SOA phase product by Jaoui et al. (2003), under conditions when some secondary ozonolysis of the first-generation product distribution was likely. As discussed in Sect. 2.2, and shown in Figs. 5 and $6, \mathrm{C} 131 \mathrm{CO} 2 \mathrm{H}$ is a likely major product of the ozonolysis of $\beta$-caryophyllonic acid $(\mathrm{C} 141 \mathrm{CO} 2 \mathrm{H})$, and its vapour pressure is estimated here to be lower than that of $\mathrm{C} 141 \mathrm{CO} 2 \mathrm{H}$ by approaching an order of magnitude. The present calculations thus predict $\mathrm{C} 141 \mathrm{CO} 2 \mathrm{H}$ to be only partially present $(18 \%)$ in the SOA phase (thereby allowing significant reaction with $\mathrm{O}_{3}$ in the gas phase), but $\mathrm{C} 131 \mathrm{CO} 2 \mathrm{H}$ to be mainly (63\%) in the SOA phase, for the simulated conditions at the end of "experiment 3".

\section{Results and discussion: photo-oxidation conditions}

Evaluation of the MCM v3.2 scheme under photo-oxidation conditions initially focused on the set of ACES experiments summarized in Table 1, and described above in Sect. 3.2. Figure 10 shows the main features of the MCM v3.2 chemistry, appropriate to the early stages of those experiments. Primary removal of $\beta$-caryophyllene occurs via ozonolysis, following the photolysis of the reagent $\mathrm{NO}_{2}$ to form $\mathrm{NO}$ and $\mathrm{O}_{3}$. Because of the high initial $\left[\mathrm{NO}_{2}\right] /[\mathrm{NO}]$ ratios applied in the ACES experiments, this process occurs efficiently in the system and is the predominant initiation process. The reaction of $\mathrm{O}_{3}$ with $\beta$-caryophyllene leads to the formation of $\mathrm{OH}$, which also reacts with $\beta$-caryophyllene. Although the primary yield of $\mathrm{OH}$ is comparatively small $(10 \%)$, the importance of the OH-initiated chemistry is amplified by the presence of $\mathrm{NO}$ in the system, allowing the (conventional) $\mathrm{OH}$ regenerating, catalytic cycle shown in Fig. 10 to occur, with this also leading to NO-to- $\mathrm{NO}_{2}$ conversion and subsequent $\mathrm{O}_{3}$ formation. The cycle is mainly terminated by the formation of the hydroxy nitrates (BCANO3, BCBNO3 and $\mathrm{BCCNO} 3$ ), and the branching ratio assigned to their formation from the reactions of the corresponding peroxy radicals with NO controls the chain length of the catalytic cycle. The chemistry of the co-radicals, formed with $\mathrm{OH}$ following $\beta$-caryophyllene ozonolysis (BCALAO2, BCALBO2 and BCALCO2; denoted ' $\mathrm{R}$ ' $\mathrm{O}_{2}$ " in Fig. 10), also potentially 


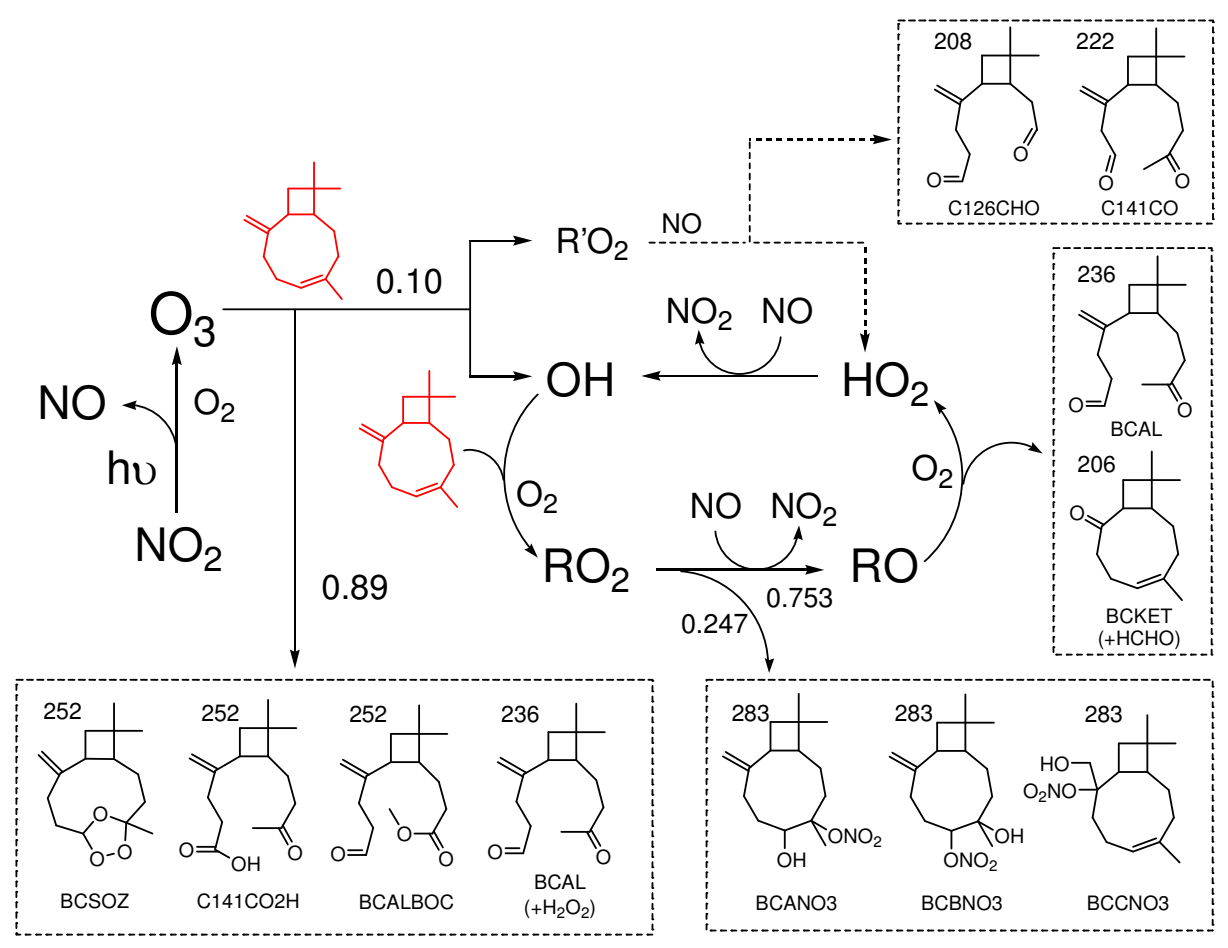

Fig. 10. Schematic of the main features of MCM v3.2 chemistry of $\beta$-caryophyllene- $\mathrm{NO}_{\mathrm{x}}$ photo-oxidation, appropriate to the early stages of the ACES experiments in the Manchester chamber. Primary removal of $\beta$-caryophyllene occurs via ozonolysis, following reagent $\mathrm{NO}_{2}$ photolysis, with the importance of the $\mathrm{OH}$-initiated chemistry amplified in the presence of $\mathrm{NO}$ (see discussion in text). " $\mathrm{RO}_{2}$ " is used to denote the collective population of $\mathrm{BCAO} 2, \mathrm{BCBO} 2$ and $\mathrm{BCCO}$; " $\mathrm{RO}$ " to denote the collective population of $\mathrm{BCAO}$, $\mathrm{BCBO}$ and $\mathrm{BCCO}$; and " $\mathrm{R}^{\prime} \mathrm{O}_{2}$ " to denote the collective population of BCALAO2, BCALBO2 and BCALCO2. The molecular masses of the products are also shown.

feeds into the catalytic cycle, by virtue of generation of some $\mathrm{HO}_{2}$ from radical propagation reactions in the presence of NO. In practice, however, this is comparatively limited because the radical propagating chemistry of BCALAO2 and BCALBO2 is likely to be interrupted by the formation of PAN and complex PANs (C136PAN and C137PAN) as temporary radical reservoirs (see Sect. 2.1.1).

\subsection{Evaluation using $\beta$-caryophyllene, $\mathrm{NO}_{\mathrm{x}}$ and ozone data}

The general MCM v3.2 reaction framework was initially evaluated using the gas phase observations of $\beta$ caryophyllene, $\mathrm{O}_{3}$ and $\mathrm{NO}_{\mathrm{x}}$, as shown in Fig. 11 for the example of ACES experiment 03-07-08 (broken lines). The simulations showed the mechanism to perform reasonably well, but indicated that the system was over-reactive, leading to a decay of $\beta$-caryophyllene that was too rapid, and an efficiency of NO-to- $\mathrm{NO}_{2}$ conversion and $\mathrm{O}_{3}$ formation that was too high. Within the reaction framework outlined in Fig. 10, this indicates that the efficiency of the OH-initiated chemistry is over-estimated. This can be formalised by the following equations:

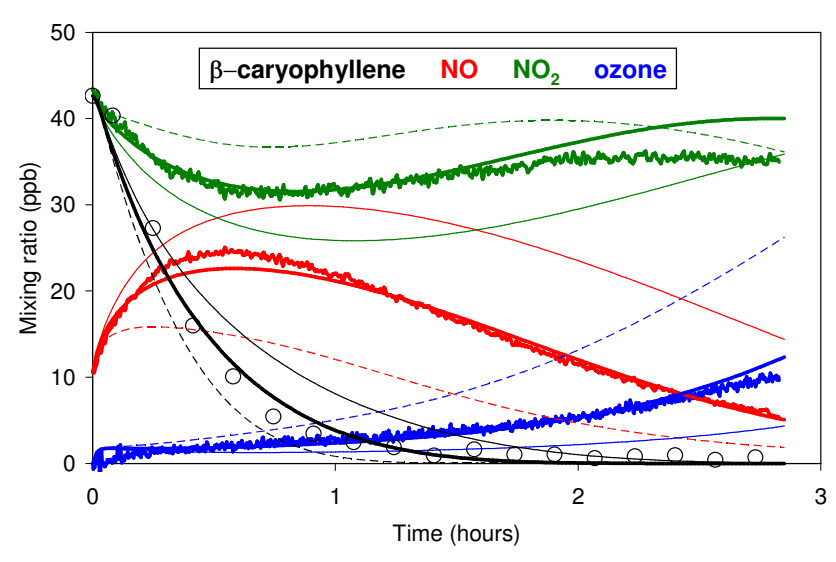

Fig. 11. Time profiles of $\beta$-caryophyllene, $\mathrm{NO}, \mathrm{NO}_{2}$ and ozone for ACES photo-oxidation experiment 03-07-08. The observed $\beta$ caryophyllene data are shown as open circles, with the observed $\mathrm{NO}, \mathrm{NO}_{2}$ and ozone data as continuous lines. The smooth lines show the results of simulations using the MCM v3.2 scheme, with different yields of $\mathrm{OH}$ (and co-radicals) from $\beta$-caryophyllene ozonolysis. Broken lines: $\mathrm{OH}$ yield $=10 \%$ (i.e., the base MCM v3.2 run); Heavy continuous lines: $\mathrm{OH}$ yield $=6 \%$; Feint continuous lines: $\mathrm{OH}$ yield $=3 \%$. 
$\mathrm{Y}_{\mathrm{OH}}=\mathrm{P}_{\mathrm{OH}} \cdot \mathrm{CL}$

$\mathrm{CL}=1 /(1-x)$

where $\mathrm{Y}_{\mathrm{OH}}$ is the total $\mathrm{OH}$ yield, $\mathrm{P}_{\mathrm{OH}}$ is the primary $\mathrm{OH}$ yield, $x$ is the fractional regeneration of $\mathrm{OH}$ in each operation of the catalytic cycle, and CL is the chain length of the catalytic cycle. The over-efficiency of the $\mathrm{OH}$-initiated chemistry can therefore by addressed by a reduction in either $\mathrm{P}_{\mathrm{OH}}$ or CL.

The value of $\mathrm{P}_{\mathrm{OH}}$ is set at $10 \%$ in $\mathrm{MCM}$ v3.2 (see Sect. 2.1.1). As shown in Fig. 10, the value of CL is determined by the branching ratio (or yield) assigned to the formation of the hydroxy nitrates (BCANO3, BCBNO3 and $\mathrm{BCCNO} 3$ ) from the reactions of the corresponding $\mathrm{RO}_{2}$ radicals with NO, this branching ratio being $(1-x)$. There have been no determinations of the branching ratio, and an estimated value of 0.247 is applied in MCM v3.2. This is based on a reported value of 0.228 for the structurally-similar set of $\mathrm{C}_{10}$ peroxy radicals in the limonene system (Ruppert et al., 1999), scaled to account for the increase in carbon number using the expression recommended by Arey et al. (2001). This value of $(1-x)$ leads to a value of about 4 for $\mathrm{CL}$, such that the total $\mathrm{OH}$ yield, $\mathrm{Y}_{\mathrm{OH}}$, is about $40 \%$ in the base MCM v3.2 simulations.

As shown in Fig. 11, simulations of the system were found to be very sensitive to the value assigned to $\mathrm{P}_{\mathrm{OH}}$, and a reduction from $10 \%$ to about $6 \%$ (i.e., $\mathrm{Y}_{\mathrm{OH}}$ decreased to about $25 \%$ ) provided a good description in all the experiments. As discussed in Sect. 2.1.1, this reduced value of $\mathrm{P}_{\mathrm{OH}}$ remains consistent with the range of reported determinations. Consistent with Eqs. (6) and (7) above, a similarly improved description of the system could be achieved by leaving $\mathrm{P}_{\mathrm{OH}}$ at $10 \%$, and increasing the branching ratio, $(1-x)$, from 0.247 to about 0.4 (or by using intermediate combinations of $\mathrm{P}_{\mathrm{OH}}$ and $(1-x)$ within the considered ranges). It is not possible to determine these parameters independently within the context of this work, and further studies to reduce the uncertainty on the primary $\mathrm{OH}$ yield, and to quantify the yields of the hydroxy nitrates from the $\mathrm{OH}$-initiated chemistry, would clearly be valuable. However, it is noted that currently available information suggests that the presence of a $\beta$-hydroxy group has a significant lowering influence on nitrate yields from $\mathrm{RO}_{2}+\mathrm{NO}$ reactions (e.g., O'Brien et al., 1998; Matsunaga and Ziemann, 2009), such that values in excess of that applied in MCM v3.2 would seem unreasonble for $\mathrm{C}_{15} \beta$-hydroxy peroxy radicals. For the remainder of the evaluation of the MCM v3.2 chemistry using the ACES photo-oxidation data, an optimised value of $\mathrm{P}_{\mathrm{OH}}$ of $6 \%$ is therefore applied, with $(1-x)$ unchanged from the value of 0.247 applied in MCM v3.2. With this reduced efficiency of the $\mathrm{OH}$-initiated chemistry, simulations indicated that $\beta$-caryophyllene removal was about $80 \%$ due to reaction with $\mathrm{O}_{3}$ and about $20 \%$ due to reaction with $\mathrm{OH}$, con-

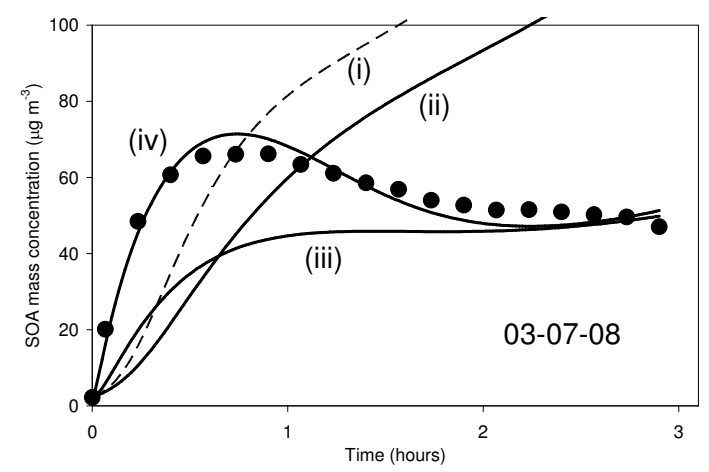

Fig. 12. Time profiles of secondary organic aerosol (SOA) mass concentration for ACES photo-oxidation experiment 03-07-08. The observed data are shown as points. The lines are results of simulations using: (i) MCM v3.2 with gas-aerosol partitioning code; (ii) as (i), but with a $6 \%$ yield of $\mathrm{OH}$ (and co-radicals) from $\beta$ caryophyllene ozonolysis; (iii) as (ii), but with gas-aerosol partitioning into observationally-constrained SOA mass loading, and inclusion of wall partitioning with [wall $]_{\mathrm{eff}}=1.5 \mathrm{mg} \mathrm{m}^{-3}$; (iv) as (ii), but with inclusion of (illustrative) transient formation of $\alpha$-hydroxyhydroperoxides (see text) and wall partitioning with [wall $]_{\mathrm{eff}}=1.5 \mathrm{mg} \mathrm{m}^{-3}$.

sistent with the reduced, optimised value of $\mathrm{Y}_{\mathrm{OH}}$ of about $25 \%$ and scavenging of $\mathrm{OH}$ predominantly by reaction with $\beta$-caryophyllene in the early stages of the experiment. Reaction with $\mathrm{NO}_{3}$ was simulated to account for $0.2 \%$ of $\beta$ caryophyllene removal under the conditions of these experiments.

\subsection{Evaluation using SOA mass concentrations}

Figure 12 shows the results of a number of simulations of SOA mass concentrations, compared with the observed temporal profile, for the example of ACES experiment 03-07-08. The MCM v3.2 chemistry with $\mathrm{P}_{\mathrm{OH}}$ values of either $10 \%$ (simulation (i)) or $6 \%$ (simulation (ii)), results in a progressive increase in simulated SOA mass concentrations throughout the duration of the experiment, consistent with the expected progressive increase in the condensability of the product distribution with sequential oxidation of the two double bonds. In each case, the simulated profile underestimates the initial accumulation of SOA, but leads to a significant overestimation towards the end of the experiment. This overestimation can be addressed by inclusion of competitive gas-wall partitioning of the oxygenated products (using the representation described in Sect. 4.2), which results in removal of material from both the gaseous and SOA phases. As shown in Fig. 13a (simulation (i)), it was found that use of an effective wall mass concentration, [wall] eff, of $1.5 \mathrm{mg} \mathrm{m}^{-3}$ (in conjunction with $\mathrm{P}_{\mathrm{OH}}=6 \%$ ) resulted in an SOA mass loading at the end of the experiment which agrees well with that observed. 
Table 3. Summary of ions detected using CIR-TOF-MS and their species assignments ${ }^{\mathrm{a}}$.

\begin{tabular}{|c|c|c|c|}
\hline$m / z^{\mathrm{b}}$ & Ion identity & Species identity (MCM name) $)^{\mathrm{c}}$ & Molecular mass \\
\hline $271^{\mathrm{d}}$ & $\mathrm{MH}^{+} .\left(\mathrm{H}_{2} \mathrm{O}\right)-\left(\mathrm{HNO}_{3}\right)$ & C131PAN, C137PAN & 315 \\
\hline 269 & $\mathrm{MH}^{+}-\left(\mathrm{HNO}_{3}\right)$ & C151NO3, BCSOZNO3 & 331 \\
\hline 269 & $\mathrm{MH}^{+} .\left(\mathrm{H}_{2} \mathrm{O}\right)-\left(\mathrm{HNO}_{3}\right)$ & C141PAN & 313 \\
\hline $\begin{array}{l}\mathbf{2 5 5}^{\mathrm{e}}, \quad\{237, \quad 219, \\
209\}^{\mathrm{f}, \mathrm{g}}\end{array}$ & $\begin{array}{l}\mathbf{M H}^{+} \quad\left\{\mathrm{MH}^{+}-\left(\mathrm{H}_{2} \mathrm{O}\right),\right. \\
\left.\mathrm{MH}^{+}-(\mathrm{HCOOH})\right\}\end{array}$ & $\begin{array}{l}\mathrm{BCKSOZ}, \underset{\mathrm{C} 131 \mathrm{CO} 2 \mathrm{H}, \text { BCLKBOC, }}{\mathrm{C} 137 \mathrm{CO} 2 \mathrm{H}}\end{array}$ & 254 \\
\hline $\begin{array}{l}\mathbf{2 5 3}, 235,217,\{207\}^{\mathrm{f}} \\
177,153,139,127\end{array}$ & $\begin{array}{lcl}\mathbf{M H}^{+}, & \mathrm{MH}^{+}-\left(\mathrm{H}_{2} \mathrm{O}\right), & \mathrm{MH}^{+}- \\
\left(\mathrm{H}_{2} \mathrm{O}\right)_{2}, & \{\mathrm{MH}+-(\mathrm{HCOOH})\}, & \mathrm{MH}^{+}- \\
\left(\mathrm{H}_{2} \mathrm{O}\right)_{2} \cdot \mathrm{CH}_{2} \mathrm{CCH}_{2} & \end{array}$ & BCSOZ, C141CO2H, BCALBOC & 252 \\
\hline 239, $\{220,209\}^{\mathrm{g}}, 195$ & $\begin{array}{l}\mathbf{M H}^{+},\left\{\mathrm{MH}^{+}-\left(\mathrm{H}_{2} \mathrm{O}\right), \mathrm{MH}^{+}-(\mathrm{HCHO})\right\} \\
\mathrm{MH}^{+}-\left(\mathrm{H}_{2} \mathrm{O}\right) \cdot \mathrm{CHCH}\end{array}$ & BCLKET & 238 \\
\hline $\begin{array}{l}\mathbf{2 3 7}, 219,\{207\}^{\mathrm{f}}, 193, \\
179\end{array}$ & $\begin{array}{l}\mathbf{M H}^{+}, \quad \mathrm{MH}^{+}-\left(\mathrm{H}_{2} \mathrm{O}\right), \quad\{\mathrm{MH}+-(\mathrm{HCHO})\} \\
\mathrm{MH}^{+}-\left(\mathrm{H}_{2} \mathrm{O}\right) \cdot \mathrm{CHCH}, \\
\mathrm{MH}^{+}-\left(\mathrm{H}_{2} \mathrm{O}\right) \cdot \mathrm{CH}_{2} \mathrm{CCH}_{2}\end{array}$ & BCAL & 236 \\
\hline $225,\{207\}^{\mathrm{f}}$ & $\mathbf{M H}^{+},\left\{\mathrm{MH}^{+}-\left(\mathrm{H}_{2} \mathrm{O}\right)\right\}$ & $\mathrm{C} 131 \mathrm{CO}, \mathrm{C} 137 \mathrm{CO}$ & 224 \\
\hline 223 & $\mathbf{M H}^{+}$ & $\mathrm{C} 141 \mathrm{CO}$ & 222 \\
\hline $221,203^{i}$ & $\mathrm{MH}^{+}-\left(\mathrm{HNO}_{3}\right), \mathrm{MH}^{+}-\left(\mathrm{HNO}_{3}\right) \cdot \mathrm{H}_{2} \mathrm{O}$ & BCANO3, BCBNO3, BCCNO3 & 283 \\
\hline 211, $\{193\}^{\mathrm{f}, \mathrm{g}}, 175$ & $\mathbf{M H}^{+}, \mathrm{MH}^{+}-\left(\mathrm{H}_{2} \mathrm{O}\right), \mathrm{MH}^{+}-\left(\mathrm{H}_{2} \mathrm{O}\right)_{2}$ & $\mathrm{C} 116 \mathrm{CHO}^{\mathrm{j}}$ & 210 \\
\hline $\mathbf{2 0 9}^{\mathrm{c}, \mathrm{f}}, 191,173^{\mathrm{k}}$ & $\mathbf{M H}^{+}, \mathrm{MH}^{+}-\left(\mathrm{H}_{2} \mathrm{O}\right), \mathrm{MH}^{+}-\left(\mathrm{H}_{2} \mathrm{O}\right)_{2}$ & $\mathrm{C}_{126 \mathrm{CHO}^{1}}$ & 208 \\
\hline $\mathbf{2 0 7}^{\mathrm{c}, \mathrm{f}}, 189$ & $\mathbf{M H}^{+}$ & BCKET & 206 \\
\hline $207^{\mathrm{c}, \mathrm{f}}$ & $\mathrm{MH}^{+}-\left(\mathrm{HNO}_{3}\right)$ & C141NO3 & 269 \\
\hline $\begin{array}{l}\mathbf{2 0 5}, 149,135,123 \\
121,109,95,81\end{array}$ & $\begin{array}{l}\mathbf{M H}^{+}, \mathrm{MH}^{+}-\mathrm{C}_{4} \mathrm{H}_{8}, \mathrm{MH}^{+}-\mathrm{C}_{5} \mathrm{H}_{10}, \\
\mathrm{MH}^{+}-\mathrm{C}_{6} \mathrm{H}_{10}, \quad \mathrm{MH}^{+}-\mathrm{C}_{6} \mathrm{H}_{12}, \quad \mathrm{MH}^{+}- \\
\mathrm{C}_{7} \mathrm{H}_{12}, \mathrm{MH}^{+}{ }_{-} \mathrm{C}_{8} \mathrm{H}_{14}, \mathrm{MH}^{+}{ }_{-} \mathrm{C}_{9} \mathrm{H}_{16}\end{array}$ & $\beta$-caryophyllene (BCARY) & 204 \\
\hline 197 & $\mathrm{MH}^{+} .\left(\mathrm{H}_{2} \mathrm{O}\right)-\left(\mathrm{HNO}_{3}\right)\left(-\mathrm{H}_{2} \mathrm{O}\right)$ & C1011PAN & 259 \\
\hline 133 & $\mathrm{MH}^{+} .\left(\mathrm{H}_{2} \mathrm{O}\right)-\left(\mathrm{HNO}_{3}\right)$ & C46PAN & 177 \\
\hline 85 & $\mathrm{MH}^{+}-\left(\mathrm{H}_{2} \mathrm{O}\right)$ & $\mathrm{CHOC} 2 \mathrm{CO} 2 \mathrm{H}^{\mathrm{m}}$ & 102 \\
\hline 71 & $\mathrm{MH}^{+}-\left(\mathrm{H}_{2} \mathrm{O}\right)$ & $\mathrm{HCOCH} 2 \mathrm{CO} 2 \mathrm{H}^{\mathrm{n}}$ & 88 \\
\hline
\end{tabular}

\footnotetext{
${ }^{a}$ Unassigned ion signals also detected at $\mathrm{m} / \mathrm{z} 201,179,167,161,159,151,147,141 ;{ }^{\mathrm{b}} \mathrm{m} / \mathrm{z}$ assignments discussed in detail in Sects. 6.3.1-6.3.4; ${ }^{\mathrm{c}}$ Species structures shown in Figs. 1 and 3-8; and/or available at http://mcm.leeds.ac.uk/MCM using species search with MCM name; ${ }^{\mathrm{d}}$ italic text denotes tentative assignment; ${ }^{\mathrm{e}}$ bold text denotes parent $\mathrm{MH}^{+}$ion; ${ }^{\mathrm{f}}$ potentially coincident with one or more other ions of same nominal mass and of similar abundance; ${ }^{\mathrm{g}}$ potentially coincident with one or more other ions of same nominal mass and of greater abundance; ${ }^{\mathrm{h}} \mathrm{C} 137 \mathrm{CO} 2 \mathrm{H}$ simulated to make negligible contribution in the presence of $\mathrm{NO}_{\mathrm{x}}$ (see text); ${ }^{\mathrm{i}}$ correlating signal detected at $\mathrm{m} / \mathrm{z} 165 ; \mathrm{j}$ possible additional contribution from 4-(3,3-dimethyl-2-propyl-cyclobutyl)-4-oxo-butyraldehyde (see text); ${ }^{\mathrm{k}}$ correlating signal detected at $\mathrm{m} / \mathrm{z}$ 147;

${ }^{1}$ possible additional contribution from 4-(3,3-dimethyl-2-propyl-cyclobutyl)-pent-4-enal (see text); ${ }^{\mathrm{m}} \mathrm{CH}(=\mathrm{O}) \mathrm{CH}{ }_{2} \mathrm{CH}{ }_{2} \mathrm{C}(=\mathrm{O}) \mathrm{OH} ;{ }^{\mathrm{n}} \mathrm{CH}(=\mathrm{O}) \mathrm{CH}{ }_{2} \mathrm{C}(=\mathrm{O}) \mathrm{OH}$.
}

Sensitivity tests were carried out to investigate possible causes of the initial underestimation in SOA accumulation. A series of uniform reductions in vapour pressure $\left(p_{\mathrm{L}}^{\circ}\right)$ for all partitioning species were initially investigated, with reductions of up to a factor of 20 being considered (see Fig. 13a). This resulted in increases in the initial simulated production rate of SOA which, in combination with progressive increases in the optimised value of [wall $]_{\mathrm{eff}}$, produced temporal SOA profiles that were increasingly more consistent with that observed. However, even a factor of 20 reduction in $p_{\mathrm{L}}^{\circ}$ values was insufficient to reproduce the observed initial SOA formation rate, with simulations of this initial phase also being relatively insensitive to further reductions in $p_{\mathrm{L}}^{\circ}$. As shown in Fig. 13b, the considered reductions in $p_{\mathrm{L}}^{\circ}$, and the associated increases in [wall] $]_{\text {eff }}$, also had a significant (and unsupportable) impact on simulations of the time profiles of $\mathrm{O}_{3}$ and the $\mathrm{NO}_{\mathrm{x}}$ species. Because of the elevated removal of product organic material from the gas phase, the system becomes less able to promote NO-to- $\mathrm{NO}_{2}$ conver- sion, and therefore form $\mathrm{O}_{3}$, in the latter stages of the experiment. On the basis of these sensitivity tests, it appears that the observations cannot support a significant uniform reduction in $p_{\mathrm{L}}^{\circ}$ values, or values of [wall $]_{\mathrm{eff}}$ that are significantly greater than about $1.5 \mathrm{mg} \mathrm{m}^{-3}$. It is noted that this value of [wall $]_{\text {eff }}$ is somewhat lower than the values of $10 \mathrm{mg} \mathrm{m}^{-3}$ and $24 \mathrm{mg} \mathrm{m}^{-3}$, reported by Matsunaga and Ziemann (2010) for wall partitioning of long-chain 2-alcohols and 2-ketones, respectively, in Teflon chambers (see Sect. 4.2). There are a number of possible factors which may contribute to this difference. These include the lower surface-to-volume ratio of the Manchester chamber, the high relative humidity $(\sim 70 \%)$ employed in these experiments, compared with the dry conditions employed by Matsunaga and Ziemann (2010), the presence of illumination, and the greater structural complexity of the $\beta$-caryophyllene oxidation products.

Figure 12 (simulation (iii)) shows the results of a simulation in which the extent of partitioning of the oxygenated 

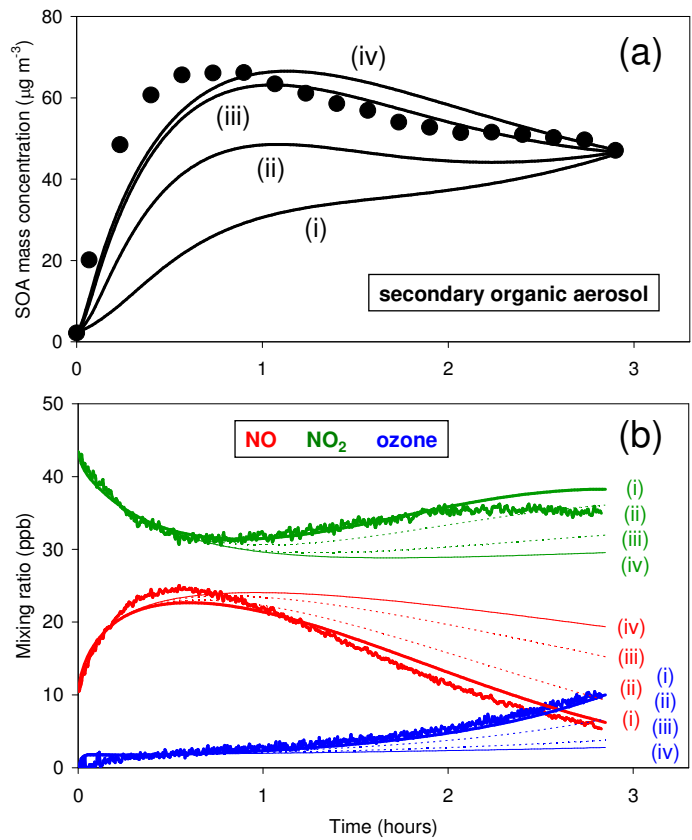

Fig. 13. Time profiles of: (a) secondary organic aerosol (SOA) mass concentration; and (b) $\mathrm{NO}, \mathrm{NO}_{2}$ and ozone; for ACES photooxidation experiment 03-07-08. The observed profiles are as in Figs. 11 and 12. The lines are simulations showing the impact of uniform reductions in $p_{\mathrm{L}}^{\circ}$, with the following scaling factors: (i) 1.0 ; (ii) 0.3 ; (iii) 0.1 and (iv) 0.05 . In each case, the value of [wall $]_{\text {eff }}$ was optimised to recreate the final SOA mass loading, leading to [wall] eff values of: (i) $1.5 \mathrm{mg} \mathrm{m}^{-3}$; (ii) $3.3 \mathrm{mg} \mathrm{m}^{-3}$; (iii) $6.6 \mathrm{mg} \mathrm{m}^{-3}$; and (iv) $10.3 \mathrm{mg} \mathrm{m}^{-3}$.

products into the SOA phase was constrained to the observed mass loadings of SOA, and with gas-wall partitioning governed by a value of $1.5 \mathrm{mg} \mathrm{m}^{-3}$ for [wall] eff, as optimised above. These results suggest that the species generated by the mechanism are able to account for about $40 \%$ of the observed SOA in the early stages of the simulation, with this fraction progressively increasing throughout the duration of the experiment. Additional senstivity tests demonstrated that it was only possible to reconcile this discrepancy within the model framework by implementing gross (and generally unsupportable) changes to first-generation product yields (e.g., complete replacement of $\mathrm{BCSOZ}$ formation by the less volatile $\mathrm{C} 141 \mathrm{CO} 2 \mathrm{H}$ ), or to first-generation product properties (e.g., a three order of magnitude suppression in the $p_{\mathrm{L}}^{\circ}$ value for $\mathrm{BCSOZ}$ ); with these changes invariably worsening the simulations of the shapes of the temporal profiles of the gas phase components, as characterized using CIR-TOFMS (see Sect. 6.3).

As discussed further below (Sect. 6.3.1), the CIR-TOFMS observations of some major first-generation product signals show a distinct time-lag in their initial detection in the gas phase, and it seems probable that this missing material must account, to some extent, for the initial accumu- lation of SOA mass loading. Although it is not possible to determine the precise mechanism responsible for these observations, they appear characteristic of initial formation of one or more low volatility species which have a relatively short lifetime prior to further reaction to form the accepted "first-generation" products. As an illustration of this type of behaviour, Fig. 12 (simulation (iv)) shows the impact of including initial formation of a pair of transient $\alpha$ hydroxyhydroperoxides, formed from the reactions of the Criegee intermediates, $\mathrm{BCAOO}$ and $\mathrm{BCBOO}$, with $\mathrm{H}_{2} \mathrm{O}$. As discussed, for example, by Atkinson et al. (2006: datasheet II.A6.152), the rearrangement and decomposition of the $\alpha$ hydroxyhydroperoxides, leads to formation of either $\mathrm{H}_{2} \mathrm{O}$ and an acid product (in this case $\mathrm{C} 141 \mathrm{CO} 2 \mathrm{H}$ ), or $\mathrm{H}_{2} \mathrm{O}_{2}$ and an aldehyde product (in this case BCAL), as shown in Fig. 1. The present simulation assumes the same ultimate yields of $\mathrm{C} 141 \mathrm{CO} 2 \mathrm{H}$ and BCAL as in MCM v3.2, but with the $\alpha$ hydroxyhydroperoxides possessing an optimised lifetime of $30 \mathrm{~s}$ with respect to rearrangement and decomposition in the gas phase. The $\alpha$-hydroxyhydroperoxides are relatively involatile, having estimated $p_{\mathrm{L}}^{\circ}$ values that are factors of 30 and 60 lower than that of $\mathrm{C} 141 \mathrm{CO} 2 \mathrm{H}$, and are therefore significantly partitioned into the SOA phase (where they are assumed to be stable with respect to decomposition). As shown in Fig. 12 (simulation (iv)), this type of mechanism is able to account for the shortfall in SOA formation in the early stages of the experiment. It is emphasised, however, that this is simply an illustration of the type of process required, but for which there is currently no other supporting evidence.

\subsection{Evaluation using CIR-TOF-MS data}

An example mass spectrum, recorded using CIR-TOF-MS during a typical ACES $\beta$-caryophyllene photo-oxidation experiment (03-07-08), is shown in Fig. 14. The data have been integrated over the entire experiment (about $3 \mathrm{~h}$ ), background subtracted, and the major spectral features have been labelled. For clarity the peaks belonging to the precursor $\beta$-caryophyllene (see Table 3 ) have been removed. The CIR-TOF-MS measurements allowed approximately 45 time-resolved product ion signals to be detected. These were assigned to $\beta$-caryophyllene photo-oxidation products on the basis of the product species in MCM v3.2, and their probable fragmentation patterns following the initial reagent ion-molecule reaction, as summarised in Table 3. The chamber simulations provided temporal profiles for all MCM v3.2 species generated from the photo-oxidation of $\beta$-caryophyllene, and the partitioning of closed-shell products between the gaseous and aerosol phases and the chamber wall. The CIR-TOF-MS data were used to evaluate the performance of the MCM v3.2 chemistry, through comparison with the temporal profiles simulated for the most abundant gaseous components. Although the scheme includes about 300 closed-shell products, the majority of species were simulated to be present at very low mixing ratios, owing 


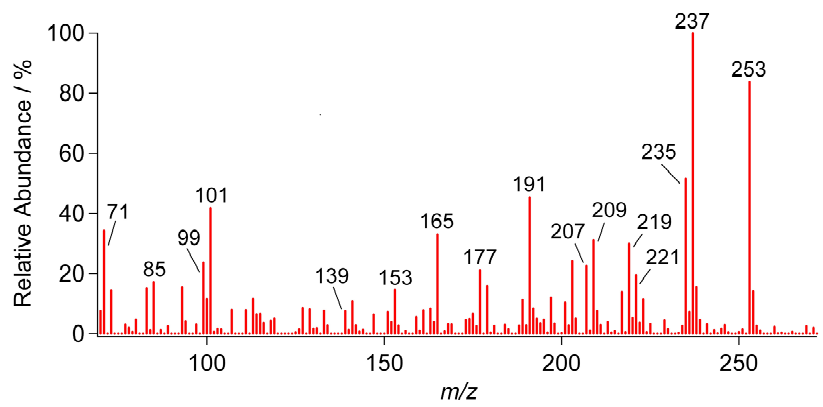

Fig. 14. An example mass spectrum, recorded using CIR-TOF-MS during ACES photo-oxidation experiment 03-07-08. The data show the relative abundances of signals integrated over the entire experiment. For clarity, signals due to reagent $\beta$-caryophyllene have been subtracted.

to a combination of a low intrinsic yield under the experimental conditions, and/or a high propensity to transfer to the condensed SOA phase or the chamber wall. As a result, only about 30 species were simulated to exceed $50 \mathrm{ppt}$ at some point in the series of simulations, thereby providing a comparatively high level of screening for the modelmeasurement comparison. Comparisons of the observed and simulated temporal profiles are discussed in the following subsections. In each case, the simulations incorporate partitioning into the observationally-constrained SOA mass loading, and to the chamber walls with a [wall $]_{\text {eff }}$ value of $1.5 \mathrm{mg} \mathrm{m}^{-3}$. As indicated in Sect. 3.2, the observed signals have been calibrated for the major product ion families (corresponding to parent ions of $m / z 253$ and $m / z$ 237). In other cases, the data are presented as the measured ion count rate (normalised counts per second, ncps), and the profile shapes are compared with those simulated for potentially contributing products.

\subsubsection{First-generation products}

Figure 15 shows the model-measurement comparisons for a number of (mainly or exclusively) first-generation products. These can be related directly to the major product ion signals detected by CIR-TOF-MS as follows:

$m / z$ 253: As discussed above (Sect. 2), three isomeric firstgeneration products of molecular mass 252 are potentially formed, namely BCSOZ, C141CO2H and BCALBOC. The estimated proton affinities, polarizabilities and dipole moments of these compounds (Table 2) confirm that they will readily undergo ion-molecule reactions with hydronium and hydrated hydronium ions to produce protonated molecular ions, $\mathrm{MH}^{+}(\mathrm{m} / \mathrm{z}, 253)$. For the conditions of these experiments, BCSOZ, $\mathrm{C} 141 \mathrm{CO} 2 \mathrm{H}$ and BCALBOC are simulated to be formed in a collectively high yield (approximately $50 \%$ ), by virtue of their generation from the $\mathrm{O}_{3}$-initiated chemistry (see Figs. 1 and 10). Accordingly, the $\mathrm{m} / \mathrm{z} 253$ peak was observed to be amongst the most abundant product ion signals in the CIR-TOF-MS mass spectrum (Fig. 14).

It is well documented that large and complex molecules such as BCSOZ, C141CO2H and BCALBOC, may undergo some degree of fragmentation following proton transfer reaction (PTR) ionisation to yield various daughter ions (Blake et al., 2009). Secondary ozonide species such as BCSOZ have not been well characterized under PTR conditions, hence their fragmentation mechanisms are not well known. However, aldehyde, ketone and acid bearing compounds, such as $\mathrm{C} 141 \mathrm{CO} 2 \mathrm{H}$ and BCALBOC, are known to dehydrate following protonation to yield an $\mathrm{MH}^{+}\left(-\mathrm{H}_{2} \mathrm{O}\right)$ daughter ion (e.g. Smith and Spanel, 2005; Blake et al., 2006). Furthermore, it is possible for multifunctional carbonyl compounds to eject a second water molecule following protonation, to yield a daughter ion equivalent to $\mathrm{MH}^{+}\left(-\mathrm{H}_{2} \mathrm{O}\right)_{2}$. Ions of $\mathrm{m} / z 235$ and 217 , corresponding to the loss of one and two water molecules respectively, from a parent of $\mathrm{m} / \mathrm{z}, 253$, were observed in all experiments and in each case with temporal profiles highly correlated with that of $\mathrm{m} / \mathrm{z}$ 253. As such, these ions are believed to constitute daughter fragments of the $\mathrm{m} / \mathrm{z} 253$ species. Additionally, ions of $\mathrm{m} / \mathrm{z}$ 177, 153, 139 and 127 were observed to have temporal profiles that were highly correlated with the $\mathrm{m} / \mathrm{z} 253$ trace and, as such, represent further potential daughter ions. For example, the ion of $\mathrm{m} / \mathrm{z} 177$ can be explained by the further loss of a section of the hydrocarbon chain $\left(\mathrm{C}_{3} \mathrm{H}_{4}\right)$, following the ejection of two water molecules from the parent $\mathrm{MH}^{+}$ions.

It should also be noted that following PTR ionisation from the hydronium ion, complex acid bearing molecules (e.g. $\mathrm{C} 141 \mathrm{CO} 2 \mathrm{H}$ ) have been observed to fragment via the loss of formic acid to produce $\mathrm{MH}^{+}(-\mathrm{HCOOH})$ ions (Spanel and Smith, 1998). The equivalent processes for $\mathrm{C} 141 \mathrm{CO} 2 \mathrm{H}$ would yield an ion of $\mathrm{m} / \mathrm{z} 207$ which, as shown in Fig. 15, does show some degree of correlation with that of $\mathrm{m} / \mathrm{z} 253$. Owing to the potential for contributions from other ions to $\mathrm{m} / \mathrm{z} 207$, it is discussed separately below.

As shown in Fig. 15, the collective simulated profile for $\mathrm{BCSOZ}, \mathrm{C} 141 \mathrm{CO} 2 \mathrm{H}$ and BCALBOC is in reasonable agreement with the observations, although the observations show a clear time lag in the rise that is not apparent in the simulated composite profile. The secondary ozonide, $\mathrm{BCSOZ}$, makes the major contribution to the simulated abundance, owing to a combination of its high yield and a low propensity to transfer to the aerosol phase or the chamber wall (its estimated $p_{\mathrm{L}}^{\circ}$ value being over three orders of magnitude higher than that of $\beta$-caryophyllonic acid, $\mathrm{C} 141 \mathrm{CO} 2 \mathrm{H}$ ). Although significantly partitioned between the phases, $\mathrm{C} 141 \mathrm{CO} 2 \mathrm{H}$ is also simulated to make a significant contribution to the composite gas phase profile. The impact of invoking (speculative) transient formation of $\alpha$-hydroxyhydroperoxides (as discussed above in Sect. 6.2) is also illustrated in Fig. 15, confirming that this leads to a delay in the formation of the simulated composite signal. However, the effect is comparatively small because, as represented, it only influences $\mathrm{C} 141 \mathrm{CO} 2 \mathrm{H}$ formation. A 

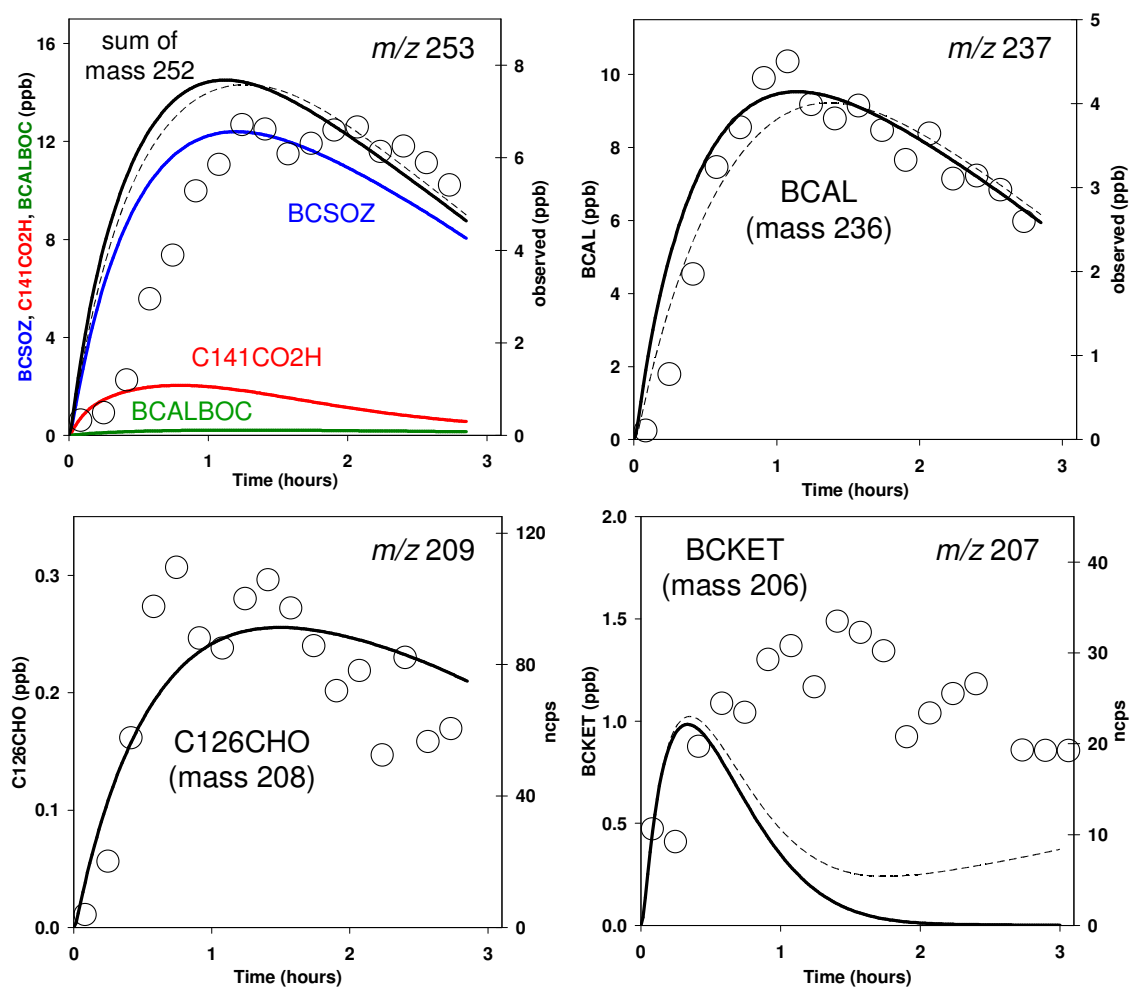

Fig. 15. Example time profiles simulated for selected first-generation oxygenated products (lines), compared with those for corresponding product ion signals measured using CIR-TOF-MS (points), during ACES photo-oxidation experiments. Measured signals for a given $m / z$ incorporate the corresponding daughter ion signals identified in Table 3. Signals for the $\mathrm{m} / \mathrm{z}, 253$ and $\mathrm{m} / \mathrm{z} 237$ families were calibrated as described in the text (see discussion of method and uncertainties in Sects. 3.2 and 6.3.1). Other signals are uncalibrated and presented as normalised counts per second (npcs). Comparisons are for experiments 03-07-08 ( $\mathrm{m} / \mathrm{z}, 253,237$ and 209) and 10-07-08 (m/z 207). Broken lines in the $\mathrm{m} / \mathrm{z}, 253$ and $\mathrm{m} / \mathrm{z}, 237$ panels show the effect of including speculative formation of $\alpha$-hydroxyhydroperoxides in the mechanism (see text). Broken line in $\mathrm{m} / \mathrm{z} 207$ panel is the results of a sensitivity test considering potential interfering signals (see text).

major impact would clearly require a mechanism which delays formation of BCSOZ.

With no calibration material available, the BCSOZ, $\mathrm{C} 141 \mathrm{CO} 2 \mathrm{H}$ and BCALBOC signals were quantified collectively, using the calculation method described in Sect. 3.2. To a first approximation, $\mathrm{BCSOZ}, \mathrm{C} 141 \mathrm{CO} 2 \mathrm{H}$ and BCAL$\mathrm{BOC}$ were assumed to comprise the $\mathrm{MH}^{+}$ion and all known potential fragments (discussed above), excluding $\mathrm{m} / \mathrm{z} 207$. The corresponding $\mathrm{C}_{13}$ signals of $\mathrm{m} / \mathrm{z}, 254,236,218$ and 178 were also included. The resultant profile (Fig. 15), shows a peak measured mixing ratio of $(6.7 \pm 2.7) \mathrm{ppb}$ (where the estimated $\pm 40 \%$ error limits include all quantifiable uncertainties), compared to the peak mixing ratio of about $14.5 \mathrm{ppb}$ predicted by the model. There are a number of factors that could contribute to this discrepancy between the measured and simulated absolute magnitudes, suggesting that this is acceptable agreement for such a complex system. These include:

i. Potential missing contributions from unidentified daughter ions, such that the measured signal represents a lower limit. For example, inclusion of the $m / z 207$ po- tential fragment signal, commented on above, increases the measured peak mixing ratio by about $0.5 \mathrm{ppb}$. Furthermore, PTR ionisation of a complex product mixture is likely to produce certain common daughter ions not clearly attributable to a specific parent (e.g. $\mathrm{m} / \mathrm{z}$. 43: de Gouw and Warneke, 2007; Blake et al., 2006). The inclusion of an appropriate fraction of such common fragment signals, when using equation (1) to determine the analyte concentration, would clearly increase the ultimate quantified signal.

ii. Uncertainty in the magnitude of the $p_{\mathrm{L}}^{\circ}$ values for $\mathrm{BCSOZ}, \mathrm{C} 141 \mathrm{CO} 2 \mathrm{H}$ and BCALBOC, governing their transfer from the gas to the aerosol and wall phases, such that the simulated composite gas phase profile is an overestimate.

iii. Errors in the relative product yields of $\mathrm{BCSOZ}$, $\mathrm{C} 141 \mathrm{CO} 2 \mathrm{H}$ and BCALBOC, as represented in MCM $\mathrm{v} 3.2$, leading to an over-representation of the more volatile components. 
$m / z$ 237: $\beta$-caryophyllon aldehyde (BCAL) is a major first-generation product of $\beta$-caryophyllene oxidation. For the conditions of the ACES experiments, it is simulated to be produced significantly from both the $\mathrm{O}_{3}$ - and $\mathrm{OH}$-initiated chemistry (as summarised in Fig. 10), with an overall yield of about $30 \%$. Accordingly, the $m / z 237 \mathrm{MH}^{+}$ion, produced from reaction of BCAL with both hydronium and hydrated hydronium ions (Table 2), is one of the most abundant product ion signals in the CIR-TOF-MS mass spectrum (Fig. 14).

A number of ions were observed to have temporal profiles that showed some degree of correlation with the $\mathrm{m} / \mathrm{z} 237$ trace, potentially resulting from daughter ions formed following fragmentation of the nascent $\mathrm{MH}^{+}$ion. Of these the $\mathrm{m} / \mathrm{z} 219$ ion had the strongest signal intensity, and its temporal profile had the strongest correlation with that of $\mathrm{m} / \mathrm{z} 237$. Owing to the presence of an aldehyde functional group in the parent molecule, $\mathrm{m} / \mathrm{z} 219$ is assigned to be the dehydrated daughter ion of protonated BCAL. The temporal profiles of the $m / z 193$ and $m / z 175$ ions also exhibited some degree of correlation with the $m / z 237$ trace, and are potentially BCAL daughter ions, formed via acetylene $\left(\mathrm{C}_{2} \mathrm{H}_{2}\right)$ loss from the $\mathrm{MH}^{+}\left(-\mathrm{H}_{2} \mathrm{O}\right)$ ion, followed by further fragmentation of the hydrocarbon chain (loss of $\mathrm{C}_{3} \mathrm{H}_{4}$ ), respectively. It should be noted here that the $m / z 193$ ion may also contain some contribution from the fragment of a second-generation compound (albeit one with a significantly lower yield than BCAL); this will be discussed separately below. Further to this, in all experiments the $m / z 207$ trace was also observed to be well correlated with that of $m / z 237$ (as shown in Fig. 15). A potential explanation for this could be $\mathrm{MH}^{+}$fragmentation via the loss of formaldehyde to produce the $\mathrm{MH}^{+}(-\mathrm{HCHO})$ daughter ion, following a mechanism analogous to $\mathrm{HCOOH}$ loss from protonated carboxylic acids, as identified above for $\mathrm{C} 141 \mathrm{CO} 2 \mathrm{H}$. Owing to its potential coincidence with other ions of the same nominal mass, the $\mathrm{m} / \mathrm{z}, 207$ ion will be discussed in further detail below.

Simulations of the time dependence of BCAL (Fig. 15) show a profile with a shape which is in good agreement with the observations, although the observations once again show a slight time lag in the rise that is not apparent in the simulated composite profile. In this case, however, incorporation of the (speculative) transient formation of $\alpha$ hydroxyhydroperoxides leads to a clear improvement in the simulation of the initial phase. As with the $m / z 253$ species, experimental BCAL measurements were quantified using Eq. (1), assuming BCAL to comprise the $\mathrm{MH}^{+}$ion, the potential daughter fragments of $\mathrm{m} / \mathrm{z} 219$ and 175 and the $\mathrm{C}_{13}$ signals of $\mathrm{m} / \mathrm{z} 238$ and 220. As shown in Fig. 15, the simulated peak BCAL mixing ratio was once again found to be somewhat higher than that determined from the measurements. The model predicts a peak mixing ratio of about $9.5 \mathrm{ppb}$, whereas the (lower limit) measured value was (4.5 \pm 1.9$) \mathrm{ppb}$, for $\Sigma(\mathrm{m} / \mathrm{z} 238,237,220,219,175)$. This is once again considered to be acceptable agreement, given the uncertainties in CIR-TOF-MS quantification and those as- sociated with simulating the gas phase profile (as indicated above).

$m / z$ 209: The spectral peak observed at $m / z, 209$ may result from the $\mathrm{MH}^{+}$ion of MCMv3.2 species C126CHO. As shown in Figs. 3 and 10, C126CHO is generated from the $\mathrm{O}_{3}$-initiated chemistry, via formation of the $\mathrm{OH}$ co-product, BCALAO2. The simulated time dependence of $\mathrm{C} 126 \mathrm{CHO}$ (Fig. 15) generally shows a profile with a shape that is in reasonable agreement with the observations for the $\mathrm{m} / \mathrm{z} 209$ family (which is taken to include dehydrated daughter ions at $\mathrm{m} / \mathrm{z} 191$ and 173), providing some support for this assignment. However, the predicted yield of $\mathrm{C} 126 \mathrm{CHO}$ is comparatively small (about $1 \%$ for the experimental conditions), leading to a maximum simulated mixing ratio that is approximately a factor of 40 lower than that of the structurallysimilar species, BCAL. In contrast, the $m / z 209$ family ion signal is less than a factor of two lower than that of the corresponding set of ions in the $m / z 237$ family, suggesting either an exceptionally high CIR-TOF-MS sensitivity to $\mathrm{C} 126 \mathrm{CHO}$, or additional contributing species displaying a similar temporal profile. In this respect, Kanawati et al. (2008) and Winterhalter et al. (2009) have reported detection of the isobaric species, 4-(3,3-dimethyl-2-propylcyclobutyl)-pent-4-enal (respectively denoted 208-E-C1 and P3), which is not represented in MCM v3.2. As discussed by Winterhalter et al. (2009), this species may potentially be formed from elimination of $\mathrm{CO}_{2}$ from decomposition of the Criegee intermediate, BCBOO (as shown in Fig. 16), and may therefore contribute to the stabilised product yield from the ozonolysis chemistry. Owing to its structural similarity to $\mathrm{C} 126 \mathrm{CHO}$, it would be expected to display a similar temporal profile. However, it is noted that Winterhalter et al. (2009) also reported a comparatively low $\mathrm{CO}_{2}$ yield of $(3.8 \pm 2.8) \%$ from $\beta$-caryophyllene ozonolysis, which is already matched by other processes in the MCM v3.2 chemistry (see Sect. 2.1.1). This might therefore seem to place a limit on the contribution to $m / z 209$ that can be made by 4(3,3-dimethyl-2-propyl-cyclobutyl)-pent-4-enal, unless other formation mechanisms operate.

It should also be noted that there may be potential for daughter ions produced from larger molecular mass species to add some contribution to the $\mathrm{m} / \mathrm{z}, 209$ signal; the most significant of which could include ions resulting from $\mathrm{HCOOH}$ loss from $\mathrm{C} 131 \mathrm{CO} 2 \mathrm{H}\left(\mathrm{MH}^{+} m / z, 255\right)$ and $\mathrm{HCHO}$ loss from BCLKET $\left(\mathrm{MH}^{+} \mathrm{m} / z\right.$ 239). However, owing to the temporal evolution of these compounds under the experimental conditions employed, their fragment ions would primarily contribute to the $\mathrm{m} / \mathrm{z} 209$ signal towards the latter stages of the experiment, and hence an increasing signal intentsity would be expected rather than the profile shape that was observed (see below).

$m / z$ 207: The spectral peak at $\mathrm{m} / z 207$ can potentially be accounted for by the $\mathrm{MH}^{+}$parent ion of $\beta$-nocaryophyllone (BCKET). It is formed from the $\mathrm{OH}$-initiated chemistry (see Figs. 4 and 10), such that its yield is predicted to be 


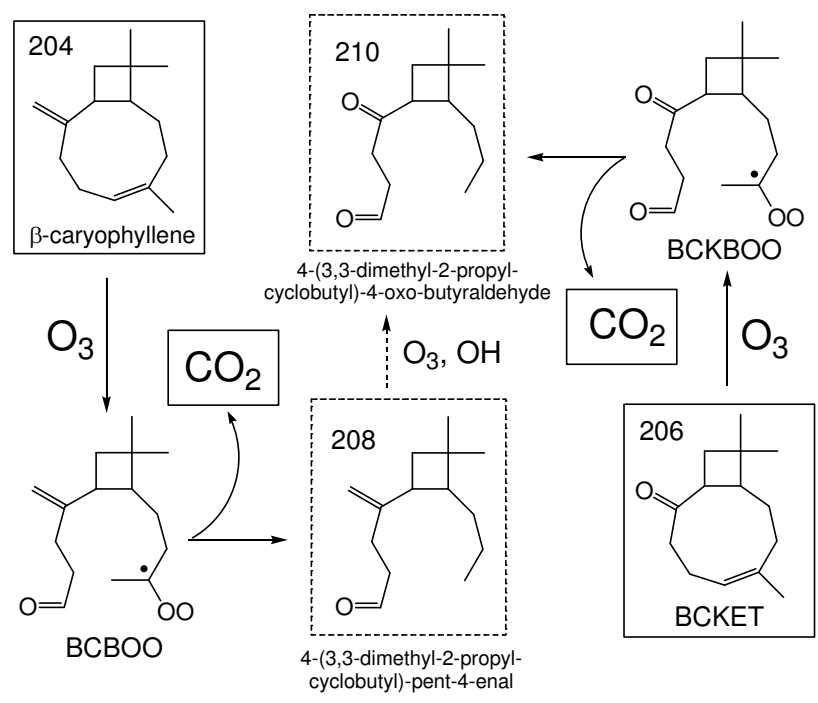

Fig. 16. Formation routes for additional products not in $\mathrm{MCM}$ v3.2 that potentially contribute to CIR-TOF-MS signals at $\mathrm{m} / \mathrm{z}, 209$ and $\mathrm{m} / \mathrm{z}$ 211. 4-(3,3-dimethyl-2-propyl-cyclobutyl)-pent-4-enal has been reported as a first-generation ozonolysis product by Kanawati et al. (2008) (denoted 208-E-C1), and Winterhalter et al. (2009) (denoted P3).

approximately $6 \%$ under the experimental conditions. The simulated time dependence of BCKET is compared with that observed for the $\mathrm{m} / \mathrm{z} 207$ family (taken to include a wellcorrelated dehydrated daughter ion at $\mathrm{m} / z$ 189) in Fig. 15. The simulated profile reflects that BCKET has a high reactivity towards $\mathrm{O}_{3}$ (by virtue of the retained endocyclic double bond), such that its lifetime in the system is comparable to that of $\beta$-caryophyllene. As a result, it reaches a (comparatively suppressed) peak mixing ratio of about $1 \mathrm{ppb}$ after less than $30 \mathrm{~min}$, and decays to a low level by the end of the experiment. This does not match that observed for the $\mathrm{m} / \mathrm{z} 207$ family, indicating that there are likely to be other significant contributions to this spectral peak. Such contributions potentially result from either the formation of other gas phase species of the same molecular mass in the system, or from the fragmentation of larger ions to produce daughter ions of this particular $\mathrm{m} / \mathrm{z}$ ratio.

A number of potential contributors were identified. First, as indicated in Table 3, the oxygenated species $\mathrm{C} 131 \mathrm{CO}$ and $\mathrm{C} 137 \mathrm{CO}$, both of molecular mass 224, were predicted to form significantly under the conditions of the ACES experiments. $\mathrm{C} 131 \mathrm{CO}$ is a third-generation product formed from the further oxidation of several second-generation products in MCM v3.2 (e.g., BCLKET), and C137CO is nominally a first-generation product formed from the chemistry of $\mathrm{C} 137 \mathrm{O} 2$ in Fig. 3. However, the production of $\mathrm{C} 137 \mathrm{O} 2$ is delayed under the ACES experimental conditions, because of the temporary formation of C137PAN, such that C137CO is simulated to accumulate gradually throughout the exper- iment. Observation of the parent $\mathrm{MH}^{+}$ion at $\mathrm{m} / \mathrm{z} 225$ provides support for the formation of $\mathrm{C} 131 \mathrm{CO}$ and $\mathrm{C} 137 \mathrm{CO}$, with the dehydrated daughter ions of each contributing to the $\mathrm{m} / z 207$ signal. In addition to these interferences, the multifuctional nitrate species C141NO3 (shown in Fig. 8) also potentially contributes to $\mathrm{m} / \mathrm{z}, 207$ by means of an $\mathrm{MH}^{+}(-$ $\mathrm{HNO}_{3}$ ) fragment (formed via the mechanisms discussed for more abundant nitrates below).

The broken line in the $m / z, 207$ panel of Fig. 15 includes a quantitative contribution to the simulated mixing ratio from C131CO, C137CO and C141NO3. This confirms that they are sufficiently abundant to provide some level of contribution to the $m / z, 207$ signal, and can at least partially help to explain the model-measurement discrepancy. Furthermore, as discussed above, the nascent $\mathrm{MH}^{+}$ions formed from protonation of $\mathrm{C} 141 \mathrm{CO} 2 \mathrm{H}(\mathrm{m} / \mathrm{z}, 253)$ and BCAL $(\mathrm{m} / z, 237)$, may fragment, to some extent, via respective losses of neutral $\mathrm{HCOOH}$ and $\mathrm{HCHO}$, leaving the $\mathrm{C}_{14} \mathrm{H}_{23} \mathrm{O}^{+}$daughter ion of $\mathrm{m} / \mathrm{z}$ 207. As can be seen in Fig. 15, the ions of $\mathrm{m} / \mathrm{z}$ 207, $\mathrm{m} / \mathrm{z} 253$ and $\mathrm{m} / \mathrm{z}, 237$ possess temporal profiles that are qualitatively similar. Consequently, the $\mathrm{m} / \mathrm{z} 207$ peak may potentially contain contributions from molecular and fragment ions from a number of different products, and it may therefore also represent a missing mass contribution when quantifying the total signals for the $\mathrm{m} / \mathrm{z}, 253$ and $\mathrm{m} / \mathrm{z} 237$ families.

\subsubsection{Higher or multi-generation products}

Model-measurement comparisons for a number of higher- or multi-generation oxygenated products are shown in Fig. 17. These can be related directly to the major product ion signals detected by CIR-TOF-MS, as follows:

$m / z$ 255: The set of MCM v3.2 species for which the parent $\mathrm{MH}^{+}$ion is at $m / z 255$ potentially has contributions from several isomeric species, namely $\mathrm{BCKSOZ}, \mathrm{C} 131 \mathrm{CO} 2 \mathrm{H}$ and BCLKBOC. These species are simulated to be significant second-generation products, formed from the $\mathrm{O}_{3}$ - and $\mathrm{OH}-$ initiated chemistry of several first-generation products (i.e., BCSOZ, C141CO2H, BCALBOC and BCKET: see Figs. 57). A further isomer is the reported first-generation ozonolysis product, $\beta$-caryophyllinic acid $(\mathrm{C} 137 \mathrm{CO} 2 \mathrm{H})$. As discussed in Sect. 2.1.1, its formation by the MCM v3.2 chemistry is strongly inhibited in the presence of $\mathrm{NO}_{\mathrm{x}}$, and it makes a negligible simulated contribution (yield $<10^{-8}$ ) for the conditions of these experiments. As shown in Fig. 17, the individual and collective simulated profiles for BCKSOZ, $\mathrm{C} 131 \mathrm{CO} 2 \mathrm{H}$ and BCLKBOC show a progressive accumulation throughout the experiment, in reasonable agreement with that observed for the $\mathrm{MH}^{+}$parent ion of $\mathrm{m} / \mathrm{z} 255$. The composite profile is dominated by BCKSOZ, which accounts for over $95 \%$ of the simulated total. This is because of the high yield of its first-generation precursor, BCSOZ, in MCM v3.2, and because of its relatively low propensity to transfer to the aerosol phase or chamber wall. 

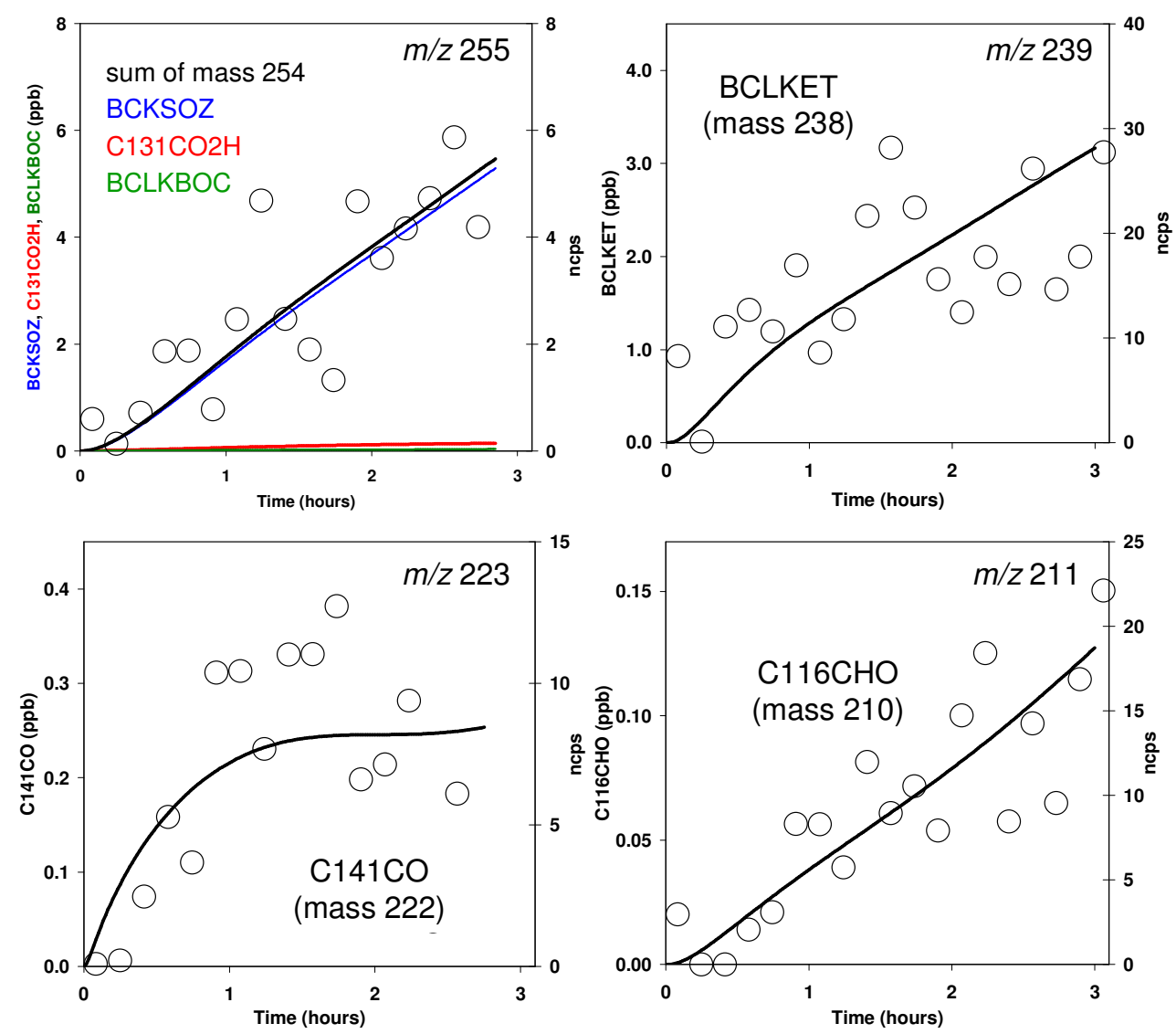

Fig. 17. Example time profiles simulated for selected higher- or multi-generation oxygenated products (lines), compared with those for corresponding product ion signals measured using CIR-TOF-MS (points), during ACES photo-oxidation experiments. Measured signals are presented as normalised counts per second (npcs), and the values for a given $\mathrm{m} / \mathrm{z}$ incorporate the corresponding daughter ion signals identified in Table 3. Comparisons are for experiment 30-06-08 ( $\mathrm{m} / \mathrm{z}, 223), 03-07-08(\mathrm{~m} / \mathrm{z}, 255), 10-07-08(\mathrm{~m} / \mathrm{z}, 239$ and 211$)$. C141CO is formed partially during the first-generation of oxidation.

Being structurally analogous to the $\mathrm{m} / \mathrm{z} 253$ species, it is likely that BCKSOZ, $\mathrm{C} 131 \mathrm{CO} 2 \mathrm{H}$ and BCLKBOC would fragment via similar mechanisms following ionisation, which could therefore potentially yield $\mathrm{MH}^{+}\left(-\mathrm{H}_{2} \mathrm{O}\right)$ and $\mathrm{MH}^{+}(-\mathrm{HCOOH})$ daughter ions (amongst others) of $\mathrm{m} / \mathrm{z} 237$ and $\mathrm{m} / \mathrm{z} 209$, respectively, although the abundance of the latter would be expected to be limited by the small contribution made by $\mathrm{C} 131 \mathrm{CO} 2 \mathrm{H}$ to the composite simulated profile.

However, it is clear that, compared to that of $\mathrm{m} / \mathrm{z} 253$, the $\mathrm{m} / \mathrm{z} 255 \mathrm{MH}^{+}$signal is very weak ( $\left.\sim 6 \mathrm{ncps}\right)$ for a set of species (dominated by BCKSOZ) that are simulated to accumulate to a mixing ratio of several ppb, and which collectively represent the major contribution to second-generation products of $\beta$-caryophyllene oxidation. Further to this, there is no significant evidence that there is any major contribution from a progressively accumulating compound of significant gas phase mixing ratio to the $\mathrm{m} / \mathrm{z} 237$ and 209 mass channels; both exhibit very different temporal profiles that are not perturbed in the latter stages of the experiment, as would be expected if the $m / z, 255$ species were contributing.

These findings may therefore indicate that BCKSOZ, $\mathrm{C} 131 \mathrm{CO} 2 \mathrm{H}$ and BCLKBOC have a greater collective propensity to transfer to the aerosol phase or chamber wall than is represented here, which could result either from their vapour pressures being systematically overestimated, or from an overestimated contribution from the relatively volatile dominant species BCKSOZ, of which $90 \%$ is simulated to be in the gas phase.

$m / z$ 239: The $\mathrm{MH}^{+}$parent ion at $m / z 239$ can be accounted for by $\beta$-nocaryophyllone aldehyde (BCLKET), formed from the $\mathrm{O}_{3}$ - and $\mathrm{OH}$-initiated oxidation of both BCAL and BCKET (see Figs. 6 and 7). Once again, the BCLKET $\mathrm{MH}^{+}$ion might be expected to fragment following PTR ionisation to yield certain daughter ions. Considering its structure and its similarity to BCAL, BCLKET might be expected to yield an $\mathrm{MH}^{+}\left(-\mathrm{H}_{2} \mathrm{O}\right)$ daughter ion of $m / z, 221$ and possibly daughter products of $m / z 195$ and 181, resulting from fragmentation of the hydrocarbon chain. Any 
potential contribution to the observed $\mathrm{m} / \mathrm{z} 221$ signal from the BCLKET dehydrated daughter ion has not been considered here, owing to a combination of its co-incidence with those ions discussed below for the major first generation hydroxynitrates (BCANO3, BCBNO3 and BCCNO3) and the relatively small $\mathrm{MH}^{+}$parent ion signal observed. Similarly, the potential $\mathrm{MH}^{+}(-\mathrm{HCHO})$ daughter ion of $\mathrm{m} / z$ 209, as discussed above, has also not been considered for the same reason. However, an ion of $\mathrm{m} / \mathrm{z} 195$ was detected in the CIRTOF-MS spectra, with a temporal profile well correlated with that of $m / z 239 \mathrm{MH}^{+}$parent ion. As shown in Fig. 17, the simulated profile for BCLKET shows a progressive accumulation throughout the experiment, in agreement with that observed for the sum of the $\mathrm{m} / \mathrm{z}, 239$ and $\mathrm{m} / \mathrm{z}, 195$ signals (which has approximately equal contributions from each).

As has been noted, the measured peak signal of the BCLKET $\mathrm{MH}^{+}$ion was relatively small $(\sim 15 \mathrm{ncps})$ considering a simulated peak mixing ratio of $\sim 3 \mathrm{ppb}$, particularly when compared to the equivalent $\mathrm{MH}^{+}$signals detected at $\mathrm{m} / \mathrm{z} 253$ and $\mathrm{m} / \mathrm{z} 237$ for BCSOZ, C141CO2H and BCAL$\mathrm{BOC}$ and BCAL, respectively. Assuming that these structurally similar compounds have similar CIR-TOF-MS sensitivities, this finding once again indicates that the model may be either overestimating the formation of BCLKET to some extent and/or underestimating its partitioning to the aerosol phase, or the chamber walls.

$\boldsymbol{m} / \boldsymbol{z}$ 223: The parent $\mathrm{MH}^{+}$ion at $m / z, 223$ can be accounted for by the species C141CO. As shown in Figs. 3, 8 and 10, $\mathrm{C} 141 \mathrm{CO}$ is formed both as a relatively minor first-generation ozonolysis product (about $1.5 \%$ yield under the experimental conditions); and also as a second-generation product from the OH-initiated oxidation of BCAL (and other routes). The simulated profile (Fig. 17) thus shows both prompt and sustained formation of $\mathrm{C} 141 \mathrm{CO}$, which is in good agreement with that observed for the parent $\mathrm{m} / \mathrm{z} 223$ ion. A potential contribution to the observed signal from a dehydrated daughter ion at $m / z 205\left(\mathrm{MH}^{+}\left(-\mathrm{H}_{2} \mathrm{O}\right)\right)$ has not been considered here, owing to its co-incidence with that of the reagent $\beta$-caryophyllene.

$m / z$ 211: The parent $\mathrm{MH}^{+}$ion at $m / z 211$ can be related to the species $\mathrm{C} 116 \mathrm{CHO}$ in MCM v3.2. As shown in Figs. 6 and 7, $\mathrm{C} 116 \mathrm{CHO}$ is formed from the $\mathrm{O}_{3}$ - and/or $\mathrm{OH}$-initiated oxidation of both $\mathrm{C} 126 \mathrm{CHO}$ and BCKET. The simulated time dependence of $\mathrm{C} 116 \mathrm{CHO}$ (Fig. 14) shows a profile that is in good agreement with the observations for the $m / z, 211$ ion. Following the PTR fragmentation mechanisms detailed above for other species, the multifunctional $\mathrm{C} 116 \mathrm{CHO}$ could be expected to fragment via dehydration channels to produce $\mathrm{MH}^{+}\left(-\mathrm{H}_{2} \mathrm{O}\right)$ and $\mathrm{MH}^{+}\left(-\mathrm{H}_{2} \mathrm{O}\right)_{2}$ ions of $\mathrm{m} / \mathrm{z} 193$ and 175, respectively. As has been discussed, the $\mathrm{m} / \mathrm{z} 193$ channel may also be occupied by a fragment of $\mathrm{BCAL}$, which is present in significantly greater abundance than C116CHO. Consequently, the $\mathrm{m} / \mathrm{z} 193$ signal has not been included in the analysis and evaluation of $\mathrm{m} / z, 211$ and C116CHO. However, a signal of $\mathrm{m} / \mathrm{z}, 175$ with a temporal profile well correlated with that of $\mathrm{m} / \mathrm{z}, 211$ was measured, providing some support for this assignment. Similarly to the comparison of simulated $\mathrm{C} 126 \mathrm{CHO}$ mixing ratios with the $\mathrm{m} / \mathrm{z} 209$ family, discussed above, the simulated mixing ratios of $\mathrm{C} 116 \mathrm{CHO}$ appear to be consistently too small to account for the observed $\mathrm{m} / \mathrm{z} 211$ family signals, again suggesting either a high sensitivity to $\mathrm{C} 116 \mathrm{CHO}$, or additional contributing species displaying a similar temporal profile. By analogy with the above discussion, the species 4-(3,3dimethyl-2-propyl-cyclobutyl)-4-oxo-butyraldehyde (shown in Fig. 16), is isobaric with $\mathrm{C} 116 \mathrm{CHO}$, and may be formed from the ozonolysis of BCKET or from further oxidation of the first-generation product, 4-(3,3-dimethyl-2-propylcyclobutyl)-pent-4-enal, detected by Kanawati et al. (2008) and Winterhalter et al. (2009).

\subsubsection{Oxidised nitrogen products}

Simulations using the MCM v3.2 scheme also logically predict formation of a large number of multi-functional species containing oxidised nitrogen groups, specifically PAN ($\left.\mathrm{C}(=\mathrm{O}) \mathrm{OONO}_{2}\right)$ and nitrate $\left(-\mathrm{ONO}_{2}\right)$ groups, from the photooxidation of $\beta$-caryophyllene/ $/ \mathrm{NO}_{\mathrm{x}}$ mixtures. Although not the most abundant, these multi-functional species nevertheless account for 12 of the top 30 gas phase species in the current simulations, and would therefore be expected to make a contribution to the major ion signals detected with CIRTOF-MS. A number of tentative assignments were made, as summarised in Table 2, allowing some previously unassigned ion signals to be accounted for. For species containing PAN groups, these assignments were based on the following ion-molecule reaction sequence, characterized by Hansel and Wisthaler (2000),

$\mathrm{RC}(=\mathrm{O}) \mathrm{OONO}_{2}+\mathrm{H}_{3} \mathrm{O}^{+} \rightarrow \mathrm{RC}(=\mathrm{O}) \mathrm{OONO}_{2} \cdot \mathrm{H}^{+}+\mathrm{H}_{2} \mathrm{O}$

$\mathrm{RC}(=\mathrm{O}) \mathrm{OONO}_{2} \cdot \mathrm{H}^{+}+\mathrm{H}_{2} \mathrm{O} \rightarrow \mathrm{RC}(\mathrm{O}) \mathrm{OOH} \cdot \mathrm{H}^{+}+\mathrm{HNO}_{3}$

such that the PAN species are essentially detected as the corresponding protonated peracids $\left(\mathrm{RC}(\mathrm{O}) \mathrm{OOH} . \mathrm{H}^{+}\right)$. For species containing nitrate groups, Aoki et al. (2007) found that the product ion distribution for larger alkyl nitrates was dominated by production of the corresponding carbenium ion $\left(\mathrm{R}^{+}\right)$, as follows:

$$
\begin{array}{r}
\mathrm{RONO}_{2}+\mathrm{H}_{3} \mathrm{O}^{+} \rightarrow \mathrm{RONO}_{2} \cdot \mathrm{H}^{+}+\mathrm{H}_{2} \mathrm{O} \\
\mathrm{RONO}_{2} \cdot \mathrm{H}^{+} \rightarrow \mathrm{R}^{+}+\mathrm{HNO}_{3}
\end{array}
$$

Model-measurement comparisons for a number of multifunctional oxidised nitrogen species are shown in Fig. 18, using assignments based on the above reasoning:

$m / z$ 271: This ion signal can be attributed to the $\mathrm{MH}^{+} \cdot\left(\mathrm{H}_{2} \mathrm{O}\right)\left(-\mathrm{HNO}_{3}\right)$ ion of the isomeric PANs, C131PAN and C137PAN, as shown in Fig. 18. C137PAN is formed as a first-generation product from the reaction of $\mathrm{NO}_{2}$ with the acyl peroxy radical, $\mathrm{C} 137 \mathrm{CO} 3$, shown in Fig. 3, whereas C131PAN is formed as a third-generation product from the $\mathrm{OH}$-initiated oxidation of BCLKET. The resultant composite 

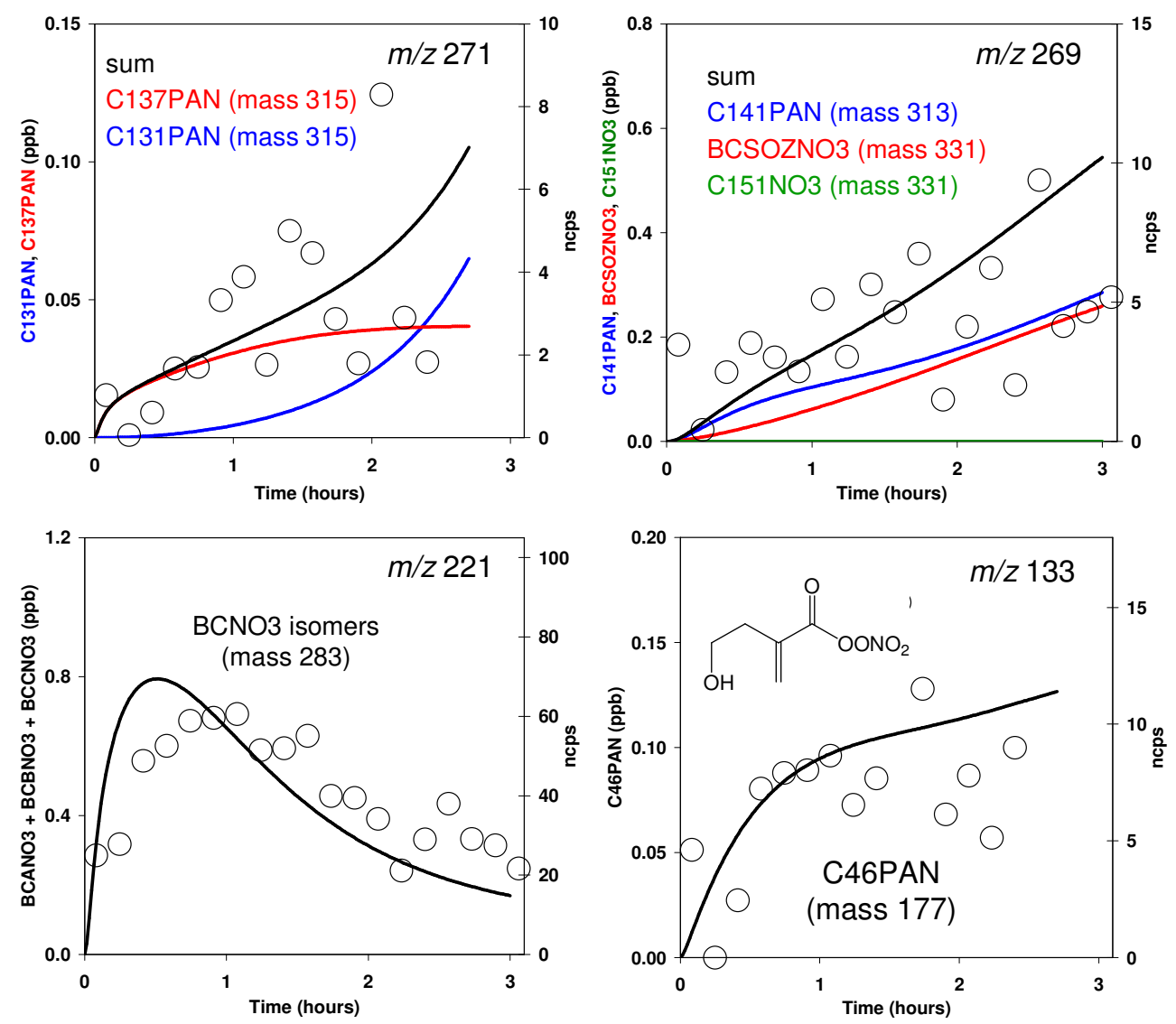

Fig. 18. Example time profiles simulated for multi-functional products containing oxygenated nitrogen groups (lines), compared with those for corresponding product ion signals measured using CIR-TOF-MS (points), during ACES photo-oxidation experiments. Measured signals are presented as normalised counts per second (npcs), for the daughter ions identified in Table 3. Comparisons are for experiments 04-07-08 $(\mathrm{m} / \mathrm{z}, 271$ and 133) and 10-07-08 ( $\mathrm{m} / \mathrm{z}, 269$ and 221). "BCNO3 isomers" is used to denote the collective population of BCANO3, BCBNO3 and BCCNO3.

time profile (Fig. 18) shows a progressive increase, generally dominated by C137PAN, but with C131PAN contributing towards the end of the experiment. Although scattered, the observed weak $\mathrm{m} / \mathrm{z}, 271$ ion signal corresponding to the $\mathrm{MH}^{+} \cdot\left(\mathrm{H}_{2} \mathrm{O}\right)\left(-\mathrm{HNO}_{3}\right)$ ion, is broadly consistent with the simulated behaviour.

$m / z$ 269: This ion signal potentially has contributions from the $\mathrm{MH}^{+} \cdot\left(\mathrm{H}_{2} \mathrm{O}\right)\left(-\mathrm{HNO}_{3}\right)$ fragment ion of C141PAN, and the $\mathrm{MH}^{+}\left(-\mathrm{HNO}_{3}\right)$ fragment ions of the hydroxynitrates $\mathrm{BC}-$ SOZNO3 and C151NO3. As shown in Figs. 7 and 8, these species are formed as second-generation products from the OH-initiated oxidation of BCAL, BCSOZ and $\mathrm{C} 141 \mathrm{CO} 2 \mathrm{H}$, respectively. In practice, $\mathrm{C} 151 \mathrm{NO} 3$ makes a negligible contribution to the composite time profile (Fig. 18), as it is simulated to be essentially exclusively in the condensed SOA phase. Although BCSOZNO3 is also simulated to be mainly $(60 \%)$ in the SOA phase, and significantly (up to $25 \%$ ) in the wall phase, it has a generally high abundance in all phases because of the major contribution made by its precursor, BC$\mathrm{SOZ}$, to the first-generation product distribution. Once again, the observed $\mathrm{m} / z 269$ profile is broadly consistent with the simulated behaviour.

$m / z$ 221: This ion signal potentially has a contribution from $\mathrm{MH}^{+}\left(-\mathrm{HNO}_{3}\right)$ fragment ions of the first-generation hydroxynitrates, BCANO3, BCBNO3 and BCCNO3. As discussed above, and shown in Figs. 4 and 10, these species are formed from the $\mathrm{OH}$-initiated $\beta$-caryophyllene chemistry in conjunction with radical termination. Their estimated overall yield for the conditions of these experiments is about $5 \%$. The observed profile for the $\mathrm{m} / \mathrm{z} 221$ family (shown in Fig. 18) is taken to include a (well-correlated) contribution from a dehydrated daughter ion of $\mathrm{m} / \mathrm{z} 203$, the formation of which is assumed to be facilitated by the presence of the adjacent - $\mathrm{OH}$ groups in the carbenium ions. The simulated composite time dependence of BCANO3, BCBNO3 and $\mathrm{BCCNO} 3$ shows a profile with a shape that is in fair agreement with the observations, providing some support for the assignment. However, in comparison with the signals for the major ions discussed above, the simulated peak mixing ratio of the hydroxynitrates $(0.8 \mathrm{ppb})$ is possibly too small 
to account fully for the observed $\mathrm{m} / \mathrm{z} 221$ family ion signal. As discussed above, BCLKET may potentially fragment following ionisation to produce a daughter ion of $\mathrm{m} / \mathrm{z} 221$. It was noted above that the intensity of the BCLKET $\mathrm{MH}^{+}$ signal $(\mathrm{m} / \mathrm{z}, 239)$ was relatively low compared with those of structurally similar species in the MCMv3.2 scheme, and any contribution from the daughter fragment to the $\mathrm{m} / \mathrm{z}, 221$ channel is therefore expected to be very small under the experimental conditions employed. Furthermore, the $\mathrm{m} / \mathrm{z}, 221$ temporal profile is not consistent with having any significant contribution from a continually accumulating product signal, as is expected for BCLKET. A further potential contribution might arise from the formation of $\beta$-caryophyllene oxide $\left(\mathrm{C}_{15} \mathrm{H}_{24} \mathrm{O}\right)$ as a first generation product in the system, this currently not being represented in MCM v3.2. $\beta$ caryophyllene oxide would likely form a parent $\mathrm{MH}^{+}$ion of $\mathrm{m} / \mathrm{z} 221$ and, as a relatively volatile product with a residual exocyclic double bond, would be expected to display a temporal profile similar to that simulated for BCSOZ (Fig. 15), and therefore reasonably similar to the $\mathrm{m} / \mathrm{z}, 221$ trace. Calogirou et al. (1997) and Jaoui et al. (2003) reported evidence for $\beta$-caryophyllene oxide formation as a $\beta$-caryophyllene ozonolysis product, with the latter study reporting a yield of $1 \%$. However, it was apparently not detected in the more recent studies of Kanawati et al. (2008) and Winterhalter et al. (2009).

$m / z$ 133: This ion signal potentially has a contribution from C46PAN. This is a $\mathrm{C}_{5}$ PAN, formed as a relatively minor product in several generations, e.g., from the further chemistry of $\mathrm{C} 137 \mathrm{O} 2$ in Fig. 3., and from the further chemistry of $\mathrm{C} 142 \mathrm{O} 2$ in Fig. 8. The simulated profile (Fig. 18) thus shows evidence of prompt and sustained formation, which is broadly consistent with the observed profile for the relatively weak ion signal.

\subsubsection{Other products}

Model-measurement comparisons for some further tentative assignments are shown in Fig. 19, which allow otherwise unassigned ions detected by CIR-TOF-MS to be related to gas phase species simulated to be in the top 30. The two bifunctional acids $(\mathrm{CHOC} 2 \mathrm{CO} 2 \mathrm{H}$ and $\mathrm{HCOCH} 2 \mathrm{CO} 2 \mathrm{H})$ are assumed to be detected as dehydrated parent $\mathrm{MH}^{+}$ ions, and the $\mathrm{C}_{11}$ PAN species, C1011PAN, is assumed to be detected following dehydration of the corresponding $\mathrm{RC}(=\mathrm{O}) \mathrm{OOHH}^{+}$ion. As shown in Fig. 19, the simulated profiles are not inconsistent with the observations, within the observed level of scatter. The tentative observation of $\mathrm{C} 1011 \mathrm{PAN}$ and $\mathrm{HCOCH} 2 \mathrm{CO} 2 \mathrm{H}$, provides some support for their related formation from the ozonolysis of $\mathrm{C} 141 \mathrm{CO} 2 \mathrm{H}$, as shown in Fig. 5 (C1011PAN also being produced from analogous chemistry of BCAL). $\mathrm{CHOC} 2 \mathrm{CO} 2 \mathrm{H}$ is formed as a minor first-generation product from the further chemistry of $\mathrm{C} 137 \mathrm{O} 2$ (in Fig. 3), and also via an analogous reaction sequence following the ozonolysis of BCKET.
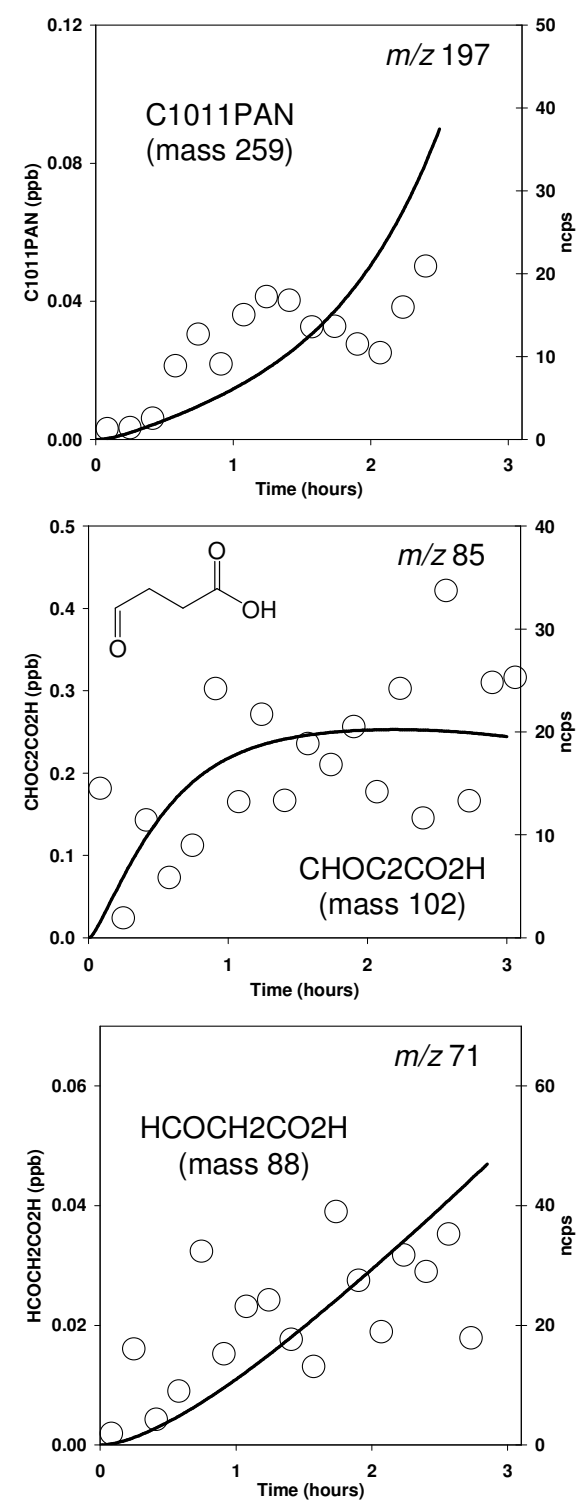

Fig. 19. Example time profiles for additional products simulated to be relatively abundant in the gas phase (lines), compared with tentative product ion signals measured using CIR-TOF-MS (points), during ACES photo-oxidation experiments. Measured signals are presented as normalised counts per second (npcs), for the daughter ions identified in Table 3. Comparisons are for experiments 04-07$08(\mathrm{~m} / \mathrm{z}, 197), 10-07-08(\mathrm{~m} / \mathrm{z}, 85)$ and $03-07-08(\mathrm{~m} / \mathrm{z}, 71)$. Structures for C1011PAN and $\mathrm{HCOCH} 2 \mathrm{CO} 2 \mathrm{H}$ shown in Fig. 5.

\subsubsection{Other studies}

The chamber photo-oxidation of $\beta$-caryophyllene/ $\mathrm{NO}_{\mathrm{x}}$ has also previously been studied by Lee et al. (2006b). They reported detection of a number of product ions using PTR-MS, and presented examples of their temporal dependences, including many of the product ions discussed above and listed in Table 3 (i.e., $\mathrm{m} / \mathrm{z}$ 253, 235, 223, 219, 211, 209, 207 and 

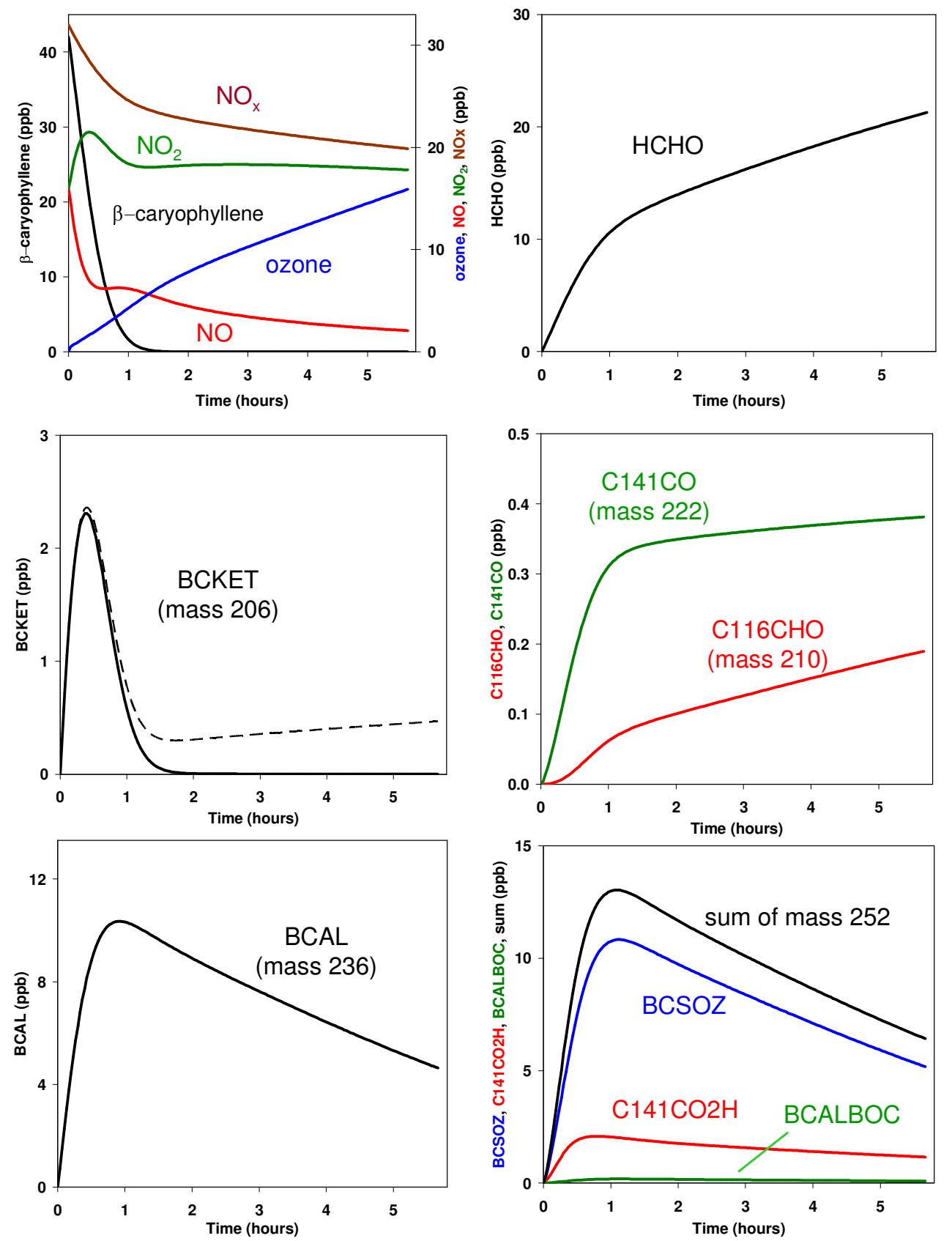

Fig. 20. Simulations designed to be indicative of the conditions of the photo-oxidation experiment reported in Figs. 1 and 3 of Lee et

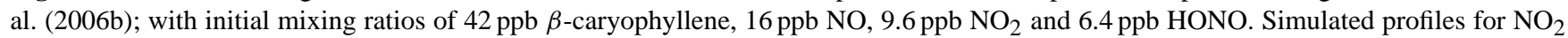
and $\mathrm{NO}_{\mathrm{x}}$ are assumed to include quantitative contributions from $\mathrm{HONO}$ and PANs (see Sect. 4.1). Product profiles can be compared with $\mathrm{m} / \mathrm{z}$ data in Fig. 3 of Lee et al. (2006b), as follows: BCKET with $\mathrm{m} / \mathrm{z}$ 207, 189; C116CHO with $\mathrm{m} / z$ 211; C141CO with $\mathrm{m} / \mathrm{z}$ 223; BCAL with $\mathrm{m} / \mathrm{z}$ 219; and sum of mass 252 with $\mathrm{m} / \mathrm{z}, 253,235$. Broken line in BCKET panel is the result of a senstivity test considering potential interfering signals (see text).

189). An illustrative simulation of their experimental conditions was therefore carried out, using the chamber model with some variations as described above in Sect. 4.1. Lee et al. (2006b) included an unspecified mixing ratio of reagent $\mathrm{HONO}$ as a photolytic source of $\mathrm{OH}$ radicals to initiate the chemistry in the system. HONO was reported to contribute to the measured $\mathrm{NO}_{2}$ signal, and the results of sensitivity tests carried out here imply that it needed to account for about $40 \%$ of the $\mathrm{NO}_{2}$ signal at the start of the experiment to allow simulation of $\beta$-caryophyllene, $\mathrm{NO}_{\mathrm{x}}$ and $\mathrm{O}_{3}$ profiles that are 

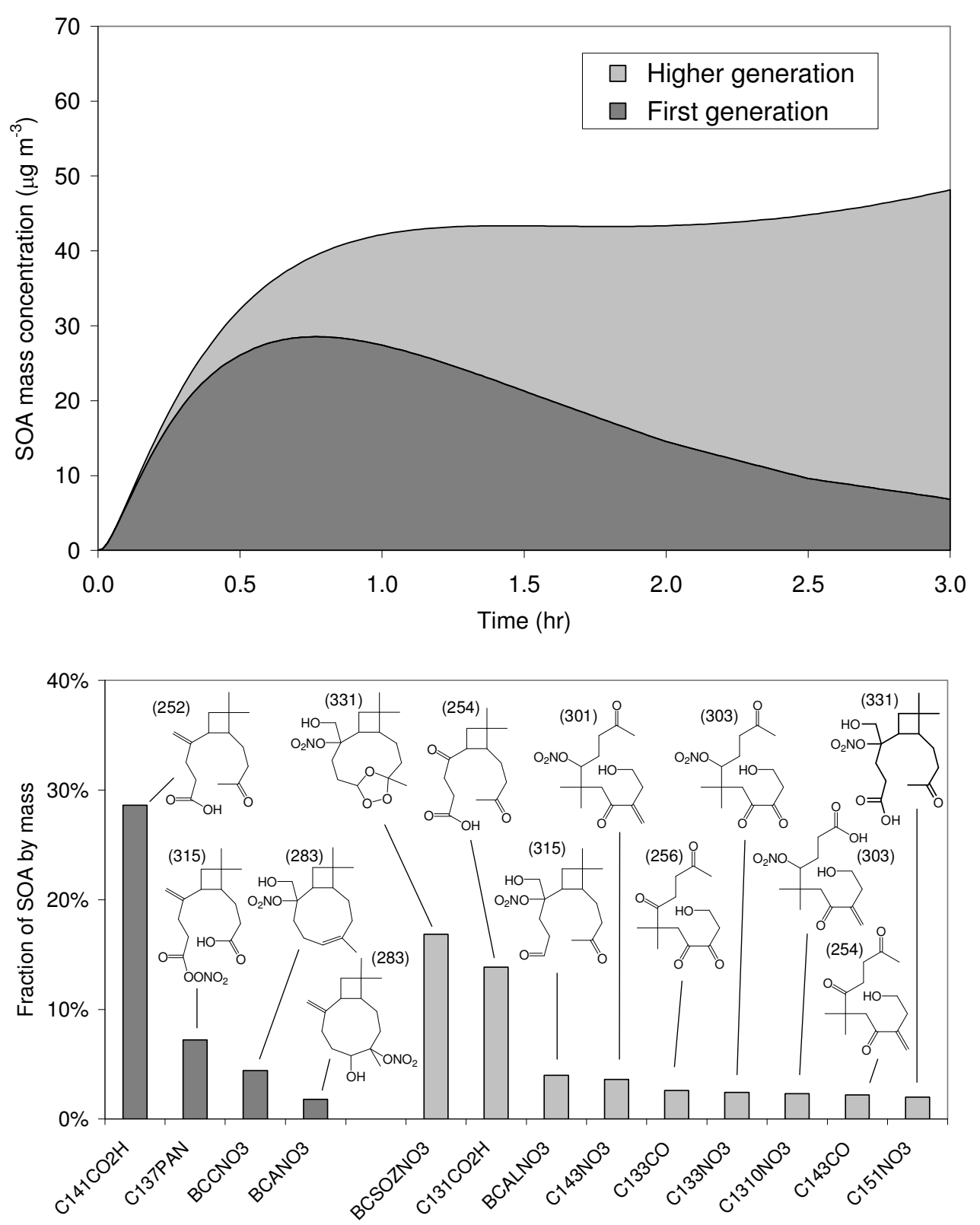

Fig. 21. Simulated SOA composition for ACES photo-oxidation experiment 03-07-08, using the MCM v3.2 scheme, with a $6 \%$ yield of $\mathrm{OH}$ (and co-radicals) from $\beta$-caryophyllene ozonolysis. The upper panel shows the simulated time dependence of the contributions of first and higher generation products to SOA. The lower panel shows the contributions of the top 13 simulated contributors, averaged over the experiment, these accounting for $\sim 92 \%$ of the total simulated SOA mass loading. N.B.: C143NO3, C133NO3, C1310NO3, C133CO and $\mathrm{C} 143 \mathrm{CO}$ have minor first-generation contributions, but are formed predominantly as higher generation products. The displayed values indicate the molecular masses of the products.

broadly comparable with those observed (see Fig. 20). The simulations showed a reduced sensitivity to the primary $\mathrm{OH}$ yield from the reaction of $\mathrm{O}_{3}$ with $\beta$-caryophyllene $\left(\mathrm{P}_{\mathrm{OH}}\right)$, owing to the use of reagent $\mathrm{HONO}$ as a primary source of $\mathrm{OH}$ radicals. However, for consistency with the appraisal of the ACES experiments above, these simulations were also carried out with a value of $6 \%$ for $\mathrm{P}_{\mathrm{OH}}$. Under these conditions, $\beta$-caryophyllene removal was simulated to be $62 \%$ due to re- action with $\mathrm{O}_{3}$ and $38 \%$ due to reaction with $\mathrm{OH}$ (compared with $60 \%$ and $40 \%$, respectively, with $\mathrm{P}_{\mathrm{OH}}=10 \%$ ).

Figure 20 shows the simulated profiles for a series of MCM v3.2 species, which were assigned above to the same set of product ions as detected by Lee et al. (2006b). A simulated profile for HCHO is also shown. The shapes of these profiles are all entirely consistent with those presented in Fig. 3 of Lee et al. (2006b), providing additional support for 
the series of assignments discussed above. In contrast to the ACES comparisons above, the shape of the simulated profile for $\beta$-nocaryophyllone (BCKET) is in good agreement with that reported for $m / z 207$ and 189 by Lee et al. (2006b), showing a peak mixing ratio about 30 minutes into the experiment, followed by a rapid decay comparable to that observed for $\beta$-caryophyllene. As discussed above, the lifetimes of these species are expected to be similar, owing to the retention of the reactive endocyclic double bond in BCKET and its associated high reactivity towards $\mathrm{O}_{3}$. To account for this rapid decay, the present simulations suggest that a few ppb of $\mathrm{O}_{3}$ must be present in the early stages of the experiment for both $\beta$-caryophyllene and BCKET to be significantly shorter-lived than the other detected products in the system (as was observed); and indeed it is not possible to suppress simulated $\mathrm{O}_{3}$ formation with significant operation of the OH-initiated chemistry in the presence of $\mathrm{NO}_{\mathrm{x}}$. It is noted, however, that the $\mathrm{O}_{3}$ profile reported by Lee et al. (2006b) shows it to be completely suppressed for the first 90 minutes of the experiment. This one aspect of the results could not be recreated or explained by the present simulations.

The differences in the shapes of the $\mathrm{m} / \mathrm{z} 207$ temporal profile reported by Lee et al. (2006b) and that observed in the ACES experiments (Fig. 15) suggest that the potentially interfering contributions discussed above in Sect. 6.3.1 are less important for the experimental conditions employed by Lee et al. (2006b). Because of the significant formation of $\mathrm{C} 141 \mathrm{CO} 2 \mathrm{H}$ and BCAL under both sets of chamber experimental conditions, the differences in any interferences from the respective fragment ions, $\mathrm{MH}^{+}(-\mathrm{HCOOH})$ and $\mathrm{MH}^{+}(-$ $\mathrm{HCHO}$ ), can only be attributed to differences in the PTRMS operating conditions, leading to less significant formation of these fragments in the Lee et al. (2006b) study. However, the potentially interfering contributions from the species $\mathrm{C} 131 \mathrm{CO}, \mathrm{C} 137 \mathrm{CO}$ and $\mathrm{C} 141 \mathrm{NO} 3$ (as shown for the ACES experiments in Fig. 15), are reduced to some extent under the chamber experimental conditions employed by Lee et al. (2006b), as shown in the BCKET panel of Fig. 20. Noting that BCKET is formed exclusively from the $\mathrm{OH}-$ initiated chemistry, and these interfering species at least partially from the $\mathrm{O}_{3}$-initiated chemistry, this can be explained partially by the greater importance of the $\mathrm{OH}$-initiated chemistry under the conditions employed by Lee et al. (2006b), compared with those in the ACES experiments. However, the generally higher $\mathrm{NO}_{2} / \mathrm{NO}$ ratios throughout the Lee et al. (2006b) experiment also tend to inhibit the formation of $\mathrm{C} 131 \mathrm{CO} \mathrm{C} 137 \mathrm{CO}$ and $\mathrm{C} 141 \mathrm{NO} 3$, through favouring the formation of the related PAN species, C131PAN, C137PAN and C141PAN and extending their lifetimes (e.g., as shown for C141PAN in relation to C141NO3 in Fig. 8).

\subsection{Simulated composition of SOA}

Figure 21 shows the time evolution of the simulated characterizable SOA mass loading for the example of ACES photooxidation experiment 03-07-08, with the collective contributions made by first- and higher-generation products identified. Consistent with the above appraisal of the gas phase components using ACES CIR-TOF-MS data, this simulation assumes that $\mathrm{P}_{\mathrm{OH}}=6 \%$, [wall $]_{\mathrm{eff}}=1.5 \mathrm{mg} \mathrm{m}^{-3}$ and that partitioning into the SOA phase is constrained by the observed mass loadings (i.e., as in Fig. 12, simulation (iii)). The results logically show an initial dominant contribution from first-generation products, but with a progressively increasing contribution from higher-generation products, which are simulated to account for over $80 \%$ of the SOA by the end of the experiment. The SOA composition becomes gradually more oxidised, with an average molecular formula of $\mathrm{C}_{14.74} \mathrm{H}_{23.65} \mathrm{O}_{3.84} \mathrm{~N}_{0.31}(\mathrm{MW}=266.6)$ after 30 minutes, and $\mathrm{C}_{14.21} \mathrm{H}_{22.90} \mathrm{O}_{5.64} \mathrm{~N}_{0.62}(\mathrm{MW}=292.7)$ by the end of the simulation.

The top 13 simulated contributors, averaged over the simulation, are also shown in Fig. 21, with these collectively accounting for $92 \%$ of the total SOA mass loading. Similarly to the dark ozonolysis conditions considered above (Sect. 5), two of the most abundant simulated contributors under these photo-oxidation conditions are the first-generation product, $\beta$-caryophyllonic acid $(\mathrm{C} 141 \mathrm{CO} 2 \mathrm{H})$, and the secondgeneration product, $\beta$-nocaryophyllonic acid $(\mathrm{C} 131 \mathrm{CO} 2 \mathrm{H})$, which collectively account for just over $40 \%$ of the averaged SOA composition. $\mathrm{C} 141 \mathrm{CO} 2 \mathrm{H}$ has been reported to be an important SOA contributor under photo-oxidation conditions by Chan et al. (2011) and recently, for the same series of ACES experiments considered here, by Alfarra et al. (2012). These studies also reported detection of $\mathrm{C} 131 \mathrm{CO} 2 \mathrm{H}$ and/or its isomeric first-generation product, $\beta$-caryophyllinic acid $(\mathrm{C} 137 \mathrm{CO} 2 \mathrm{H})$. As discussed in Sect. 2.1.1, formation of $\mathrm{C} 137 \mathrm{CO} 2 \mathrm{H}$ is strongly-inhibited in the presence of $\mathrm{NO}_{\mathrm{x}}$ in the MCM v3.2 chemistry, and it makes a negligible simulated contribution for the conditions of these experiments.

The present simulations also predict a number of multifunctional carbonyls or hydroxycarbonyls to be in the top 20 SOA contributors (with a total contribution of about $6 \%$ ). These include the doubly ring-opened species $\mathrm{C} 133 \mathrm{CO}$ and C143CO (shown in Fig. 21), and also $\beta$-nocaryophyllon aldehyde (BCLKET) and $\beta$-caryophyllon aldehyde (BCAL). These species thus show some overlap with those reported by Chan et al. (2011) and Alfarra et al. (2012), or are isomeric to or isobaric with species reported in those studies.

The remaining significant SOA contributors are simulated to be multifunctional species containing oxidised nitrogen groups, with these species accounting for just over $50 \%$ of the averaged SOA composition. Their abundance increases throughout the simulation, with the oxidised nitrogen groups themselves contributing $7.6 \%$ to the SOA mass after 30 minutes, and $13.6 \%$ by the end of the simulation (average 
$10.9 \%)$. This includes contributions from nitrate $\left(-\mathrm{ONO}_{2}\right)$ and peroxynitrate $\left(-\mathrm{OONO}_{2}\right)$ groups, which account for averages of $8.7 \%$ and $2.2 \%$ of the SOA mass, respectively. It is noted that this level of contribution of nitrate groups is comparable with the range 6-15\% reported by Rollins et al. (2010) for SOA formed from the photo-oxidation of $\alpha$ pinene, 3-carene, limonene and tridecane in the presence of $\mathrm{NO}_{\mathrm{x}}$. The most important simulated oxidised nitrogen contributors are shown in Fig. 21. These show some structural similarities to the series of species reported recently by Chan et al. (2011), but generally lie in a lower range of molecular weight, possibly due in part to the role of condensed phase reactions (as described by Chan et al., 2011). However, evidence for the formation of C151NO3 (and/or possibly its isomer BCSOZNO3) was reported, with a hydrated form of C151NO3 making a notable contribution at lower aerosol acidity (Chan et al., 2011).

\section{Summary and conclusions}

A degradation mechanism for $\beta$-caryophyllene has recently been released as part of version 3.2 of the Master Chemical Mechanism (MCM v3.2), describing in moderate detail the gas phase chemical processes involved in its complete atmospheric oxidation, as initiated by reaction with $\mathrm{O}_{3}$, $\mathrm{OH}$ radicals and $\mathrm{NO}_{3}$ radicals. The complete mechanism consists of 1626 reactions of 591 closed-shell and radical species, and incorporates kinetic and mechanistic information reported in a number of experimental and theoretical studies of $\beta$-caryophyllene degradation (see Sect. 2). This information was supplemented by the rules summarised in the MCM construction protocols (Jenkin et al., 1997; Saunders et al., 2003), and the mechanism necessarily contains a number of associated simplification measures to help limit its size. The mechanism can be viewed, and downloaded in a variety of formats, at the MCM website (http://mcm.leeds. ac.uk/MCM).

The performance of the mechanism has been evaluated in chamber simulations in which the gas phase chemistry was coupled to a representation of the gas-to-aerosol partitioning of 280 multi-functional oxidation products. This exercise considered data from a number of chamber studies of either the ozonolysis of $\beta$-caryophyllene, or the photooxidation of $\beta$-caryophyllene/ $\mathrm{NO}_{\mathrm{x}}$ mixtures, in which detailed product distributions have been reported. The most extensive evaluation made use of the results of a recent series of photo-oxidation experiments performed in the University of Manchester aerosol chamber, also reported here, in which a comprehensive characterization of the temporal evolution of the organic product distribution in the gas phase was carried out, using CIR-TOF-MS, in conjunction with measurements of $\mathrm{NO}_{\mathrm{x}}, \mathrm{O}_{3}$ and SOA mass loading. The CIR-TOFMS measurements allowed approximately 45 time-resolved product ion signals to be detected, which were assigned on the basis of the simulated temporal profiles of the more abundant MCM v3.2 species, and their probable fragmentation patterns. The evaluation studies demonstrate that the MCM v3.2 mechanism provides an acceptable description of $\beta$-caryophyllene degradation under the chamber conditions considered, with the temporal evolution of the observables identified above generally being recreated within the uncertainty bounds of key parameters within the mechanism. They also illustrate that the mechanism is necessarily not exhaustive, such that the chemistry may need to be supplemented with additional processes to explain the formation of all species that may be observed in experimental studies, or to recreate their precise temporal dependences.

This work has highlighted a number of areas of uncertainty or discrepancy, where further experimental and/or theoretical investigation would be valuable to help interpret the results of chamber studies and improve mechanistic understanding. These include the following specific areas:

- Quantification of the yield and stability of the secondary ozonide (BCSOZ), formed from $\beta$-caryophyllene ozonolysis, and elucidation of the details of its further oxidation, including whether the products retain the "ozonide" functionality. Because of the importance assigned to $\mathrm{BCSOZ}$ formation in the first-generation chemistry, and the relative volatility of species containing the ozonide functionality, these species were simulated to dominate the gas-phase profiles corresponding to a number of detected CIR-TOF-MS ion signals. Their yield and persistence therefore also influences the SOA forming potential of $\beta$-caryophyllene. It is noted that, if the high rate coefficients reported very recently for the reactions of $\mathrm{CH}_{2} \mathrm{OO}$ with $\mathrm{NO}_{2}$ and (possibly) $\mathrm{H}_{2} \mathrm{O}$ (Welz et al., 2012), also apply to the Criegee intermediates, $\mathrm{BCAOO}$ and $\mathrm{BCBOO}$, the formation of $\mathrm{BCSOZ}$ would be more inhibited than simulated here using the rate coefficients currently applied in MCM v3.2;

- Investigation of the impact of $\mathrm{NO}_{\mathrm{x}}$ on the $\beta$ caryophyllene ozonolysis mechanism, in particular its effect on the formation of $\beta$-caryophyllinic acid $(\mathrm{C} 137 \mathrm{CO} 2 \mathrm{H})$, and elucidation of the details of its formation mechanism. The provisional gas phase mechanism applied in MCM v3.2 predicts inhibition of $\mathrm{C} 137 \mathrm{CO} 2 \mathrm{H}$ formation in the presence of $\mathrm{NO}_{\mathrm{x}}$, because it requires significant operation of peroxy radical permutation reactions and/or reactions of peroxy radicals with $\mathrm{HO}_{2}$;

- Routine independent identification of $\beta$-caryophyllinic acid $(\mathrm{C} 137 \mathrm{CO} 2 \mathrm{H})$, and its potentially significant isomer $\beta$-nocaryophyllonic acid $(\mathrm{C} 131 \mathrm{CO} 2 \mathrm{H})$. The simulations presented above predict $\mathrm{C} 131 \mathrm{CO} 2 \mathrm{H}$ to be an important second-generation product under both ozonolysis and photo-oxidation conditions, and a major SOA component. 
- More precise quantification of the primary yield of $\mathrm{OH}$, and the co-radicals BCALAO2, BCALBO2 and BCALCO2, formed from $\beta$-caryophyllene ozonolysis. $\mathrm{OH}$ formation leads to secondary $\beta$-caryophyllene removal in chamber systems. This is amplified in the presence of NO, such that the chemistry in photo-oxidation systems is potentially very sensitive to the primary $\mathrm{OH}$ yield. The chemistry of the co-radicals generates a number of multifunctional products, some of which were simulated to make important contributions to firstgeneration SOA.

- Quantification of the yields of the first-generation hydroxy nitrates (BCANO3, BCBNO3 and $\mathrm{BCCNO} 3$ ) from the $\mathrm{OH}$-initiated chemistry in the presence of $\mathrm{NO}_{\mathrm{x}}$. The formation of these species controls the chain-length of the OH-initiated chemistry, which influences the temporal development of photo-oxidation systems. The hydroxy nitrates were also simulated to be important components of SOA.

In addition, further studies in general that improve the identification and quantification of products formed from both ozonolysis and photo-oxidation would be valuable, including confirmation of the simulated formation of multifunctional species containing hydroperoxide groups, and their important contribution to SOA under $\mathrm{NO}_{\mathrm{x}}$-free conditions.

Acknowledgements. The authors gratefully acknowledge support from NERC as part of the APPRAISE ACES consortium (NE/E011217/1), and Defra (under contract AQ0704) for MEJ. The authors are grateful to Andrew Ellis and Paul Cullis (University of Leicester) and Jacqui Hamilton (University of York) for useful discussions, and to Iain White (University of Leicester) for assistance with CIR-TOF-MS calibrations.

Edited by: A. B. Guenther

\section{References}

Alfarra, M. R., Hamilton, J. F., Wyche, K. P., Good, N., Ward, M. W., Carr, T., Barley, M. H., Monks, P. S., Jenkin, M. E. and McFiggans, G. B.: The effect of photochemical ageing and initial precursor concentration on the composition and hygroscopic properties of $\beta$-caryophyllene secondary organic aerosol. Atmos. Chem. Phys. Discuss., 12, 2435-2482, doi:10.5194/acpd12-2435-2012, 2012.

Andreae, M. O. and Crutzen, P. J.: Atmospheric aerosols: biogeochemical sources and role in atmospheric chemistry, Science, 276, 1052-1058, 1997.

Aoki, N., Inomata, S. and Tanimoto, H.: Detection of $\mathrm{C}_{1}-\mathrm{C}_{5}$ alkyl nitrates by proton transfer reaction time-of-flight mass spectrometry, Int. J. Mass Spectrom., 263, 12-21, 2007.

Arey, J., Aschmann, S. M., Kwok, E. S. C. and Atkinson, R.: Alkyl nitrate, hydroxyalkyl nitrate, and hydroxycarbonyl formation from the NOx-air photooxidations of $\mathrm{C}_{5}-\mathrm{C}_{8}$ n-alkanes, J. Phys. Chem. A, 105, 1020-1027, 2001.
Atkinson, R. and Arey, J.: Atmospheric degradation of volatile organic compounds, Chem. Rev., 103, 4605-4638, 2003.

Aumont, B., Szopa, S., and Madronich, S.: Modelling the evolution of organic carbon during its gas-phase tropospheric oxidation: development of an explicit model based on a self generating approach, Atmos. Chem. Phys., 5, 2497-2517, doi:10.5194/acp-52497-2005, 2005.

Bahreini, R., Keywood, M. D., Ng, N. L., Varutbangkul, V., Gao, S., Flagan, R. C., Seinfeld, J. H.,Worsnop, D. R., and Jimenez, J. L.: Measurements of secondary organic aerosol from oxidation of cycloalkenes, terpenes, and m-xylene using an Aerodyne aerosol mass spectrometer, Environ. Sci. Technol., 39, 5674-5688, 2005.

Barley, M. H. and McFiggans, G.: The critical assessment of vapour pressure estimation methods for use in modelling the formation of atmospheric organic aerosol, Atmos. Chem. Phys., 10, 749767, doi:10.5194/acp-10-749-2010, 2010.

Blake, R. S., Wyche, K. P., Ellis, A. M. and Monks, P. S.: Chemical ionisation reaction time-of-flight mass spectrometry: Multireagent analysis for determination of trace gas composition, Int. J. Mass Spectrom., 254, 85-93, 2006.

Blake, R. S., Monks, P. S., and Ellis, A. M.: Proton transfer reaction mass spectrometry, Chem. Rev., 109, 861-896, 2009.

Calogirou, A., Kotzias, D., and Kettrup, A.: Product analysis of the gas-phase reaction of beta-caryophyllene with ozone, Atmos. Environ., 31, 283-285, 1997.

Carlton, A. G., Bhave, P. V., Napelenok, S. L., Edney, E. D., Sarwar, G., Pinder, R. W., Pouliot, G. A., and Houyoux, M.: Model representation of secondary organic aerosol in CMAQv4.7,. Environ. Sci. Technol., 44, 8553-8560, 2010.

Chan, M. N., Surratt, J. D., Chan, A. W. H., Schilling, K., Offenberg, J. H., Lewandowski, M., Edney, E. O., Kleindienst, T. E., Jaoui, M., Edgerton, E. S., Tanner, R. L., Shaw, S. L., Zheng, M., Knipping, E. M., and Seinfeld, J. H.: Influence of aerosol acidity on the chemical composition of secondary organic aerosol from $\beta$-caryophyllene. Atmos. Chem. Phys., 11, 1735-1751, doi:10.5194/acp-11-1735-2011, 2011.

Cox, R. A.: The photolysis of gaseous nitrous acid, J. Photochem., 3, 175-188, 1974.

De Gouw, J. and Warneke, C.: Measurements of volatile organic compounds in the Earth's atmosphere using proton-transferreaction mass spectrometry, Mass Spectrom. Rev., 26, 223-257, 2007.

Dillon, T. J. and Crowley, J. N.: Direct detection of OH formation in the reactions of $\mathrm{HO}_{2}$ with $\mathrm{CH}_{3} \mathrm{C}(\mathrm{O}) \mathrm{O}_{2}$ and other substituted peroxy radicals, Atmos. Chem. Phys., 8, 4877-4889, doi:10.5194/acp-8-4877-2008, 2008.

Duhl, T. R., Helmig, D., and Guenther, A.: Sesquiterpene emissions from vegetation: a review, Biogeosciences, 5, 761-777, doi:10.5194/bg-5-761-2008, 2008.

Griffin, R. J., Cocker, D. R., Flagan, R. C., and Seinfeld, J. H.: Organic aerosol formation from oxidation of biogenic hydrocarbons, J. Geophys. Res., 104, 3555-3567, 1999.

Guenther, A., Hewitt, C. N., Erickson, D., Fall, R., Geron, C., Graedel, T., Harley, P., Klinger, L., Lerdau, M., McKay, W. A., Pierce, T., Scholes, B., Steinbrecher, R., Tallamraju, R., Taylor, J., and Zimmerman, P.: A global model of natural volatile organic compound emissions, J. Geophys. Res., 100, 8873-8892, 1995.

Haagen-Smit, A. J. and Fox, M. M.: Photochemical ozone formation with hydrocarbons and automobile exhaust, J. Air Pollut. 
Control Assoc., 4, 105-109, 1954.

Hallquist, M., Wenger, J. C., Baltensperger, U., Rudich, Y., Simpson, D., Claeys, M., Dommen, J., Donahue, N. M., George, C., Goldstein, A. H., Hamilton, J. F., Herrmann, H., Hoffmann, T., Iinuma, Y., Jang, M., Jenkin, M. E, Jimenez, J. L., Kiendler-Scharr, A., Maenhaut, W., McFiggans, G., Mentel, Th. F., Monod, A., Prévôt, A. S. H., Seinfeld, J. H., Surratt, J. D., Szmigielski, R., Wildt, J.: The formation, properties and impact of secondary organic aerosol: current and emerging issues, Atmos. Chem. Phys., 9, 5155-5236, doi:10.5194/acp-9-5155-2009, 2009.

Hansel, A. and Wisthaler, A.: A method for real-time detection of PAN, PPN and MPAN in ambient air, Geophys. Res. Lett., 27, 895-898, 2000.

Hansel, A., Jordan, A., Holzinger, R., Prazellar, P., Vogel, W., and Lindinger, W.: Proton transfer reaction mass spectrometry: online trace gas analysis at the ppb level, Int. J. Mass Spectrom., 149-150, 609-619, 1995.

Hasson, A. S., Tyndall, G. S., and Orlando, J. J.: A product yield study of the reaction of $\mathrm{HO}_{2}$ Radicals with ethyl peroxy $\left(\mathrm{C}_{2} \mathrm{H}_{5} \mathrm{O}_{2}\right)$, acetyl peroxy $\left(\mathrm{CH}_{3} \mathrm{C}(\mathrm{O}) \mathrm{O}_{2}\right)$, and acetonyl peroxy $\left(\mathrm{CH}_{3} \mathrm{C}(\mathrm{O}) \mathrm{CH}_{2} \mathrm{O}_{2}\right)$ radicals, J. Phys. Chem. A, 108, 5979-5989, 2004.

Hoffmann, T., Odum, J. R., Bowman, F., Collins, D., Klockow, D., Flagan, R. C., and Seinfeld, J. H.: Formation of organic aerosols from the oxidation of biogenic hydrocarbons, J. Atmos. Chem., 26, 189-222, 1997.

Jaoui, M., Leungsakul, S., and Kamens, R. M.: Gas and particle products distribution from the reaction of $\beta$-caryophyllene with ozone, J. Atmos. Chem., 45, 261-287, 2003.

Jaoui, M., Sexton, K. G., and Kamens, R. M.: Reaction of $\alpha$-cedrene with ozone: mechanism, gas and particulate products distribution, Atmos. Environ., 38, 2709-2725, 2004.

Jaoui, M., Lewandowski, M., Kleindienst, T. E., Offenberg, J. H., and Edney, E. O.: $\beta$-caryophyllinic acid: an atmospheric tracer for $\beta$-caryophyllene secondary organic aerosol, Geophys. Res. Lett., 34, L05816, doi:10.1029/2006g1028827, 2007.

Jardine, K., Serrano, A. Y., Arneth, A., Abrell, L., Jardine, A., van Haren, J., Artaxo, P., Rizzo, L. V., Ishida, F. Y., Karl, T., Kesselmeier, J., Saleska, S., and Huxman, T.: Within-canopy sesquiterpene ozonolysis in Amazonia, J. Geophys. Res., 116, D19301, doi:10.1029/2011JD016243, 2011.

Jenkin, M. E.: Modelling the formation and composition of secondary organic aerosol from $\alpha$ - and $\beta$-pinene ozonolysis using MCM v3, Atmos. Chem. Phys., 4, 1741-1757, doi:10.5194/acp4-1741-2004, 2004.

Jenkin, M. E. and Clemitshaw, K. C.: Ozone and other secondary photochemical pollutants: chemical processes governing their formation in the planetary boundary layer, Atmos. Environ., 34, 2499-2527, 2000.

Jenkin, M. E., Saunders, S. M., and Pilling M. J.: The tropospheric degradation of volatile organic compounds: a protocol for mechanism development, Atmos. Environ., 31, 81-104, 1997.

Jenkin, M. E., Shallcross, D. E., and Harvey, J. N.: Development and application of a possible mechanism for the generation of cis-pinic acid from the ozonolysis of $\alpha$ - and $\beta$-pinene, Atmos. Environ., 34, 2837-2850, 2000.

Jenkin, M. E., Hurley, M. D. and Wallington, T. J.: Investigation of the radical product channel of the $\mathrm{CH}_{3} \mathrm{C}(\mathrm{O}) \mathrm{O}_{2}+\mathrm{HO}_{2}$ reaction in the gas phase, Phys. Chem. Chem. Phys., 9, 3149-3162, 2007.

Kanakidou, M., Seinfeld, J. H., Pandis, S. N., Barnes, I., Dentener, F. J., Facchini, M. C., Van Dingenen, R., Ervens, B., Nenes, A., Nielsen, C. J., Swietlicki, E., Putaud, J. P., Balkanski, Y., Fuzzi, S., Hjorth, J., Moortgat, G. K., Winterhalter, R., Myhre, C. E. L., Tsigaridis, K., Vignati, E., Stephanou, E. G., Wilson, J.: Organic aerosol and global climate modelling: a review, Atmos. Chem. Phys., 5, 1053-1123, doi:10.5194/acp-5-1053-2005, 2005.

Kanawati, B., Herrmann, F., Joniec, S., Winterhalter, R., and Moortgat, G. K.: Mass spectrometric characterization of $\beta$ caryophyllene ozonolysis products in the aerosol studied using an electrospray triple quadrupole and time-of-flight analyzer hybrid system and density functional theory, Rapid Commun. Mass Spectrom., 22, 165-186, 2008.

Kleindienst, T. E., Jaoui, M., Lewandowski, M., Offenberg, J. H., Lewis. C. W., Bhave, P. V. and Edney, E. O.: Estimates of the contributions of biogenic and anthropogenic hydrocarbons to secondary organic aerosol at a southeastern US location, Atmos. Environ. 41, 8288-8300, 2007.

Kroll, J. H. and Seinfeld, J. H.: Chemistry of secondary organic aerosol: formation and evolution of low-volatility organics in the atmosphere, Atmos. Environ., 42, 3593-3624, 2008.

Lane, T. E., Donahue, N. M., and Pandis, S. N.: Simulating secondary organic aerosol formation using the volatility basis-set approach in a chemical transport model, Atmos. Environ., 42, 7439-7451, 2008.

Lee, A., Goldstein, A. H., Keywood, M. D., Gao, S., Varutbangkul, V., Bahreini, R., Ng, N. L., Flagan, R. C., and Seinfeld, J. H.: Gas-phase products and secondary aerosol yields from the ozonolysis of ten different terpenes, J. Geophys. Res., 111, D07302, doi:10.1029/2005JD006437, 2006a.

Lee, A., Goldstein, A. H., Kroll, J. H., Ng, N. L., Varutbangkul, V., Flagan, R. C., and Seinfeld, J. H: Gas-phase products and secondary aerosol yields from the photooxidation of 16 different terpenes, J. Geophys. Res., 111, D17305, doi:10.1029/2006JD007050, 2006b.

Li, Y. J., Chen, Q., Guzman, M. I., Chan, C. K., and Martin, S. T.: Second-generation products contribute substantially to the particle-phase organic material produced by $\beta$-caryophyllene ozonolysis, Atmos. Chem. Phys., 11, 121-132, doi:10.5194/acp11-121-2011, 2011.

Ma, Y., Russell, A. T., and Marston, G.: Mechanisms for the formation of secondary organic aerosol components from the gasphase ozonolysis of $\alpha$-pinene, Phys. Chem. Chem. Phys., 10, 4294-4312, 2008.

Ma, Y., Porter, R. A., Chappell, D., Russell, A. T., and Marston, G.: Mechanisms for the formation of organic acids in the gas-phase ozonolysis of 3-carene, Phys. Chem. Chem. Phys., 11, 4184 4197, 2009a.

Ma, Y. and Marston, G.: Formation of organic acids from the gasphase ozonolysis of terpinolene, Phys. Chem. Chem. Phys., 11, 4198-4209, 2009b.

Maksic, Z. B. and Kovacevic, B.: Towards the absolute proton affinities of 20 alpha-amino acids, Chem. Phys. Lett., 307, 497504, 1999.

Matsunaga, A. and Ziemann, P. J.: Yields of $\beta$-hydroxynitrates and dihydroxynitrates in aerosol formed from $\mathrm{OH}$ radical-initiated reactions of linear alkenes in the presence of $\mathrm{NO}_{\mathrm{x}}$, J. Phys. Chem. A, 113, 599-606, 2009. 
Matsunaga, A. and Ziemann, P. J.: Gas-wall partitioning of organic compounds in a Teflon film chamber and potential effects on reaction product and aerosol yield measurements, Aerosol Sci. Technol., 44, 881-892, 2010.

Metzger, A., Dommen, J., Gaeggeler, K., Duplissy, J., Prevot, A. S. H., Kleffmann, J., Elshorbany, Y., Wisthaler, A., and Baltensperger, U.: Evaluation of 1,3,5 trimethylbenzene degradation in the detailed tropospheric chemistry mechanism, MCMv3.1, using environmental chamber data, Atmos. Chem. Phys., 8, 6453-6468, doi:10.5194/acp-8-6453-2008, 2008.

Nannoolal, Y., Rarey, J., Ramjugernath, D., and Cordes, W.: Estimation of pure component properties Part 1, Estimation of the normal boiling point of non-electrolyte organic compounds via group contributions and group interactions, Fluid Phase Equilibr., 226, 45-63, 2004.

Nannoolal, Y., Rarey, J., and Ramjugernath, D.: Estimation of pure component properties. Part 3. Estimation of the vapor pressure of non-electrolyte organic compounds via group contributions and group interactions, Fluid Phase Equilibr., 269, 117-133, 2008.

Ng, N. L., Chhabra, P. S., Chan, A. W. H., Surratt, J. D., Kroll, J. H., Kwan, A. J., McCabe, D. C., Wennberg, P. O., Sorooshian, A., Murphy, S. M., Dalleska, N. F., Flagan, R. C., Seinfeld, J. H.: Effect of $\mathrm{NO}_{\mathrm{X}}$ level on secondary organic aerosol (SOA) formation from the photooxidation of terpenes, Atmos. Chem. Phys., 7, 5159-5174, doi:10.5194/acp-7-5159-2007, 2007.

Nguyen, T. L., Winterhalter, R., Moortgat, G., Kanawati, B., Peeters, J., and Vereecken, L.: The gas-phase ozonolysis of $\beta$-caryophyllene $\left(\mathrm{C}_{15} \mathrm{H}_{24}\right)$, Part II: A theoretical study, Phys. Chem. Chem. Phys., 11, 4173-4183, 2009.

O’Brien, J. M., Czuba, E., Hastie, D. R., Francisco, J. S., Shepson, P. B.: Determination of the hydroxy nitrate yields from the reaction of $\mathrm{C}_{2}-\mathrm{C}_{6}$ alkenes with $\mathrm{OH}$ in the presence of NO, J. Phys. Chem. A 102, 8903-8908, 1998.

Pankow, J. F.: An absorption model of the gas aerosol partitioning involved in the formation of secondary organic aerosol, Atmos. Environ., 28, 189-193, 1994.

Parshintsev, J., Nurmi, J., Kilpeläinen, I., Hartonen, K., Kulmala, M., and Riekkola, M.-L.: Preparation of $\beta$-caryophyllene oxidation products and their determination in ambient aerosol samples, Analyt. Bioanalyt. Chem., 390, 913-919, 2008.

Peeters, J., Boullart, W., and Van Hoeymissen, J.: Site specific partial rate constants for $\mathrm{OH}$ addition to alkenes and dienes. In Proc. EUROTRAC Symp. '94, Garmisch-Partenkirchen, FRG. April 1994, 110-114, 1994.

Rollins, A. W., Smith, J., Wilson, K., and Cohen, R. C.: Real time in situ detection of organic nitrates in atmospheric aerosols, Environ. Sci. Technol., 44, 5540-5545, 2010.

Ruppert, L., Becker, K. H., Nozière, B., and Spittler, M.: Development of monoterpene oxidation mechanisms: results from laboratory and smog chamber studies, edited by: Borrell, P. M., Borrell, P., Transport and Chemical Transformation in the Troposphere. Proceedings of the EUROTRAC-2 Symposium '98, pp. 63-68. WIT, Southampton, UK, 1999.

Sakulyanontvittaya, T., Guenther, A., Helmig, D., Milford, J., and Wiedinmyer, C.: Secondary organic aerosol from sesquiterpene and monoterpene emissions in the United States, Environ. Sci. Technol., 42, 8784-8790, 2008.

Saunders, S. M., Jenkin, M. E., Derwent, R. G., and Pilling, M. J.: Protocol for the development of the Master Chemical Mech- anism, MCM v3 (Part A): tropospheric degradation of nonaromatic volatile organic compounds, Atmos. Chem. Phys., 3, 161-180, doi:10.5194/acp-3-161-2003, 2003.

Shu Y. and Atkinson, R.: Rate constants for the gas phase reactions of $\mathrm{O}_{3}$ with a series of terpenes and $\mathrm{OH}$ radical formation from the $\mathrm{O}_{3}$ reactions with sesquiterpenes at $296 \pm 2 \mathrm{~K}$, Int. J. Chem. Kinet., 26, 1193-1205, 1994.

Smith, D. and Spanel, P.: Selected Ion Flow Tube Mass Spectrometry (SIFT-MS) for on-line trace gas analysis, Mass Spectrom. Rev., 24, 661-700, 2005.

Spanel, P. and Smith, D.: SIFT studies of the reactions of $\mathrm{H}_{3} \mathrm{O}^{+}$, $\mathrm{NO}^{+}$and $\mathrm{O}_{2}^{+}$with a series of volatile carboxylic acids and esters, Int. J. Mass Spectrom., 172, 137-147, 1998.

$\mathrm{Su}$, T.: Trajectory calculations of ion-polar molecule capture rate constants at low temperatures, J. Chem. Phys., 89, 5355, 1988.

$\mathrm{Su}, \mathrm{T}$. and Bower, M. T.: Ion-polar molecule collisions: the effect of ion size on ion-polar molecule rate constants; the parameterization of the average-dipole-orientation theory, Int. J. Mass Spectrom. Ion Phys., 12, 347-356, 1973.

$\mathrm{Su}, \mathrm{T}$. and Chesnavich, W. J.: Parametrization of the ion-polar molecule collision rate constant by trajectory calculations, J. Chem. Phys., 76, 5183-5185, 1982.

Tobias, H. J. and Ziemann, P. J.: Thermal desorption mass spectrometric analysis of organic aerosol formed from reactions of 1-tetradecene and $\mathrm{O}_{3}$ in the presence of alcohols and carboxylic acids, Environ. Sci. Technol., 34, 2105-2115, 2000.

Varutbangkul, V., Brechtel, F. J., Bahreini, R., Ng, N. L., Keywood, M. D., Kroll, J. H., Flagan, R. C., Seinfeld, J. H., Lee, A., and Goldstein, A. H.: Hygroscopicity of secondary organic aerosols formed by oxidation of cycloalkenes, monoterpenes, sesquiterpenes, and related compounds, Atmos. Chem. Phys., 6, 23672388, doi:10.5194/acp-6-2367-2006, 2006.

Vereecken, L. and Peeters, J.: Decomposition of substituted alkoxy radicals - part I: a generalized structure-activity relationship for reaction barrier heights, Phys. Chem. Chem. Phys., 11, 9062 9074, 2009.

Welz, O., Savee, J. D., Osborn, D. L., Vasu, S. S., Percival, C. J., Shallcross, D. E., and Taatjes, C. A.: Direct kinetic measurements of Criegee intermediate $\left(\mathrm{CH}_{2} \mathrm{OO}\right)$ formed by reaction of $\mathrm{CH}_{2} \mathrm{I}$ with $\mathrm{O}_{2}$, Science, 335, 204-207, 2012.

Went, F. W.: Blue hazes in the atmosphere, Nature, 187, 641-645, 1960.

Winer, A. M., Peters, J. W., Smith, J. P. and Pitts, J. N.: Response of commercial chemiluminescent $\mathrm{NO}-\mathrm{NO}_{2}$ analyzers to other nitrogen-containing compounds, Environ. Sci. Technol., 8, 1118-1121, 1974.

Winterhalter, R., Herrmann, F., Kanawati, B., Nguyen, T. L., Peeters, J., Vereecken, L., and Moortgat, G. K.: The gas-phase ozonolysis of $\beta$-caryophyllene $\left(\mathrm{C}_{15} \mathrm{H}_{24}\right)$, Part I: an experimental study, Phys. Chem. Chem. Phys., 11, 4152-4172, 2009.

Wyche, K. P., Blake, R. S., Ellis, A. M., Monks, P. S., Brauers, T., Koppman, R., and Apel, E.: Performance of a Chemical Ionisation Reaction Time-of-Flight Mass Spectrometer (CIR-TOFMS) for the Measurement of Atmospherically Significant Oxygenated Volatile Organic Compounds, Atmos. Chem. Phys., 7, 609-620, doi:10.5194/acp-7-609-2007, 2007.

Zhang, H. and Ying, Q.: Secondary organic aerosol formation and source apportionment in Southeast Texas, Atmos. Environ., 45, 3217-3227, 2011. 
Zhao, J. and Zhang, R.: Proton transfer rate constants between hydronium ion $\left(\mathrm{H}_{3} \mathrm{O}^{+}\right)$and volatile organic compounds, Atmos. Environ., 38, 2177-2185, 2004.
Zhao, Y., Zhang, R., Sun, X., He, M., Wang, H., Zhang, Q., and $\mathrm{Ru}, \mathrm{M}$.: Theoretical study on mechanism for $\mathrm{O}_{3}$-initiated atmospheric oxidation reaction of $\beta$-caryophyllene, J. Molecular Structure, 947, 68-75, 2010. 